\title{
VARIAÇÃO DE VAZÃO DE GOTEJADORES ENTERRADOS NA IRRIGAÇÃO DE CITROS E CAFÉ
}

\author{
LUís FERNANDO FARIA
}

Dissertação apresentada à Escola Superior de Agricultura "Luiz de Queiroz", Universidade de São Paulo, para a obtenção do título de Mestre em Agronomia, Área de concentração: Irrigação e Drenagem.

PIRACICABA

Estado de São Paulo - Brasil

Fevereiro - 2002 


\title{
VARIAÇÃO DE VAZÃO DE GOTEJADORES ENTERRADOS NA IRRIGAÇÃO DE CITROS E CAFÉ
}

\author{
LUís FERNANDO FARIA \\ Engenheiro Agrícola
}

Orientador: Prof. Dr. Rubens Duarte Coelho

\begin{abstract}
Dissertação apresentada à Escola Superior de Agricultura "Luiz de Queiroz", Universidade de São Paulo, para a

obtenção do título de Mestre em Agronomia, Área de concentração: Irrigação e Drenagem.
\end{abstract}

PIRACICABA

Estado de São Paulo - Brasil

Fevereiro - 2002 
Dados Internacionais de Catalogação na Publicação (CIP)

DIVISÃO DE BIBLIOTECA E DOCUMENTAÇÃO - ESALQ/USP

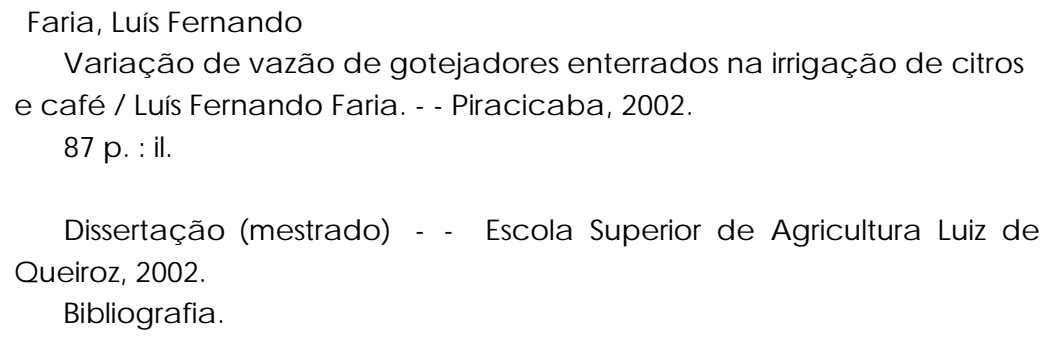

1. Café 2. Citricultura 3. Goteja dores 4. Irrigação loca liza da I. Título

CDD 631.7 
DEDICO

AOS MEUS QUERIDOS PAIS, Sônia E MAURo AOS MEUS IRMÃOS, ANDRÉ, BRUNO E ClARA 


\section{AGRADECIMENTOS}

A DEUS por ter estado sempre ao meu lado.

À Escola Superior de Agricultura "Luiz de Queiroz" (ESALQ/USP), pela oportunidade de realização do curso.

À Coordenadoria de Aperfeiçoamento de Pessoal de Nível Superior (CAPES), pela concessão da bolsa de estudos.

Ao Professor Doutor Rubens Duarte Coelho, pela orientação, dedicação e conhecimentos oferecidos.

Aos Professores José Antônio Frizzone, Tarlei Arriel Botrel e Roberto Testezlaf, pelas sugestões e colaboração ao trabalho.

Ao amigo Ronaldo Resende, pela amizade, convívio, colaboração e experiências transmitidas.

À Fundação de Amparo à Pesquisa do Estado de São Paulo (FAPESP), pelo suporte financeiro do experimento, através do Projeto de Pesquisa de $n^{\circ}$ 2000/10267-4, intitulado "Potencial de Intrusão Radicular em Gotejamento na Irrigação Subsuperficial".

Às empresas e fabricantes de sistemas de irrigação que prontamente cederam material à utilização nos ensaios.

Aos funcionários do Setor de Irrigação e Drenagem, Hélio, César, Antônio, Davilmar, Gilmar, Sandra e Osvaldo, pela colaboração.

Aos colegas de república Chryz, Rafael, Rodrigo e Valter, pelo companheirismo, amizade e pelos momentos de descontração compartilhados.

À Luciana por ter me proporcionado bons sonhos ultimamente. 


\section{SUMÁRIO}

Página

LISTA DE FIGURAS ............................................................................ vii

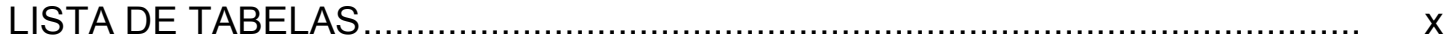

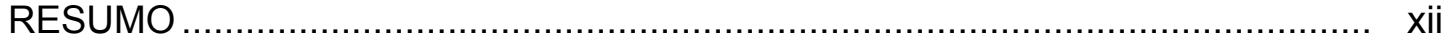

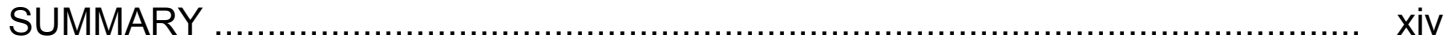

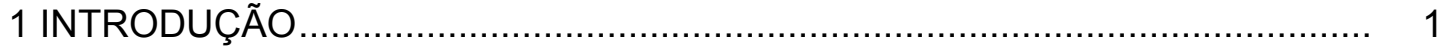

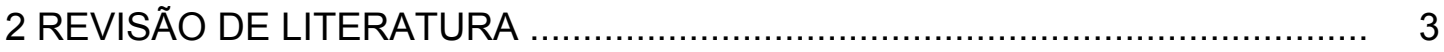

2.1 Gotejamento .......................................................................................... 4

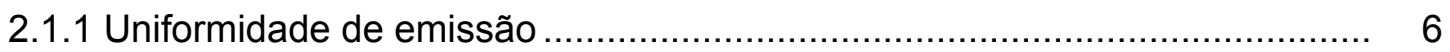

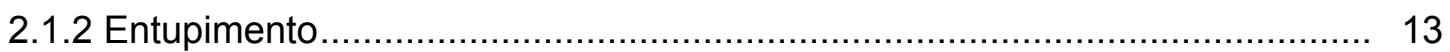

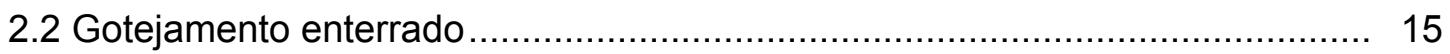

2.2.1 Prevenção contra intrusão radicular ................................................. 17

3 MATERIAL E MÉTODOS ................................................................ 20

3.1 Localização do experimento ........................................................... 20

3.2 Preparo dos vasos e espécies vegetais utilizadas .................................. 20

3.3 Emissores utilizados ...................................................................... 23

3.4 Tratamentos e delineamento estatístico ............................................... 24

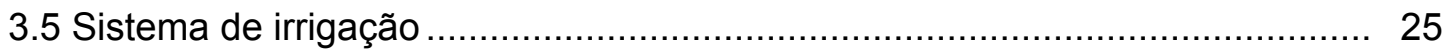

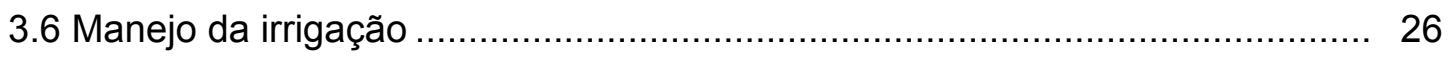

3.7 Determinação da vazão dos emissores.................................................. 27

3.8 Parâmetros avaliados ............................................................................. 28

3.8.1 Coeficiente de variação de vazão (CVQ) ........................................... 28

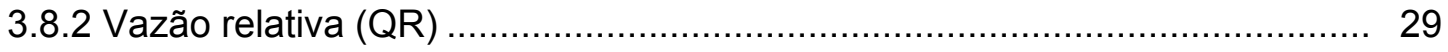

3.8.3 Critério para julgamento do desempenho dos emissores .......................... 29

4 RESULTADOS E DISCUSSÃO ..................................................... 30 


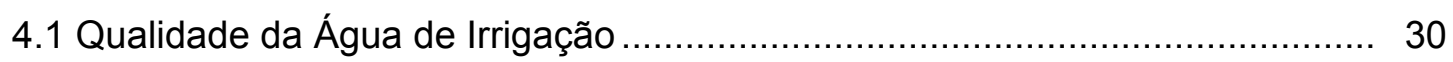

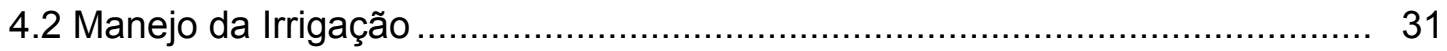

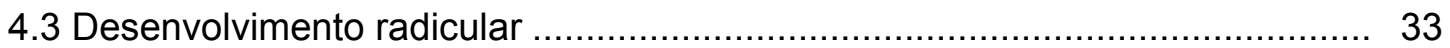

4.4 Vazão relativa e coeficiente de variação de vazão......................................... 34

4.4.1 Emissor modelo A ......................................................................... 35

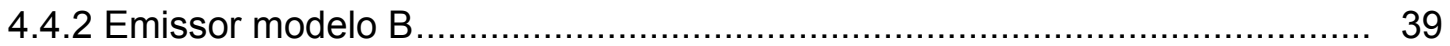

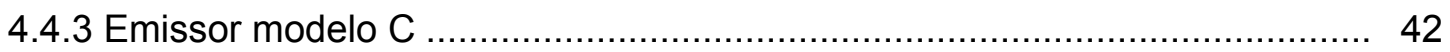

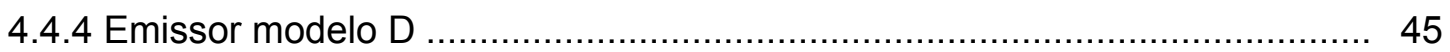

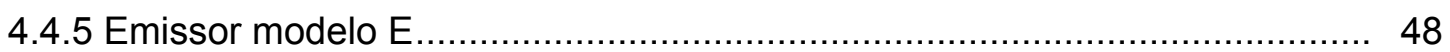

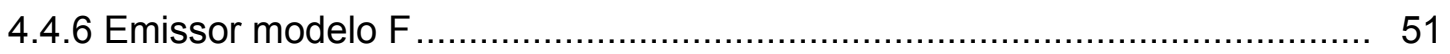

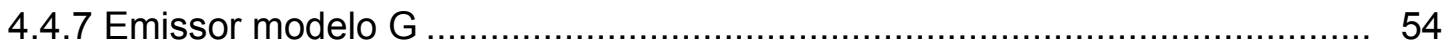

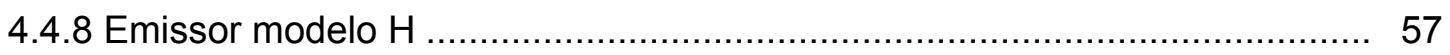

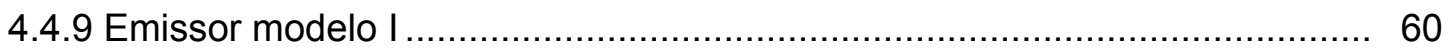

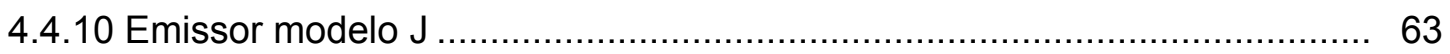

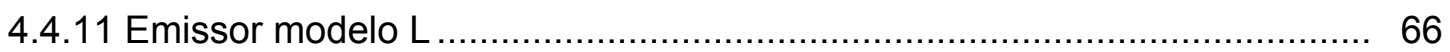

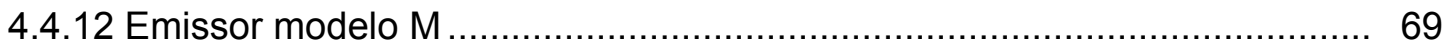

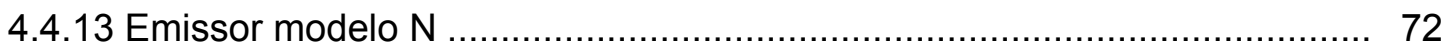

4.4.14 Emissor modelo O .................................................................... 75

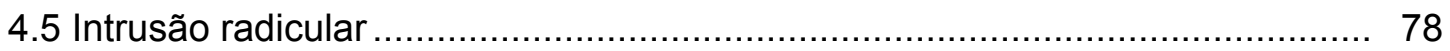

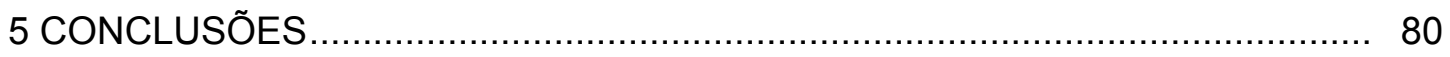

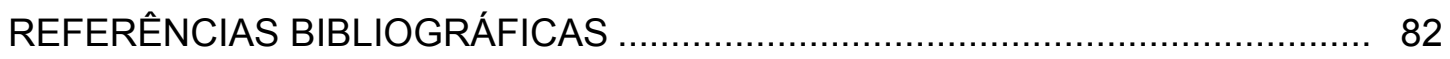




\section{LISTA DE FIGURAS}

Página

1 Classificação dos emissores segundo seu expoente

2 Preparação dos vasos para recebimento das mudas: (a) furação das dos vasos;

(b) instalação da $1^{\text {a }}$ linha de emissores; (c) preenchimento com solo; (c) Instalação da $2^{\mathrm{a}}$ linha; (d) preenchimento com solo

3 Esquema de montagem dos vasos com os tubos gotejadores

4 Disposição das mudas de café citros nos vasos

5 Vista geral do experimento 25

6 Detalhes do sistema de irrigação: (a) motobomba e (b) detalhe do cavalete. 26

7 Detalhes do medidor de vazão: (a) sensor magnético e (b) leitor digtal. 28

8 Sintomas de déficit hídrico das plantas no tratamento seco: (a) café e (b) citro .. 31

9 Umidade do solo ao longo do tempo nas culturas: (a) café e (b) citros. 32

10 Desenvolvimento radicular: (a) desenvolvimento radicular do cafeeiro no tratamento seco; (b) desenvolvimento radicular do cafeeiro no tratamento úmido; (c) desenvolvimento radicular da laranjeira no tratamento seco; (d) desenvolvimento radicular da laranjeira no tratamento úmido

11 QR e CVQ para o emissor modelo A: (a) citros seco $15 \mathrm{~cm}$; (b) citros seco 30 cm; (c) citros úmido $15 \mathrm{~cm}$; (d) citros úmido $30 \mathrm{~cm}$; (e) café seco $15 \mathrm{~cm}$; (f) café seco $30 \mathrm{~cm}$; $(\mathrm{g})$ café úmido $15 \mathrm{~cm}$; (h) café úmido $30 \mathrm{~cm}$; (i) testemunha $15 \mathrm{~cm}$; (j) testemunha $30 \mathrm{~cm}$

12 QR e CVQ para o emissor modelo B: (a) citros seco $15 \mathrm{~cm}$; (b) citros seco 30 cm; (c) citros úmido $15 \mathrm{~cm}$; (d) citros úmido $30 \mathrm{~cm}$; (e) café seco $15 \mathrm{~cm}$; (f) café seco $30 \mathrm{~cm}$; $(\mathrm{g})$ café úmido $15 \mathrm{~cm}$; (h) café úmido $30 \mathrm{~cm}$; (i) testemunha $15 \mathrm{~cm}$; (j) testemunha $30 \mathrm{~cm}$ 
13 QR e CVQ para o emissor modelo C: (a) citros seco $15 \mathrm{~cm}$; (b) citros seco 30 cm; (c) citros úmido $15 \mathrm{~cm}$; (d) citros úmido $30 \mathrm{~cm}$; (e) café seco $15 \mathrm{~cm}$; (f) café seco $30 \mathrm{~cm}$; (g) café úmido $15 \mathrm{~cm}$; (h) café úmido $30 \mathrm{~cm}$; (i) testemunha $15 \mathrm{~cm}$; (j) testemunha $30 \mathrm{~cm}$

14 QR e CVQ para o emissor modelo D: (a) citros seco $15 \mathrm{~cm}$; (b) citros seco 30 cm; (c) citros úmido $15 \mathrm{~cm}$; (d) citros úmido $30 \mathrm{~cm}$; (e) café seco $15 \mathrm{~cm}$; (f) café seco $30 \mathrm{~cm}$; (g) café úmido $15 \mathrm{~cm}$; (h) café úmido $30 \mathrm{~cm}$; (i) testemunha $15 \mathrm{~cm}$; (j) testemunha $30 \mathrm{~cm}$

15 QR e CVQ para o emissor modelo E: (a) citros seco $15 \mathrm{~cm}$; (b) citros seco 30 cm; (c) citros úmido $15 \mathrm{~cm}$; (d) citros úmido $30 \mathrm{~cm}$; (e) café seco $15 \mathrm{~cm}$; (f) café seco $30 \mathrm{~cm}$; (g) café úmido $15 \mathrm{~cm}$; (h) café úmido $30 \mathrm{~cm}$; (i) testemunha $15 \mathrm{~cm}$; (j) testemunha $30 \mathrm{~cm}$

16 QR e CVQ para o emissor modelo F: (a) citros seco $15 \mathrm{~cm}$; (b) citros seco 30 cm; (c) citros úmido $15 \mathrm{~cm}$; (d) citros úmido $30 \mathrm{~cm}$; (e) café seco $15 \mathrm{~cm}$; (f) café seco $30 \mathrm{~cm}$; $(\mathrm{g})$ café úmido $15 \mathrm{~cm}$; (h) café úmido $30 \mathrm{~cm}$; (i) testemunha $15 \mathrm{~cm}$; (j) testemunha $30 \mathrm{~cm}$

17 QR e CVQ para o emissor modelo G: (a) citros seco $15 \mathrm{~cm}$; (b) citros seco 30 $\mathrm{cm}$; (c) citros úmido $15 \mathrm{~cm}$; (d) citros úmido $30 \mathrm{~cm}$; (e) café seco $15 \mathrm{~cm}$; (f) café seco $30 \mathrm{~cm}$; (g) café úmido $15 \mathrm{~cm}$; (h) café úmido $30 \mathrm{~cm}$; (i) testemunha $15 \mathrm{~cm}$; (j) testemunha $30 \mathrm{~cm}$

18 QR e CVQ para o emissor modelo $H$ : (a) citros seco $15 \mathrm{~cm}$; (b) citros seco 30 cm; (c) citros úmido $15 \mathrm{~cm}$; (d) citros úmido $30 \mathrm{~cm}$; (e) café seco $15 \mathrm{~cm}$; (f) café seco $30 \mathrm{~cm}$; (g) café úmido $15 \mathrm{~cm}$; (h) café úmido $30 \mathrm{~cm}$; (i) testemunha $15 \mathrm{~cm}$; (j) testemunha $30 \mathrm{~cm}$

19 QR e CVQ para o emissor modelo I: (a) citros seco $15 \mathrm{~cm}$; (b) citros seco 30 $\mathrm{cm}$; (c) citros úmido $15 \mathrm{~cm}$;(d) citros úmido $30 \mathrm{~cm}$; (e) café seco $15 \mathrm{~cm}$; (f) café seco $30 \mathrm{~cm}$; $(\mathrm{g})$ café úmido $15 \mathrm{~cm}$; (h) café úmido $30 \mathrm{~cm}$; (i) testemunha $15 \mathrm{~cm}$; (j) testemunha $30 \mathrm{~cm}$

20 QR e CVQ para o emissor modelo J: (a) citros seco $15 \mathrm{~cm}$; (b) citros seco 30 cm; (c) citros úmido $15 \mathrm{~cm}$; (d) citros úmido $30 \mathrm{~cm}$; (e) café seco $15 \mathrm{~cm}$; (f) café seco $30 \mathrm{~cm}$; $(\mathrm{g})$ café úmido $15 \mathrm{~cm}$; (h) café úmido $30 \mathrm{~cm}$; (i) testemunha $15 \mathrm{~cm}$; (j) testemunha $30 \mathrm{~cm}$ 
21 QR e CVQ para o emissor modelo L: (a) citros seco $15 \mathrm{~cm}$; (b) citros seco 30 cm; (c) citros úmido $15 \mathrm{~cm}$; (d) citros úmido $30 \mathrm{~cm}$; (e) café seco $15 \mathrm{~cm}$; (f) café seco $30 \mathrm{~cm}$; (g) café úmido $15 \mathrm{~cm}$; (h) café úmido $30 \mathrm{~cm}$; (i) testemunha $15 \mathrm{~cm}$; (j) testemunha $30 \mathrm{~cm}$

22 QR e CVQ para o emissor modelo M: (a) citros seco $15 \mathrm{~cm}$; (b) citros seco 30 $\mathrm{cm}$; (c) citros úmido $15 \mathrm{~cm}$; (d) citros úmido $30 \mathrm{~cm}$; (e) café seco $15 \mathrm{~cm}$; (f) café seco $30 \mathrm{~cm}$; (g) café úmido $15 \mathrm{~cm}$; (h) café úmido $30 \mathrm{~cm}$; (i) testemunha $15 \mathrm{~cm}$; (j) testemunha $30 \mathrm{~cm}$

23 QR e CVQ para o emissor modelo N: (a) citros seco $15 \mathrm{~cm}$; (b) citros seco 30 cm; (c) citros úmido $15 \mathrm{~cm}$; (d) citros úmido $30 \mathrm{~cm}$; (e) café seco $15 \mathrm{~cm}$; (f) café seco $30 \mathrm{~cm}$; $(\mathrm{g})$ café úmido $15 \mathrm{~cm}$; (h) café úmido $30 \mathrm{~cm}$; (i) testemunha $15 \mathrm{~cm}$; (j) testemunha $30 \mathrm{~cm}$

24 QR e CVQ para o emissor modelo O: (a) citros seco $15 \mathrm{~cm}$; (b) citros seco 30 cm; (c) citros úmido $15 \mathrm{~cm}$; (d) citros úmido $30 \mathrm{~cm}$; (e) café seco $15 \mathrm{~cm}$; (f) café seco $30 \mathrm{~cm}$; $(\mathrm{g})$ café úmido $15 \mathrm{~cm}$; (h) café úmido $30 \mathrm{~cm}$; (i) testemunha $15 \mathrm{~cm}$; (j) testemunha $30 \mathrm{~cm}$

25 Intrusão radicular nos emissores: (a) emissor cilíndrico; (b) emissor plano; (c) emissores diversos; (d) emissor plano; (e) emissor cilíndrico; (f) emissor botão 78 


\section{LISTA DE TABELAS}

Página

1 Classificação dos valores de UD ............................................................ 11

2 Principais características dos tubos gotejadores utilizados.............................. 23

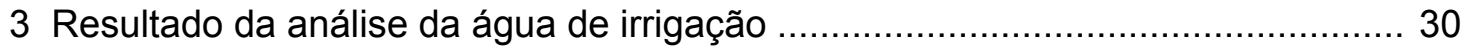

4 Vazões do emissor modelo $A$ em L. $h^{-1}$ para as cinco leituras realizadas $(1 \mathrm{~L}$ até $5 \mathrm{~L}$ ), dez repetições (R1 até R10) para todos os tratamentos (CTS15, CTS30, CTU15, CTU30, CFS15, CFS30, CFU15, CFU30, TT15 e TT30)

5 Vazões do emissor modelo $B$ em L. $h^{-1}$ para as cinco leituras realizadas $(1 \mathrm{~L}$ até $5 \mathrm{~L}$ ), dez repetições (R1 até R10) para todos os tratamentos (CTS15, CTS30, CTU15, CTU30, CFS15, CFS30, CFU15, CFU30, TT15 e TT30)

6 Vazões do emissor modelo $\mathrm{C}$ em L. $\mathrm{h}^{-1}$ para as cinco leituras realizadas $(1 \mathrm{~L}$ até $5 \mathrm{~L}$ ), dez repetições (R1 até R10) para todos os tratamentos (CTS15, CTS30, CTU15, CTU30, CFS15, CFS30, CFU15, CFU30, TT15 e TT30)

7 Vazões do emissor modelo $D$ em L. ${ }^{-1}$ para as cinco leituras realizadas ( $1 \mathrm{~L}$ até $5 \mathrm{~L}$ ), dez repetições (R1 até R10) para todos os tratamentos (CTS15, CTS30, CTU15, CTU30, CFS15, CFS30, CFU15, CFU30, TT15 e TT30)

8 Vazões do emissor modelo $\mathrm{E}$ em L. $\mathrm{h}^{-1}$ para as cinco leituras realizadas (1L até $5 \mathrm{~L}$ ), dez repetições (R1 até R10) para todos os tratamentos (CTS15, CTS30, CTU15, CTU30, CFS15, CFS30, CFU15, CFU30, TT15 е TT30)

9 Vazões do emissor modelo $\mathrm{F}$ em L. $\mathrm{h}^{-1}$ para as cinco leituras realizadas ( $1 \mathrm{~L}$ até $5 \mathrm{~L}$ ), dez repetições (R1 até R10) para todos os tratamentos (CTS15, CTS30, CTU15, CTU30, CFS15, CFS30, CFU15, CFU30, TT15 e TT30)

10 Vazões do emissor modelo $\mathrm{G} \mathrm{em} \mathrm{L.h}{ }^{-1}$ para as cinco leituras realizadas $(1 \mathrm{~L}$ até $5 \mathrm{~L}$ ), dez repetições (R1 até R10) para todos os tratamentos (CTS15, CTS30, CTU15, CTU30, CFS15, CFS30, CFU15, CFU30, TT15 е TT30) 
11 Vazões do emissor modelo H em L.h $\mathrm{h}^{-1}$ para as cinco leituras realizadas $(1 \mathrm{~L}$ até $5 \mathrm{~L}$ ), dez repetições (R1 até $\mathrm{R} 10$ ) para todos os tratamentos (CTS15, CTS30, CTU15, CTU30, CFS15, CFS30, CFU15, CFU30, TT15 е TT30)

12 Vazões do emissor modelo I em L. $\mathrm{h}^{-1}$ para as cinco leituras realizadas ( $1 \mathrm{~L}$ até $5 \mathrm{~L}$ ), dez repetições (R1 até $\mathrm{R} 10$ ) para todos os tratamentos (CTS15, CTS30, CTU15, CTU30, CFS15, CFS30, CFU15, CFU30, TT15 e TT30)

13 Vazões do emissor modelo I em L. $\mathrm{h}^{-1}$ para as cinco leituras realizadas (1L até $5 \mathrm{~L}$ ), dez repetições (R1 até $\mathrm{R} 10$ ) para todos os tratamentos (CTS15, CTS30, CTU15, CTU30, CFS15, CFS30, CFU15, CFU30, TT15 e TT30).

14 Vazões do emissor modelo $L$ em L. $h^{-1}$ para as cinco leituras realizadas ( $1 \mathrm{~L}$ até $5 L$ ), dez repetições (R1 até R10) para todos os tratamentos (CTS15, CTS30, CTU15, CTU30, CFS15, CFS30, CFU15, CFU30, TT15 e TT30).

15 Vazões do emissor modelo $M$ em L.h ${ }^{-1}$ para as cinco leituras realizadas $(1 \mathrm{~L}$ até $5 \mathrm{~L}$ ), dez repetições (R1 até R10) para todos os tratamentos (CTS15, CTS30, CTU15, CTU30, CFS15, CFS30, CFU15, CFU30, TT15 e TT30).

16 Vazões do emissor modelo $\mathrm{N}$ em L. $\mathrm{h}^{-1}$ para as cinco leituras realizadas (1L até $5 \mathrm{~L}$ ), dez repetições (R1 até R10) para todos os tratamentos (CTS15, CTS30, CTU15, CTU30, CFS15, CFS30, CFU15, CFU30, TT15 e TT30).

17 Vazões do emissor modelo $\mathrm{O}$ em L.h ${ }^{-1}$ para as cinco leituras realizadas $(1 \mathrm{~L}$ até $5 \mathrm{~L}$ ), dez repetições (R1 até R10) para todos os tratamentos (CTS15, CTS30, CTU15, CTU30, CFS15, CFS30, CFU15, CFU30, TT15 e TT30). 77 


\title{
VARIAÇÃO DE VAZÃO DE GOTEJADORES ENTERRADOS NA IRRIGAÇÃO DE CITROS E CAFÉ
}

\author{
Autor: Luís Fernando Faria \\ Orientador: Prof. Dr. Rubens Duarte Coelho
}

\section{RESUMO}

Este trabalho teve como objetivo obter informações sobre o desempenho de gotejadores enterrados (irrigação subsuperficial), quanto ao aspecto de variação de vazão em função da intrusão radicular das culturas de citros e café. $O$ experimento foi conduzido em ambiente protegido (estufa plástica) durante o ano de 2001, na Escola Superior de Agricultura "Luiz de Queiroz" / USP, em Piracicaba SP. As mudas de café e laranja foram plantadas em vasos de cimento amianto com $100 \mathrm{~L}$ de capacidade, irrigadas

por 14 modelos diferentes de gotejadores enterrados (autocompensantes e normais), em duas profundidades (15 e $30 \mathrm{~cm}$ ) e em dois níveis de depleção de água no solo (seco e úmido). Foram realizadas cinco determinações de vazões individuais dos emissores, em intervalo de 60 dias entre a primeira e a segunda e de 30 dias entre as demais leituras, utilizando-se um medidor de vazão magnético indutivo com $0,3 \%$ de precisão. Os dados de vazão dos emissores foram analisados a cada leitura, através dos parâmetros: a) vazão relativa $(Q R \%)$, tendo como referência à vazão obtida na primeira leitura e b) 
coeficiente de variação de vazão (CVQ\%) da amostra analisada. Concluiu-se que: a) a intrusão radicular é aleatória, não tendo havido um modelo de emissor que se destacasse quanto à penetração de raízes; b) os níveis de irrigação não apresentaram resultados conclusivos no período analisado, porém, observaram-se evidências de que o sistema radicular é mais agressivo tanto na camada superficial de solo $(15 \mathrm{~cm})$ para as plantas bem irrigadas, quanto nas camadas mais profunda de solo $(30 \mathrm{~cm})$ para as plantas sob déficit hídrico; c) variações de vazão foram mais evidentes para os emissores a $30 \mathrm{~cm}$ de profundidade no cafeeiro; e d) os emissores autocompensáveis apresentaram maior instabilidade de vazão, na presença de raízes e partículas de solo, enquanto os emissores normais tiveram desempenho mais estável. Distúrbios de vazão nos gotejadores ensaiados foram mais pronunciados em determinados modelos de alguns fabricantes, o que evidencia a diferença tecnológica entre as empresas de equipamentos de irrigação analisadas. 


\title{
FLOW VARIATION OF EMITTERS UNDER SUBSURFACE DRIP IRRIGATION IN CITRUS AND COFFEE CROPS
}

\author{
Author: Luís Fernando Faria \\ Adviser: Prof. Dr. Rubens Duarte Coelho
}

\section{SUMMARY}

This work aimed to quantify drippers performance under subsurface drip irrigation (SDI), regarding the flow variation due to root intrusion under citrus and coffee crops. The experiment was carried out inside a greenhouse during the year of 2001, at the University of Sao Paulo (ESALQ), in Piracicaba SP. Coffee seedlings and orange scions planted in vases with 100 liters of capacity, irrigated by fourteen different models of commercial drippers (self-compensated end regular devices), in two depths (15 and 30 centimeters) and in two soil water depletion levels (dry and humid). It was accomplished five determinations of individual flows, in intervals of 60 days between first and the second readiness and of 30 days among other readings, using an inductive magnetic flow meter with $0,3 \%$ of precision. The flow data of the emitters were analyzed for each reading, though the parameters: a) relative flow (QR\%), having as reference the initial flow rate measured and b) Flow coefficient of variation (CVQ\%) of the analyzed 
sample. It was concluded that the root intrusion is not related to a specifics model randomly distributed. The irrigation levels did not resulted conclusive results regarding the root intrusion; flow variations were more evident for emitters at 30 centimeters depth under coffee crop. Self-compensated emitters tended to be more unstable, increasing the average flow rate with root and soil particles presence. Regular emitters tended to be more stable, decreasing the average flow rate with root and soil particles presence. 


\section{INTRODUÇÃO}

A irrigação localizada possibilita a aplicação direta de água ao solo, minimizando as perdas por evaporação, deriva e escoamento superficial. Este método, quando adequadamente manejado, possibilita um melhor aproveitamento hidroenergético, pois trata-se de um sistema que tem o potencial de requerer uma menor potência instalada por unidade de área, quando adequadamente dimensionado em decorrência da menor pressão de operação e baixa vazão dos emissores. A possibilidade de aplicação de produtos como fertilizantes e defensivos na água de irrigação é mais um atrativo para a adoção do sistema.

O gotejamento subsuperficial (enterrado) é uma variação do gotejamento superficial, diferenciando-se basicamente pelo enterrio das linhas de polietileno a pequenas profundidades. Em algumas regiões do mundo, o gotejamento enterrado tem sido empregado na irrigação de gramados, jardins, cana-de-açúcar, citrus, uvas, hortaliças e café. Os principais atrativos para os irrigantes optarem por sistema de irrigação por gotejamento subsuperficial são: (a) proteção das linhas laterais contra ataque de roedores e outros animais; (b) proteção contra a sabotagem ou acidentes (capinas com enxadas) que eventualmente atinjam as linhas laterais; (c) maior eficiência do uso da água; (d) manutenção do gotejador sempre na mesma posição em que o sistema radicular encontra-se bem adaptado à irrigação localizada no terreno; (e) possibilidade de aplicação de elementos de baixa mobilidade diretamente na zona radicular das culturas. 
O gotejamento subsuperficial está sujeito à maioria dos problemas que ocorrem no gotejamento superficial, somando-se, ainda, a obstrução dos emissores por sucção de partículas sólidas e a possibilidade de penetração do sistema radicular das culturas e plantas daninhas nos emissores, causando danos à vazão, acréscimo de perda de carga localizada nas linhas laterais, prejudicando a vazão dos emissores a jusante do ponto de intrusão bem como desequilíbrio hidráulico ao sistema. O requerimento de maior controle no sistema, como filtragem eficiente, níveis de umidade no solo que não causem déficit hídrico nas plantas, aplicação de agentes contra a intrusão radicular, sistema de limpeza das linhas laterais e monitoramento constante das leituras dos hidrômetros, faz-se imprescindível, pois trata-se de um sistema de difícil identificação de problemas.

No Brasil, o gotejamento enterrado encontra-se instalado em algumas áreas de citros e café.

No ano de 1999, o Estado de São Paulo produziu cerca de 387 milhões de caixas da fruta, e a produção nacional foi de 456 milhões de caixas.

A cafeicultura brasileira destaca-se mundialmente, quer pela quantidade, quer pela qualidade do produto. A produção nacional no ano de 1999 foi de 30 milhões de sacas, fazendo com que o Brasil continuasse a ocupar o primeiro lugar o ranking mundial.

Tendo em vista o caráter irreversível e danoso da intrusão radicular em gotejamento enterrado, este trabalho objetiva verificar as seguintes hipóteses: (1) existem diferenças entre emissores no aspecto construtivo quanto à susceptibilidade à penetração de raízes (barreiras físicas); (2) a profundidade de instalação dos emissores pode ter efeito no grau de intrusão radicular; (3) não havendo déficit nos solo, não haverá intrusão radicular nos emissores; (4) diferentes culturas (citros e café) apresentam poder diferenciado de intrusão radicular nos gotejadores. 


\section{REVISÃO DE LITERATURA}

O Brasil ocupa posição de destaque na produção de suco de laranja, conseguindo produzir a tonelada de suco por US\$1.000,00 não havendo, assim, nenhum outro país que ofereça concorrência em relação ao custo de produção. No ano de 1999, o Estado de São Paulo produziu cerca de 387 milhões de caixas da fruta, e a produção nacional foi de 456 milhões de caixas. As próprias indústrias estão concentrando a produção da fruta, implantando novos pomares, adotando tecnologias para incrementar a produção, procurando reduzir custos (FNP: Consultoria e Comercio, 2001). Amaro (1999) afirma que a área colhida de laranja no Brasil em 1999 foi de 1,05 milhão de hectares. A participação do mercado interno no destino da laranja ficou ao redor de $30 \%$, sendo o restante da produção paulista destinado ao processamento. Neves (2000) relata que o Estado de São Paulo é o maior produtor de laranja do mundo, estando à frente do segundo maior país produtor, Estados Unidos. O mesmo autor afirma que as exportações citrícolas captaram divisas na ordem de US\$1,35 bilhão, correspondente a 2,8\% das exportações brasileiras em 1999 e 9,9\% das exportações dos agronegócios do país. A prática da irrigação tem acompanhado muitos dos novos pomares na busca por maior produtividade e menor custo de produção.

Produto de exportação mundial, o café representa para $30 \%$ dos países exportadores mais da metade de sua receita cambial, e para os $70 \%$ restantes contribui com $25 \%$ do valor das exportações totais (Caixeta, 1998). 
A produção nacional no ano de 1999 foi de 30 milhões de sacas, fazendo com que o Brasil continuasse a ocupar o primeiro lugar no ranking mundial, seguido por Colômbia e Vietnã, com produções de 11 e 7,6 milhões de sacas, respectivamente. A procura por terras mecanizáveis, livres de geadas e de baixo custo de aquisição, fez com que a atividade migrasse para regiões de cerrado com déficit hídrico mais acentuado, tornando necessário o emprego da irrigação (FNP: Consultoria e Comercio, 2001).

Segundo Christofidis (2001), a área irrigada total no Brasil em 1999

era de 2,95 milhões de hectares. Os métodos pressurizados ocupavam 1,3 milhões de hectares (44\% do total), sendo que, do total, 212.168 hectares eram de irrigação localizada, ou seja, $7,2 \%$ da área total irrigada e $16,2 \%$ da área irrigada por métodos pressurizados.

A utilização da irrigação localizada pode proporcionar alta eficiência de uso da água, quando comparada aos métodos tradicionais de aspersão convencional e à irrigação por superfície. Tal fato possibilita uma maior precisão de aplicação de água, fertilizantes e defensivos, bem como aumento da área irrigada, para uma mesma vazão requerida, devido às menores vazões específicas demandadas pelo método.

\subsection{Gotejamento}

Com o domínio da tecnologia dos plásticos, tornou-se possível a construção de tubos gotejadores com padrão de produção aceitável, a custos de aquisição relativamente baixo. $O$ emprego da irrigação localizada, através do método de gotejamento, tem grande potencial para crescimento no Brasil, possibilitado uma irrigação mais racional de fruteiras e olerícolas.

Os gotejadores são emissores conectados às linhas laterais, capazes de dissipar a pressão disponível na linha lateral e aplicar vazões pequenas e constantes (Bernardo, 1995). Esses emissores devem fornecer 
uma vazão relativamente baixa, constante e uniforme, apresentando uma seção transversal de fluxo relativamente grande, o que minimiza problemas de entupimento, além de serem baratos, resistentes e compactos (Karmeli \& Keller, 1975).

Keller \& Bliesner (1990) citam também, como características desejáveis aos emissores em irrigação localizada, uma relação vazão versus pressão favorável que resulta vazões uniformes com baixa sensibilidade à variação de pressão. A equação 1 expressa a relação vazão versus pressão para emissores.

$$
q=k \cdot H^{x}
$$

em que:

$$
\begin{aligned}
& \text { q - vazão; } \\
& \text { k - constante da equação; } \\
& \text { H - pressão de operação do emissor; } \\
& \text { x - expoente de descarga. }
\end{aligned}
$$

O valor do expoente de descarga $(x)$ caracteriza o regime de escoamento e/ou o dispositivo de autocompensação. Quando mais próximo de zero for o valor de $\mathrm{x}$, menor será a sensibilidade do emissor à variação de pressão (autocompensação). Por outro lado, aproximando-se de 10 valor de X, a curva vazão pressão tende a formar um ângulo de $45^{\circ}$ com o eixo das abscissas (eixo $X$, pressões), caracterizando um emissor com alta sensibilidade à variação de pressão, respondendo em vazão proporcionalmente à pressão aplicada (Lopez et al., 1992). 
Keller \& Bliesner (1990) utilizam o valor do coeficiente de descarga (x) para classificar o regime de escoamento no emissor, conforme Figura 1.

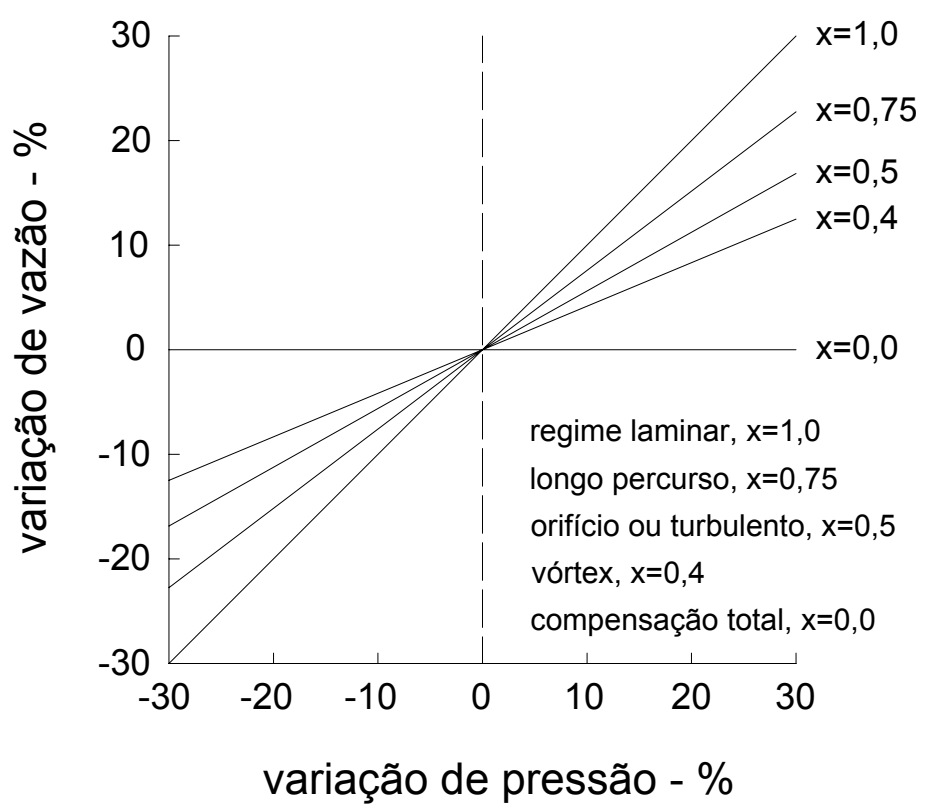

Figura 1 - Classificação dos emissores segundo seu expoente.

\subsubsection{Uniformidade de emissão}

A uniformidade de emissão de água pelos gotejadores é fator fundamental ao sucesso do empreendimento. Para a realização de um eficiente manejo de água e fertirrigação, é necessário que a uniformidade de aplicação de água pelos emissores seja a maior possível, pois, com a prática sucessiva da fertirrigação, algumas plantas podem estar recebendo quantidade menor de fertilizantes que outras, e respondendo diferentemente em produção. A equação 2 é usada para determinação do CVF para uma amostra de emissores. 


$$
C V F=\frac{S}{q_{m}}
$$

em que:

$$
\begin{gathered}
\text { CVF - coeficiente de variação de fabricação; } \\
S \text { - desvio-padrão da vazão da amostra; } \\
q_{m} \text { - vazão média da amostra. }
\end{gathered}
$$

Para Solomon (1985), os fatores que afetam a uniformidade de aplicação de água seguem a seguinte ordem: obstruções, coeficiente de variação de fabricação, expoente de descarga do emissor, sensibilidade do emissor à temperatura, variações de pressão, etc.

O processo de fabricação dos emissores deve seguir um rigoroso controle de qualidade, de tal maneira que o coeficiente de variação de fabricação (CVF) esteja abaixo do limite estabelecido como ideal.

Para Hillel (1982), os emissores são agrupados em 2 categorias, sendo qualificados de acordo com o coeficiente de variação de fabricação, da seguinte forma:

Grupo 1 - Gotejadores, Miniaspersores e Difusores

CVF até $5 \% \ldots \ldots \ldots \ldots \ldots \ldots \ldots \ldots \ldots$ bons;

CVF entre 5 e $10 \%$....................médios;

CVF entre 10 e $15 \% \ldots \ldots \ldots \ldots \ldots . . . .$. deficiente;

CVF acima de $15 \%$.................... inaceitáveis.

Grupo 2 - Tubo gotejadores

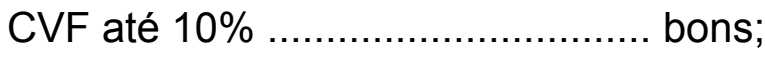

CVF entre 10 e $20 \%$..................... médios;

CVF acima de $20 \%$..................... inaceitáveis. 
Solomon (1984) sugere os seguintes parâmetros para o coeficiente de variação de fabricação de emissores:

CVF abaixo de $3 \%$ uniformidade excelente;

CVF entre 4 e $7 \%$ uniformidade média;

CVF entre 8 e $10 \%$ uniformidade marginal;

CVF entre 11 e $14 \%$ uniformidade ruim;

CVF acima de $15 \%$ uniformidade inaceitável.

A Associação Brasileira de Normas Técnicas, em seu projeto de norma ABNT 12:02.08-022/86, classifica os emissores da seguinte maneira:

CVF até $10 \%$ uniformidade boa;

CVF entre 10 e $20 \%$ uniformidade média;

CVF de 20 a $30 \%$ uniformidade margina; CVF acima de $30 \%$ uniformidade inaceitável.

A norma ISO 9261 estabelece duas categorias de emissores: A e B. Na categoria A estão classificados os emissores com CVF inferior a 5\%, sendo o desvio-padrão da vazão atual em relação à nominal inferior a $5 \%$. Na categoria B estão os emissores com CVF entre 5\% e 10\%, com desviopadrão da vazão em relação à nominal não-superior a $10 \%$.

Para a determinação do coeficiente de variação de fabricação dos emissores, a ABNT sugere que se utilize uma amostra de no mínimo 50 emissores para gotejadores e 20 emissores para microaspersores, retiradas aleatoriamente da linha de produção.

Diversos são os índices para avaliação do desempenho dos sistemas de irrigação, sendo o primeiro proposto por Christiansen (1942), para uso em aspersão. Este coeficiente ainda é bastante utilizado pela sua 
grande popularidade. O Coeficiente de Uniformidade de Christiansen (CUC) para a irrigação localizada é apresentado na equação 3 .

$$
C U C=1-\frac{\sum_{i=1}^{n}\left|q_{i}-q_{m}\right|}{n \cdot q_{m}}
$$

em que:

CUC - coeficiente de uniformidade de Christiansen;

$\mathrm{q}_{\mathrm{i}}$ - vazão de cada emissor;

$\mathrm{q}_{\mathrm{m}}$ - vazão média dos emissores;

n - número de emissores.

Bernardo (1985) admite $80 \%$ com valor mínimo de CUC para a irrigação localizada dentro da parcela de irrigação.

Karmeli \& Keller (1975) propuseram um índice de uniformidade de emissão (UE) empírico para dimensionamento de sistemas de irrigação localizada, que considera o coeficiente de variação de fabricação e o critério de dimensionamento hidráulico da parcela de irrigação. Esse índice é apresentado na equação 4:

$$
U E=\left[1-1,27(C V F) n^{-0,5}\right]\left(\frac{q_{n}}{q_{m}}\right) \cdot 100
$$

em que:

$$
\begin{aligned}
& \text { UE - uniformidade de emissão; } \\
& \text { CVF - coeficiente de variação de fabricação; } \\
& n \text { - número de emissores por planta; } \\
& q_{n} \text { - vazão mínima na parcela; } \\
& q_{m} \text { - vazão máxima na parcela. }
\end{aligned}
$$


Os mesmos autores propuseram uma modificação da equação de uniformidade de emissão, chamada de uniformidade de emissão absoluta $\left(E U_{a}\right)$. Esta equação inclui as razões das vazões máxima e mínima dos emissores com a média, conforme a equação 5.

$$
U E_{a}=100 \cdot \frac{1}{2}\left(\frac{q_{n}}{q_{m}}+\frac{q_{m}}{q_{x}}\right)
$$

em que:

$\mathrm{UE}_{\mathrm{a}}$ - uniformidade de emissão absoluta;

$\mathrm{q}_{\mathrm{n}}$ - média das 25\% menores vazões observadas;

$q_{x}$ - média das $12,5 \%$ maiores vazões observadas;

$\mathrm{q}_{\mathrm{m}}$ - média das vazões observadas.

Outro índice bastante utilizado tanto para avaliações de campo quanto para dimensionamento, como sugere Pizarro Cabello (1996), é a uniformidade de emissão (UE), ou uniformidade de distribuição (UD), conforme equação 6 .

$$
U D=\frac{q_{25 \%}}{q_{m}}
$$

em que:

UD - uniformidade de distribuição;

$\mathrm{q}_{25 \%}$ - vazão média do menor quartil;

$q_{m}$ - média de todas as vazões. 
Botrel \& Frizzone (1996) descrevem, para avaliação de um sistema de irrigação localizada em campo, a utilização da uniformidade de emissão (UE), empregando o procedimento de selecionar ao longo da linha de derivação a primeira lateral, a lateral situada a 1/3 do comprimento, a situada a 2/3 e a última lateral. Em cada lateral selecionada, avaliar 4 emissores seguindo o mesmo critério de posicionamento (primeiro, 1/3, 2/3, e último), totalizando 16 emissores.

Podem-se adotar como parâmetros para UD os seguinte valores:

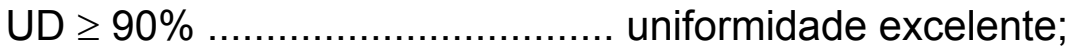

$$
\begin{aligned}
& 80 \% \leq \text { UD }<90 \% \text {....................... uniformidade boa; } \\
& 70 \% \leq \text { UD }<80 \% \text {....................... uniformidade regular; }
\end{aligned}
$$

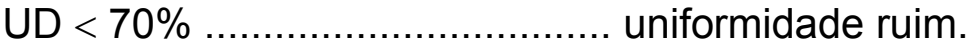

A interpretação dos valores de uniformidade de emissão pode ser realizada admitindo-se os valores de UD, relacionados com o tipo de aplicação, espaçamento entre emissores e declividade da área, conforme Tabela 1.

\begin{tabular}{|c|c|c|c|c|}
\hline Tipo de aplicação & Esp. (m) & Topografia da área & Declividade & UD (\%) \\
\hline \multirow{2}{*}{$\begin{array}{l}\text { Emissão pontual em } \\
\text { culturas perenes }\end{array}$} & & Uniforme & $<2$ & 90 a 95 \\
\hline & $>4$ & $\begin{array}{l}\text { Declivosa ou } \\
\text { ondulada }\end{array}$ & $>2$ & 85 a 90 \\
\hline \multirow{2}{*}{$\begin{array}{l}\text { Emissão pontual em } \\
\text { culturas semi- } \\
\text { permanentes ou perenes }\end{array}$} & & Uniforme & $<2$ & 85 a 90 \\
\hline & $<4$ & $\begin{array}{l}\text { Declivosa ou } \\
\text { ondulada }\end{array}$ & $>2$ & 80 a 90 \\
\hline \multirow{2}{*}{$\begin{array}{l}\text { Emissão linear em } \\
\text { culturas anuais ou } \\
\text { perenes }\end{array}$} & \multirow{2}{*}{ Qualquer } & Uniforme & $<2$ & 80 a 90 \\
\hline & & $\begin{array}{l}\text { Declivosa ou } \\
\text { ondulada }\end{array}$ & $>2$ & 70 a 85 \\
\hline
\end{tabular}

Tabela 1. Classificação dos valores de UD.

Fonte: ASAE EP 405.1 (1994) 
O coeficiente de uniformidade estatístico (Equação 7) também quantifica a uniformidade de aplicação de água, como sugerem Bralts \& Kesner (1983).

$$
E U_{S}=100\left(1-\frac{s_{q}}{q_{m}}\right)
$$

em que:

$U_{\mathrm{s}}$ - uniformidade de emissão estatística;

$\mathrm{s}_{\mathrm{q}}$ - desvio-padrão dos valores;

$\mathrm{q}_{\mathrm{m}}$ - vazão média.

Para a interpretação dos valores deve-se seguir:

$$
\begin{aligned}
& \mathrm{UE}_{\mathrm{S}} \geq 90 \% \ldots \ldots \ldots \ldots \ldots \ldots \ldots \ldots . . . . . . . . . \ldots \text { uniformidade excelente; } \\
& 80 \% \leq \mathrm{UE}_{\mathrm{S}}<90 \% \text {................. uniformidade muito boa; } \\
& 70 \% \leq \mathrm{UE}_{\mathrm{S}}<80 \% \text {................. uniformidade regular; } \\
& 60 \% \leq \mathrm{UE}_{\mathrm{S}}<70 \% \text {................. uniformidade ruim; } \\
& \mathrm{UE}_{\mathrm{S}}<60 \% \ldots \ldots \ldots \ldots \ldots \ldots \ldots . . . . . . . . . . . . . . .1 \text { unformidade inaceitável. }
\end{aligned}
$$

Estudos realizados por Favetta et al. (1993), correlacionado resultados de uniformidade de emissão (UE), uniformidade de emissão estatística $\left(E U_{s}\right)$ e uniformidade de emissão absoluta $\left(U E_{a}\right)$, demonstram haver alta correlação entre os índices, permitindo, portanto, avaliar os sistemas de irrigação implantados pelos diferentes métodos, executando-se os cálculos para um método e estimando-se os outros pelas equações de correlação. 


\subsubsection{Entupimento}

O entupimento dos emissores na malha hidráulica é um grande desafio para operação e manutenção de um sistema de irrigação por gotejamento, tendo levado muitos irrigantes ao insucesso com essa tecnologia (Ghaemi \& Chieng, 1999).

Os emissores apresentam diferentes potenciais ao entupimento de acordo com a qualidade da água, dependendo do diâmetro mínimo de passagem da água, da velocidade do fluxo e das características físicas de construção do emissor (tipos de labirintos, perda de carga localizada na lateral, etc). Os emissores de baixa vazão apresentam diâmetro de passagem interno de água entre 0,3 e 1,0 mm, enquanto os de alta vazão têm diâmetro maior que 2 mm. Para Pizarro Cabello (1996), os emissores podem ser agrupados em três categorias quanto à sensibilidade ao entupimento em função do diâmetro de passagem d'água:

$$
\begin{aligned}
& \varnothing<0,7 \mathrm{~mm} \text {....................... alta sensibilidade à obstrução; } \\
& \varnothing \text { entre } 0,7 \text { e 1,5 mm ........... média sensibilidade à obstrução; } \\
& \varnothing>1,5 \mathrm{~mm} \text {........................ baixa sensibilidade à obstrução. }
\end{aligned}
$$

Estudos realizados por Bralts et al. (1987) identificaram cinco situações em um sistema de microirrigação em que acontece tipicamente o entupimento: (1) entupimento parcial que afeta todos os emissores igualmente; (2) entupimento parcial que afeta uma proporção específica dos emissores igualmente; (3) entupimento completo afetando todos os emissores igualmente; (4) entupimento completo afetando uma proporção específica dos emissores; (5) uma combinação de entupimento parcial e completo. A quinta situação é um caso geral e os outros podem ser 
derivados disso. Em situações de campo há normalmente alguns emissores que são parcial ou completamente entupidos.

Lau et al. (1978), citados por Povoa \& Hills (1994), relataram experiências de campo nas quais mostraram que o entupimento é predominante na extremidade final da lateral. Wu et al. (1991) confirmaram que o entupimento não é distribuído uniformemente ao longo da linha lateral.

A baixa qualidade da água de irrigação pode obstruir rapidamente os emissores. Em geral, as causas do entupimento de emissores podem ser divididas em três categorias: (1) componentes físicos, como areia, partículas de PVC proveniente da montagem do sistema; (2) materiais biológicos; (3) substâncias químicas precipitadas, tais como $\mathrm{CaCO}_{3}$. Podem ser eliminados os entupimentos físicos com o uso de sistemas de filtragem eficiente, os biológicos com cloração e outros métodos de desinfecção, e a precipitação química com controle do pH da água de irrigação (Yuan et al, 1998). Outras causas de entupimento dos gotejadores são a sucção de partículas sólidas e a intrusão radicular em sistema subsuperficiais.

Para a determinação do risco de obstrução pelo teor de cálcio presente na água de irrigação, Nakayama (1986) recomenda utilizar o Índice de Saturação de Langelier (IS). Com este procedimento, calcula-se o pH da água e a diferença entre o $\mathrm{pH}$ calculado e o $\mathrm{pH}$ lido $\left(I S=p H_{\text {lido }}-p H_{\text {calculado }}\right)$. Se resultar em valores positivos, indica haver tendência de produção de precipitados químicos de $\mathrm{CaCO}_{3}$; sendo negativo, há tendência em manter o $\mathrm{CaCO}_{3}$ dissolvido em solução, não produzindo precipitados químicos.

Leite (1995), estudando a suscetibilidade de tubos gotejadores ao entupimento por precipitados químicos de carbonato de cálcio, concluiu que para as condições experimentais todos os emissores, de 5 diferentes fabricantes, sofreram redução de vazão superior a $80 \%$.

Costa (2000), estudando a suscetibilidade de tubos gotejadores ao entupimento por precipitados, concluiu que águas com teor de $3 \mathrm{mg} / \mathrm{L}$ de ferro total são inviáveis para o gotejamento, causando elevada redução de 
vazão dos emissores estudados. O mesmo autor observou, também, existir diferença entre emissores em termos de resistência ao entupimento quanto ao aspecto construtivo, sendo os gotejadores planos ("Flats") mais resistentes do que os integrados (Tapes).

Resende (1999) concluiu que há diferenças significativas entre os cinco modelos de gotejadores avaliados quanto à suscetibilidade ao entupimento de origem biológica.

A combinação entre fatores, como uniformidade de fabricação, dimensionamento criterioso do sistema, manutenção periódica e manejo adequado, são elementos fundamentais ao sucesso da agricultura irrigada por gotejamento. A presença isolada de um dos fatores relacionados anteriormente não garante o sucesso do empreendimento, pois a alta eficiência de um emissor passa a ser irrelevante em um projeto hidráulico mal dimensionado ou instalado no campo.

\subsection{Gotejamento enterrado}

No gotejamento subsuperficial (enterrado), as linhas laterais são instaladas a profundidades variadas, de acordo com características do solo e cultura a ser irrigada, entre outros fatores. O fato de não se poder detectar visualmente problemas como entupimento, faz com que medidas preventivas, como filtragem eficiente, monitoramento da qualidade da água, aplicação de produtos químicos para a limpeza da tubulação, cuidados na montagem dos sistemas, sejam considerados relevantes, colaborando para o sucesso do empreendimento.

Ayars et al. (1999) afirmaram que a área irrigada por microirrigação na Califórnia EUA, em 1995, era de 626.000 hectares, sendo 99.000 hectares por gotejamento subsuperficial. Os mesmos autores citam também como vantagem dos sistemas de gotejamento enterrado o melhor 
aproveitamento da água de irrigação e dos nutrientes aplicados nesta, o que deverá resultar em melhor qualidade dos produtos agrícolas. Sánchez (1996) cita também como vantagens do gotejamento subsuperficial a aplicação de fertilizantes de baixa mobilidade no solo, via água de irrigação, próximos as raízes, resultando em maior aproveitamento deste, e também a proteção das linhas laterais quanto a danos mecânicos, ataque de roedores e vandalismo.

Zoldoske et al. (1998) afirmam que os sistemas de gotejamento enterrado, tanto para culturas de ciclo curto quanto para as culturas perenes, poderão ter vida útil igual ou superior a 20 anos. Eles afirmam também que há significativa redução na aplicação de herbicidas para controle de ervas nas entrelinhas em lavouras com culturas perenes, bem como na redução do tráfego de máquinas, poupando combustível e provocando menor compactação do solo, devido à não-ocorrência de umedecimento da superfície do solo, resultando em entrelinhas livres de ervas plantas daninhas.

Segundo Pizarro Cabello (1996), os sistemas de irrigação por gotejamento subsuperficial não diferem muito dos sistemas de irrigação por gotejamento superficial, a não ser na maior densidade de dispositivos antivácuo e de limpeza no final das linhas laterais.

Em gotejamento superficial, os dispositivos antivácuo têm a função de proteger a tubulação contra o colapso dos tubos provocados pelo vácuo formado após as válvulas, quando a irrigação da parcela é interrompida, ocorrendo drenagem da água nos pontos de cota inferior da área. No gotejamento subsuperficial, os dispositivos antivácuo devem atender, além do colapso, à sucção de partículas sólidas que podem provocar distúrbios de vazão nos emissores. Estes dispositivos devem estar presentes em todos os pontos altos das parcelas (Ruskin, 1995).

A utilização de tubos gotejadores com espessura de parede reduzida poderá ser um problema quando empregado em áreas de solo não consolidado e sujeito a tráfego intenso de máquinas, pois o desmoronamento 
do solo pode causar o colapso do tubo, provocando maior perda de carga e desequilíbrio hidráulico na linha lateral (Hills et al., 1989).

A utilização de tubulação auxiliar para a limpeza das linhas laterais é recomendada em gotejamento enterrado, pois facilita a remoção de material sedimentado nas linhas laterais, evitando o entupimento (Burt, 1995).

Maciel (1998), monitorando a distribuição de fósforo e potássio no perfil do solo aplicados via água de irrigação em gotejamento subsuperficial, concluiu que os dois elementos tiveram boa distribuição nos sentidos vertical ascendente $(0,15 \mathrm{~m})$ e descendente $(0,35 \mathrm{~m})$, e no sentido horizontal $(0,50$ m) dentro do bulbo úmido, tendo o emissor como ponto de referência.

Para Suarez-Rey et al. (1999), o fato de se aplicar água diretamente na zona radicular possibilita a utilização de águas residuais, pois reduz o risco de transmissão de doenças, além de minimizar as perdas de água por evaporação.

Segundo Pizarro Cabello (1996), os principais problemas que podem ocorrem aos gotejadores enterrados são: a sucção de partículas sólidas do solo quando o sistema de irrigação é desligado, fato este controlável com utilização de válvulas antivácuo e intrusão de raízes no gotejador que resulta em entupimento.

O gotejamento superficial utilizando tubogotejadores comerciais cresce a uma taxa maior do que o subsuperficial, pois problemas como entupimento e intrusão radicular têm acontecido, tornando a primeira opção mais viável (Camp, 1998).

\subsubsection{Prevenção contra intrusão radicular}

Ruskin \& Ferguson (2000) relatam existir no mercado norteamericano quatro maneiras de se evitar a intrusão radicular: (1) emissores com barreiras mecânicas; (2) adição do herbicida trifluralina na água de 
irrigação; (3) incorporação da trifluralina no plástico do emissor; (4) incorporação de trifluralina no filtro de discos.

A trifluralina é um herbicida do grupo da dinitroanilina. Seu principio ativo apresenta persistência média no ambiente, degradando-se por fotodecomposição e por ação de microorganismos. Este produto não apresenta deslocamento para regiões vizinhas, e a maioria das culturas tem tolerância provisória de até 0,05 ppm do produto no solo (Gelmini, 1991).

A trifluralina, sendo um herbicida nitrogenado, impede 0 crescimento das raízes secundárias sem causar danos às raízes principais, impedindo que haja penetração nos emissores. Como qualquer herbicida nitrogenado, a trifluralina se degrada com a temperatura e a umidade, fazendo com que sua aplicação seja realizada entre intervalos de 5 a 6 meses (Pizarro Cabello, 1996).

Almeida \& Rodrigues (1985) afirmam que a fotodecomposição e a volatilização são os principais fatores responsáveis pelo desaparecimento da trifluralina no solo, e que sua incorporação ao solo colabora na redução às perdas.

Com o desenvolvimento radicular na região do bulbo úmido, poderá ocorrer intrusão das raízes no interior dos emissores, prejudicando sua vazão. Entretanto, dependendo da textura do solo e da freqüência de irrigação, tal intrusão pode não ocorrer (Sánchez, 1996).

Problemas com intrusão radicular em tubos perfurados a laser e em emissores cilíndricos foram observados em gotejamento enterrado irrigando gramados quando não houve tratamento químico preventivo. Na mesma condição, emissores que possuem trifluralina em sua composição, não apresentaram intrusão radicular. Entretanto, um modelo de emissor comercial que não contém o herbicida em sua composição apresentou resistência à penetração das raízes, fato este explicável pelo aspecto construtivo do emissor, que apresenta barreira física impedindo a penetração radicular. As barreiras físicas demonstram ser eficientes na prevenção à 
intrusão radicular; porém, ainda não se pode afirmar com precisão quais as características de projeto dos emissores que têm resultado comprovado nesse aspecto (Solomon \& Jorgensen, 1993).

A freqüência de irrigação é fator fundamental à prevenção contra a intrusão radicular. O sistema radicular não invade emissores em solos saturados ou próximos à saturação; portanto, não havendo depleção elevada de água no solo, não ocorrerá intrusão radicular (Mead, 2001).

Poucas informações científicas estão disponíveis até o momento sobre a suscetibilidade à intrusão radicular em gotejamento enterrado, e tampouco sobre as características construtivas dos emissores portadores de barreiras físicas. A utilização de produtos já consagrados contra a intrusão radicular, com emissores impregnados com trifluralina, nem sempre é economicamente viável, pois esses produtos têm custo de aquisição em torno de $100 \%$ mais elevados que produtos convencionais comercializados no Brasil. Deve-se considerar também a possibilidade de acidentes na injeção de produtos preventivos à intrusão radicular, provocando danos ao meio ambiente e, em casos extremos, danos aos cultivos irrigados em questão. 


\section{MATERIAL E MÉTODOS}

\subsection{Localização do experimento}

O presente ensaio foi realizado em Piracicaba-SP, no Departamento de Engenharia Rural, Setor de Irrigação e Drenagem da Escola Superior de Agricultura "Luiz de Queiroz" - ESALQ/USP, em condição de ambiente protegido (estufa com cobertura plástica) entre os meses de abril e dezembro de 2001.

\subsection{Preparo dos vasos e espécies vegetais utilizadas}

As espécies vegetais utilizadas são o cafeeiro Icatu e a laranjeira Pêra com enxerto de tangerina Cleópatra por serem variedades utilizadas pelos produtores que planejam suas lavouras para o sistema de produção irrigado. Utilizaram-se mudas das duas espécies, a primeira produzida em tubetes plásticos e a segunda produzida em sacos plásticos.

As mudas foram transplantadas para vasos de cimento amianto $(0,58 \times 0,43 \times 0,43 \mathrm{~m})$ com $100 \mathrm{~L}$ de capacidade. Os vasos foram previamente preparados para receber as mudas conforme o esquema da Figura 2, com duas camadas de furos sendo que, a primeira a $15 \mathrm{~cm}$ de profundidade e a segunda a $30 \mathrm{~cm}$. Cada camada foi formada por 14 
perfurações, totalizando 14 tubos gotejadores por profundidade, sendo que em cada segmento de tubo havia somente um gotejador conforme esquema da Figura 3. A ordem dos gotejadores em cada camada foi obtida por sorteio para garantir a condição de aleatoriedade, procurando quando possível manter o gotejador posicionado para cima. Foram feitos furos na parte inferior dos vasos para drenagem de eventuais irrigações excessivas. Para proporcionar a drenagem segura, sem haver carreamento de substrato, foi posta uma camada de $2 \mathrm{~cm}$ de espessura de brita $\mathrm{n}^{0} 1$, sobreposta por uma manta de geotêxtil. Foram transplantadas nove mudas de café e seis mudas de laranja para cada vaso (Figura 4).
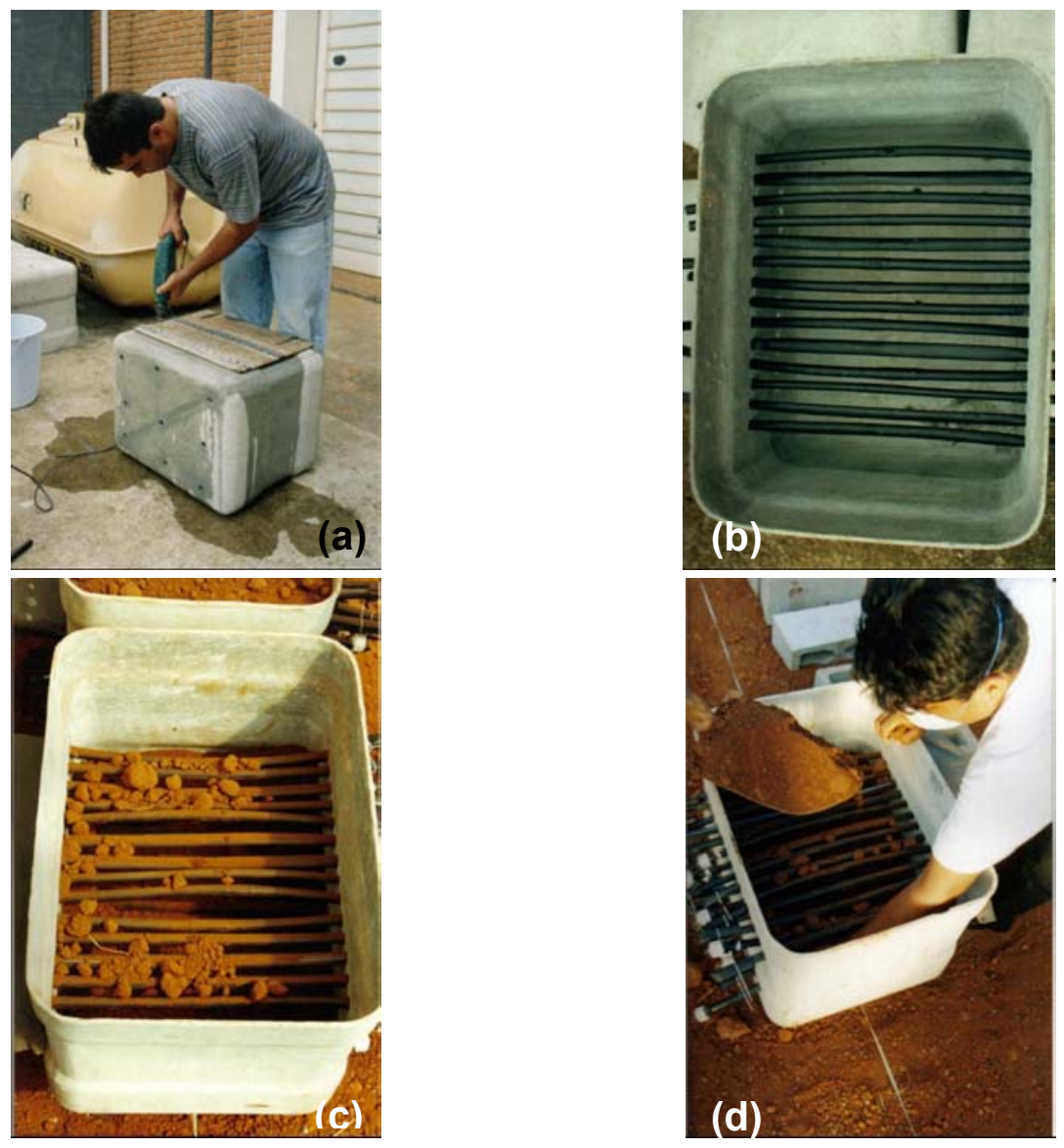

Figura 2 - Preparação dos vasos para recebimento das mudas: (a) furação das dos vasos; (b) instalação da $1^{\text {a }}$ linha de emissores; (c) preenchimento com solo; (c) Instalação da $2^{\mathrm{a}}$ linha; (d) preenchimento com solo. 

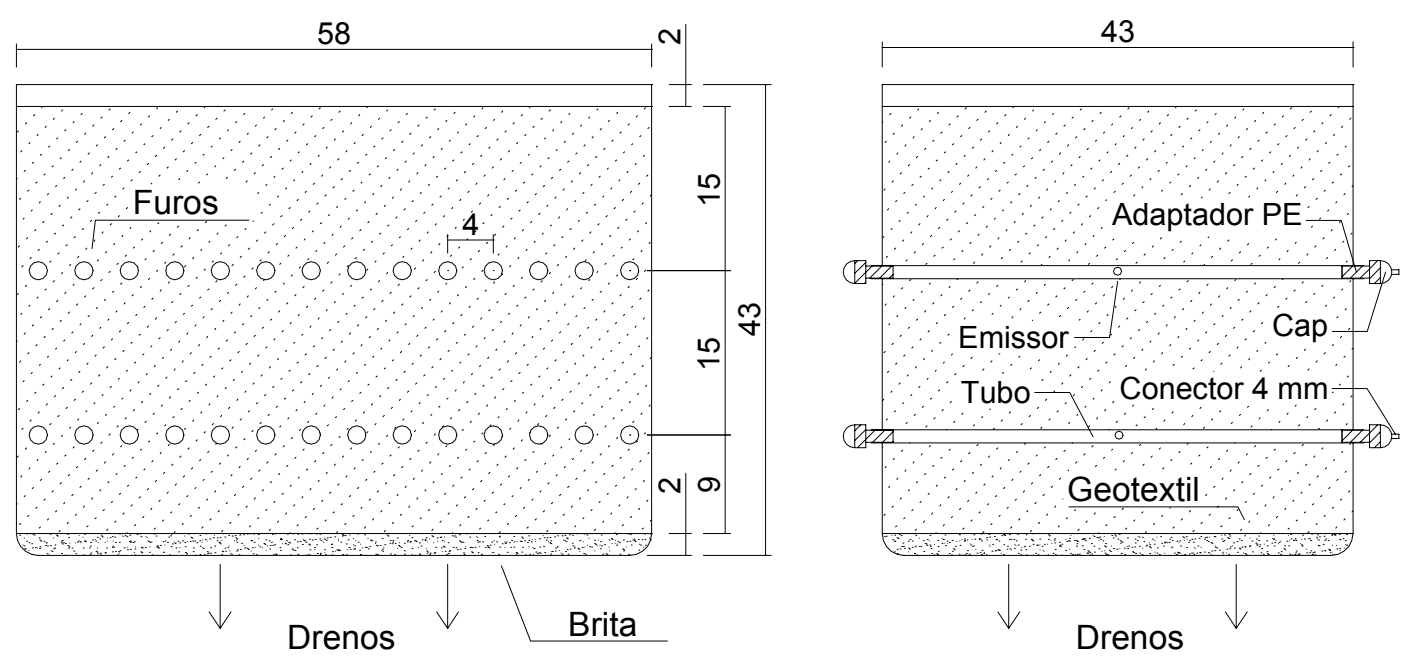

Figura 3 - Esquema de montagem dos vasos com os tubos gotejadores.

CAFÉ

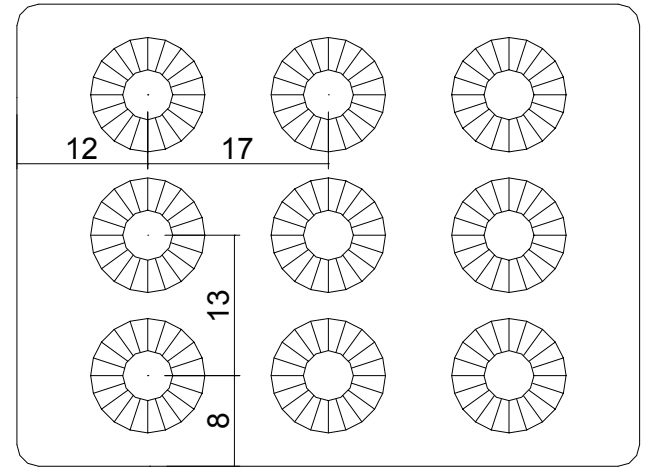

CITROS

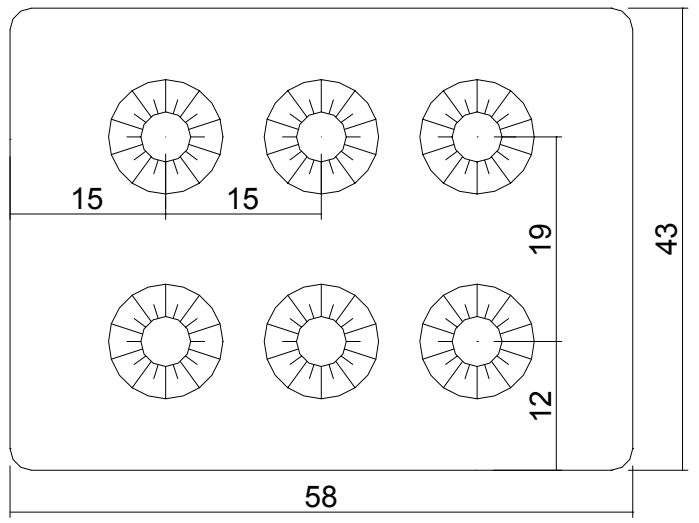

Figura 4 - Disposição das mudas de café e citros nos vasos.

O solo utilizado no preparo do substrato para preenchimento dos vasos foi um Latossolo Vermelho-Amarelo, classificado como textura arenosa, com $67 \%$ de areia, $5 \%$ de silte e $28 \%$ de argila, sendo a fração areia construída por $3 \%$ de areia grossa, $24 \%$ de areia média e $40 \%$ de areia fina. A opção pelo solo arenoso, deu-se pela melhor drenagem do excesso d'água de irrigação, pela menor capacidade de retenção de água e pela maior facilidade de crescimento do sistema radicular em solos dessa textura. 
Realizou-se uma calagem no solo com calcário dolomítico para a correção do $\mathrm{pH}$ e da saturação de bases (V\%). A adubação química dos cultivos, baseou-se em fertilizante de liberação lenta (Osmocote), de acordo com a recomendação do fabricante para plantas em viveiros de mudas.

\subsection{Emissores utilizados}

Escolheram-se 14 modelos de gotejadores, dando prioridade aos recomendados pelos fabricantes em sistemas enterrados, e também aos mais comercializados no Brasil. Procurou-se formar um grupo de no máximo 14 gotejadores, que poderiam ser instalados em uma mesma camada nos vasos. Dentro do grupo selecionado de emissores, observa-se a presença de gotejadores com e sem mecanismo de autocompensação, emissores tipo cilíndrico, tipo botão, tipo plano e fita gotejadora. $\mathrm{Na}$ Tabela 2 são apresentados os emissores selecionados e as principais características de cada um deles.

Tabela 2. Principais características dos tubos gotejadores utilizados.

\begin{tabular}{cccccc}
\hline Fabricante & Modelo & Vazão $\left(\mathrm{L} . \mathrm{h}^{-1}\right)$ & $\mathrm{H}(\mathrm{kPa})$ & Fluxo & Emissor \\
\hline Carborundum & Carbodrip & 2,20 & 100 & Normal & Cilíndrico \\
Carborundum & Carbodrip PC & 2,20 & 100 & Auto comp. & Cilííndrico \\
Drip In & Drip In Classic & 1,52 & 100 & Normal & Cilíndrico \\
Drip In & Drip In PC & 4,00 & 100 & Auto comp. & Cilíndrico \\
Irrimom & Vip & 3,60 & 100 & Auto comp. & Botão \\
Naan & Naan Tif PC & 1,60 & 100 & Auto comp. & Cilíndrico \\
Netafim & Ram 17L & 2,30 & 100 & Auto comp. & Plano \\
Netafim & Tiram 2000 & 2,05 & 100 & Normal & Plano \\
Netafim & Typhoon & 2,00 & 100 & Normal & Plano \\
Plastro & Hydro Drip II & 2,30 & 100 & Normal & Plano \\
Plastro & Hydrogol & 2,00 & 100 & Normal & Cilíndrico \\
Plastro & Hydro PC & 2,20 & 100 & Auto comp. & Cilíndrico \\
Rain Bird & Drip Line & 3,40 & 100 & Auto comp. & Cilíndrico \\
Toro Ag. & Aqua Traxx & 1,14 & 70 & Normal & Fita \\
\hline
\end{tabular}

Fonte: Catálogos dos fabricantes 
Como os emissores ensaiados são produtos comerciais, os dados e análises aqui apresentadas foram codificados para evitar qualquer tipo de especulação comercial dos resultados apresentados. As letras utilizadas na codificação dos modelos de emissores $(A, B, C, \ldots, O)$, não têm nenhuma relação com os nomes comerciais dos produtos e nem com a seqüência de emissores apresentada na Tabela 1.

\subsection{Tratamentos e delineamento estatístico}

Os tratamentos utilizados no experimento foram: (1) modelo de emissor; (2) profundidade de instalação; (3) nível de irrigação; (4) tipo de cultura.

Foram montados 20 vasos para cada cultura, sendo que cada vaso recebeu 14 emissores diferentes em cada profundidade de instalação (15 e $30 \mathrm{~cm}$ ), totalizando 28 emissores por vaso. O tratamento nível de irrigação foi aplicado para 10 dos 20 vasos por espécie vegetal. Cada tratamento possuía 10 repetições (10 vasos), sendo portanto 10 vasos com a cultura do café com o tratamento seco e 10 vasos com o tratamento úmido. A mesma distribuição foi feita para a laranja. Foram montados 10 vasos sem cultivos como testemunhas, totalizando 50 vasos, conforme esquematizado na Figura 5.

O delineamento estatístico idealizado inicialmente, seguiu um esquema inteiramente casualizado, com parcelas subdivididas e fatorial $2 \mathrm{x}$ 14, constando de 10 repetições (gotejadores) por parcela, sendo a profundidade a subparcela. Os 10 vasos sem cultivos da testemunha, foram utilizados no sentido de isolar q quantificar outras causas de obstrução dos emissores, que não à intrusão radicular. 


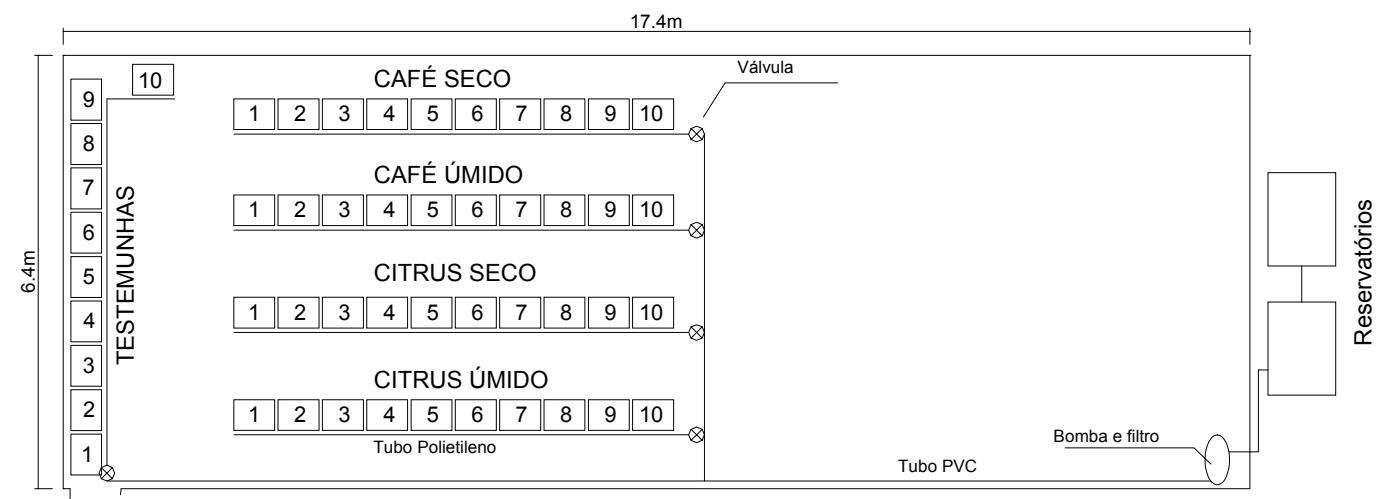

Figura 5 - Vista geral do experimento.

\subsection{Sistema de irrigação}

O sistema de irrigação foi composto por dois reservatórios d'água com capacidade de $1 \mathrm{~m}^{3}$ cada, acoplados em sistema de vasos comunicantes. A água utilizada na irrigação era de consumo doméstico, tratada para atingir os padrões de potabilidade da ABNT.

A água era pressurizada por um conjunto eletrobomba com potência de 1cv. O sistema de filtragem foi composto por um filtro de discos com filtragem de 86 micra (200 mesh), conforme Figura 6a. Após a filtragem, a água é conduzida até cavaletes (Figura 6b), através de tubulação em PVC subterrânea. Os cavaletes foram construídos em PVC, apresentando uma válvula hidráulica e uma válvula antivácuo em cada um deles. Seqüencialmente, após os cavaletes, existiam duas linhas de distribuição em tubos de polietileno, as quais alimentavam os microtubos conectados aos segmentos dos tubos gotejadores. O sistema de irrigação era composto também por válvula reguladora de pressão, registro de gaveta, registro de esfera, controlador eletrônico e acessórios. 

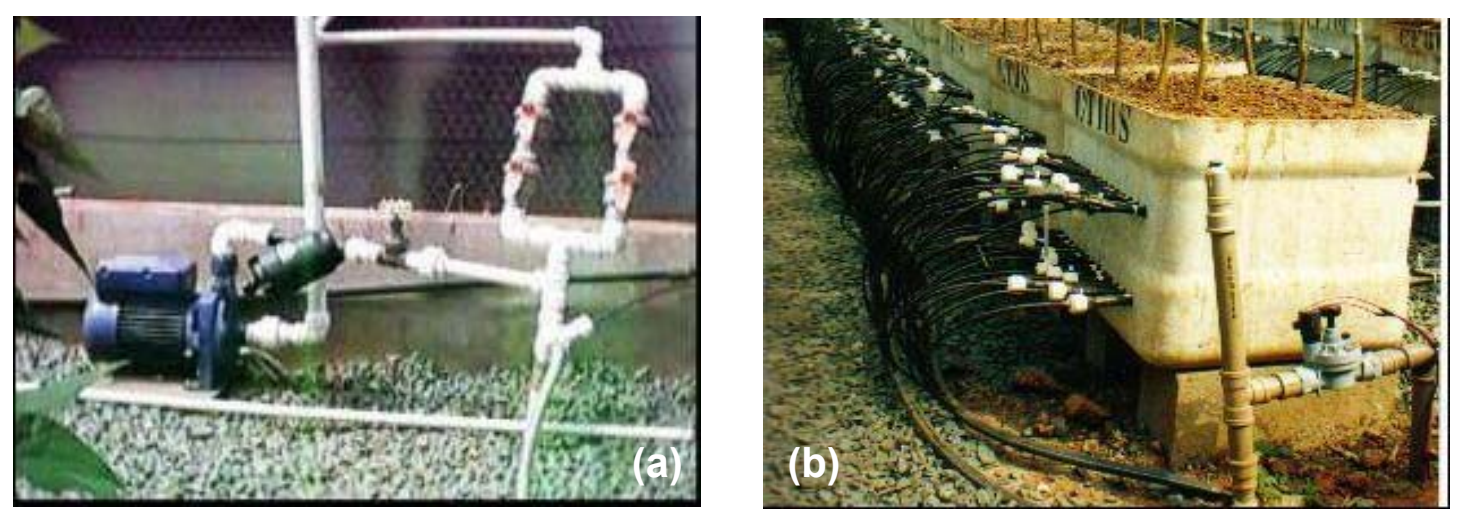

Figura 6- Detalhes do sistema de irrigação: (a) motobomba e (b) detalhe do cavalete.

Para coleta de dados ou determinação da vazão individual de cada gotejador, criou-se uma rede hidráulica que conduzia a água a apenas um gotejador por vez, através de uma mangueira conectada após o sistema de filtragem, retornando a vazão excedente aos reservatórios.

\subsection{Manejo da irrigação}

O manejo da irrigação foi realizado com o auxilio de uma bateria de tensiômetros para cada tratamento (cultura $x$ nível de irrigação). As leituras tensiométricas foram realizadas sempre no início da manhã. No tratamento úmido, para as duas culturas, determinou-se como limite de tensão de água no solo o valor de $-30 \mathrm{kPa}$ para o tensiômetro superficial à $7,5 \mathrm{~cm}$ de profundidade para dar início à irrigação. Já no tratamento seco, para ambas as duas culturas, esperou-se que as plantas apresentassem sintomas de estresse hídrico pela manhã (murchamento das folhas) para iniciar a irrigação. Nesse tratamento, procurou-se não promover a saturação do solo nem tampouco elevar a umidade do solo à capacidade de campo, 
promovendo continuamente déficit hídrico moderado de água no solo, de modo que a planta não viesse a morrer.

\subsection{Determinação da vazão dos emissores}

Para a determinação da vazão individual dos gotejadores, utilizouse um medidor magnético indutivo, modelo IFC-090-F, fabricado pela empresa Krohne/Conaut, capaz de medir vazões na faixa de vazão de 0 a 10 L. $\mathrm{h}^{-1}$, com precisão de $0,3 \%$ (Figura $7 \mathrm{a}, 7 \mathrm{~b}$ ). Como cada gotejador era abastecido isoladamente, foi possível determinar a vazão individual de cada emissor, desconectando o microtubo de abastecimento de cada gotejador da rede de PVC e conectando-o ao medidor de vazão.

Adaptou-se um sistema de acoplamento através de engate rápido para facilitar o acoplamento e desacoplamento da tubulação a jusante do medidor. A pressão de ensaio foi monitorada através de um manômetro digital instalado no medidor de vazão. Todos os modelos de emissores foram ensaiados à pressão de $100 \mathrm{kPa}$, exceto o modelo Aquatraxx, cuja pressão de serviço recomendada pelo fabricante é de $70 \mathrm{kPa}$.

As leituras foram registradas manualmente. Condicionou-se 0 momento de leitura quando o mostrador do medidor apresentava estabilização. Este medidor de vazão, por se tratar de um equipamento eletromagnético, quando adequadamente aterrado, tende a estabilizar rapidamente as leituras, diminuindo significativamente o tempo total de ensaio. $O$ fio de terra foi instalado somente após a realização da terceira leitura. As datas de início de cada leitura foram: 01/07, 01/09, 01/10, 01/11 e 01/12 do ano de 2001. 

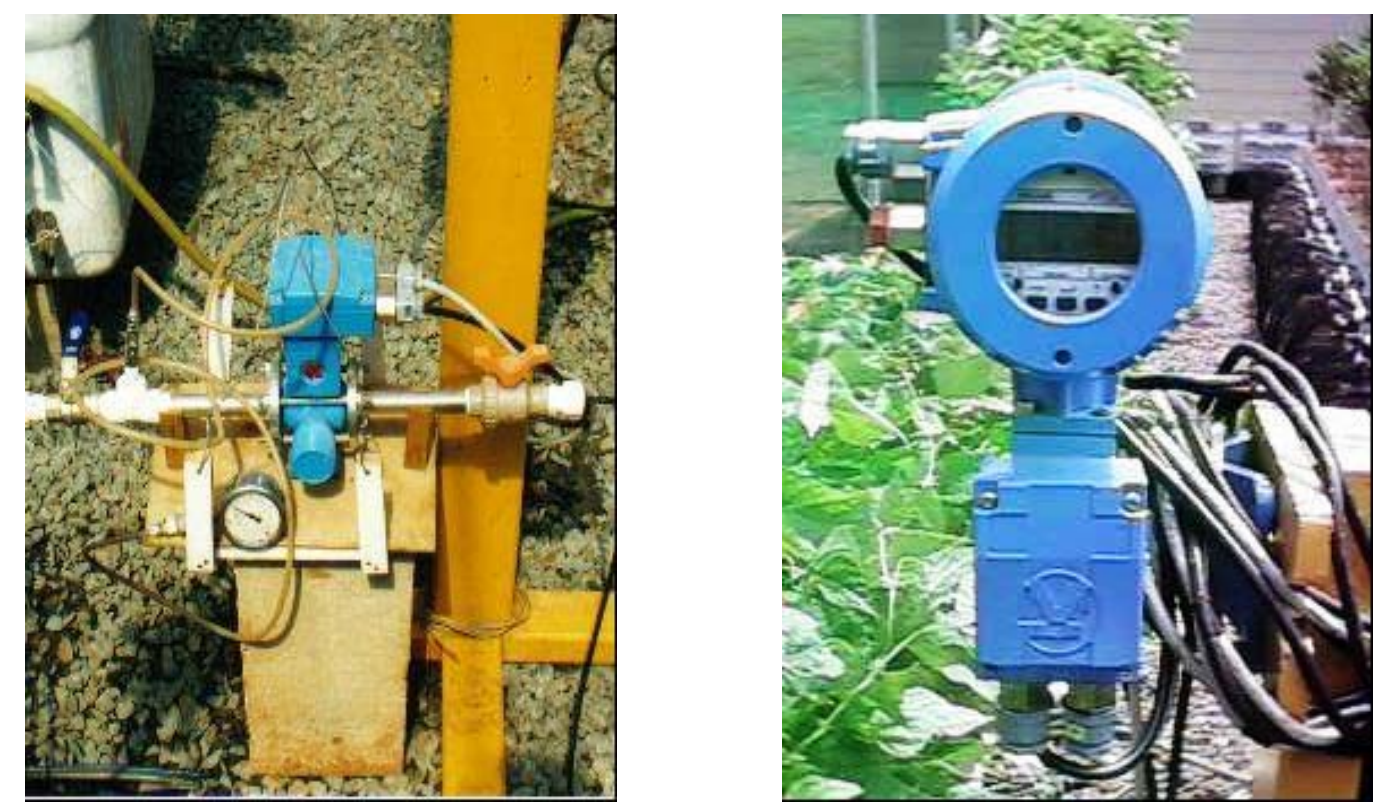

Figura 7 - Detalhes do medidor de vazão: (a) sensor magnético e (b) leitor digital.

As determinações de vazões foram realizadas mensalmente; porém, o intervalo entre a primeira e a segunda leitura foi de dois meses. Esse maior intervalo entre a primeira e a segunda leitura ocorreu, com o intuito de permitir a manifestação do tratamento de manejo da irrigação nos resultados.

\subsection{Parâmetros avaliados}

Para a avaliação do desempenho dos emissores, utilizaram-se os seguintes parâmetros:

\subsubsection{Coeficiente de variação de vazão (CVQ)}

Realizou-se o procedimento de cálculo apresentado na equação 2 para todos os modelos de emissores utilizados no ensaio, em todas as condições de tratamentos (café seco, café úmido, citros seco, citros úmido e 
testemunha). Esse coeficiente foi utilizado com o nome de coeficiente de variação de vazão (CVQ), pois, como o coeficiente de variação de fabricação (CVF), só poderia ser empregado em amostra de emissores novos.

\subsubsection{Vazão relativa $(Q R)$}

Este índice refere-se às vazões iniciais de cada modelo no instante da realização da primeira leitura. Foi obtido dividindo-se a vazão em qualquer instante pela vazão inicial do emissor.

Ressalta-se que a ABNT recomenda a utilização de uma amostra formada por 50 indivíduos; entretanto, como cada tratamento possuía apenas 10 repetições, foram utilizadas amostras de 10 indivíduos.

\subsubsection{Critério para julgamento do desempenho dos emissores}

Adotou-se um roteiro básico para o julgamento do desempenho dos emissores, de forma a estabelecer um padrão idêntico para todos os emissores. Esse roteiro seguiu a ordem: (1) análise do CVQ inicial dos emissores e do CVQ inicial geral dos emissores desse modelo, presentes em todos os tratamentos; (2) tendência geral do comportamento da vazão; (3) análise dos picos do CVQ; (4) efeito dos tratamentos, (5) desempenho da testemunha; (6) descrição das particularidades de desempenho de alguns emissores. 


\section{RESULTADOS E DISCUSSÃO}

\subsection{Qualidade da Água de Irrigação}

Realizou-se uma análise físico-química da água de irrigação em abril de 2001, cujos parâmetros são apresentados na Tabela 3.

Tabela 3. Resultado da análise da água de irrigação.

\begin{tabular}{ccc}
\hline Parâmetro & Unidade & Resultado \\
\hline Alcalinidade $\left(2 \mathrm{CO}_{3}{ }^{2-}+\mathrm{HCO}_{3}{ }^{-}\right)$ & $\mathrm{mg} \cdot \mathrm{L}^{-1}$ & 36,4 \\
Cloreto $\left(\mathrm{Cl}^{-}\right)$ & $\mathrm{mg} \cdot \mathrm{L}^{-1}$ & 8,1 \\
Nitrato $\left({\left.\mathrm{N}-\mathrm{NO}_{3}\right)}\right)$ & $\mathrm{mg} \cdot \mathrm{L}^{-1}$ & 4,1 \\
Sulfato $\left(\mathrm{SO}_{4}{ }^{2-}\right)$ & $\mathrm{mg} \cdot \mathrm{L}^{-1}$ & 48,1 \\
Fósforo $(\mathrm{P})$ & $\mathrm{mg} \cdot \mathrm{L}^{-1}$ & 0,16 \\
Nitrogênio Amoniacal $\left(\mathrm{N}-\mathrm{NH}_{3}\right)$ & $\mathrm{mg} \cdot \mathrm{L}^{-1}$ & 0,3 \\
Sódio $\left(\mathrm{Na}^{+}\right)$ & $\mathrm{mg} \cdot \mathrm{L}^{-1}$ & 8,9 \\
Potássio $\left(\mathrm{K}^{+}\right)$ & $\mathrm{mg} \cdot \mathrm{L}^{-1}$ & 3,4 \\
Cálcio $\left.\left(\mathrm{Ca}^{2+}\right)^{2+}\right)$ & $\mathrm{mg} \cdot \mathrm{L}^{-1}$ & 12,7 \\
Magnésio $\left(\mathrm{Mg}{ }^{-1}\right)$ & $\mathrm{mg} \cdot \mathrm{L}^{-1}$ & 7,3 \\
Ferro $(\mathrm{Fe})$ & $\mathrm{mg} \cdot \mathrm{L}^{-1}$ & 0,2 \\
Cobre $(\mathrm{Cu})$ & $\mathrm{mg} \cdot \mathrm{L}^{-1}$ & 0,04 \\
Manganês $(\mathrm{Mn})$ & $\mathrm{mg} \cdot \mathrm{L}^{-1}$ & 0,05 \\
Zinco $(\mathrm{Zn})$ & $\mathrm{mg} \cdot \mathrm{L}^{-1}$ & 0,03 \\
Cor & $\mathrm{PtCo}$ & 2 \\
Turbidez & $\mathrm{FTU}$ & 2 \\
Sedimentos & $\mathrm{mg} \cdot \mathrm{L}^{-1}$ & 19,0 \\
Condutividade Elétrica $(\mathrm{CE})$ & $\mathrm{mS} \cdot \mathrm{cm}^{-1}$ & 0,16 \\
pH & & 7,2 \\
Gás Carbônico & $\mathrm{mg} \cdot \mathrm{L}^{-1}$ & 3,3 \\
Acidez & $\mathrm{mg} \cdot \mathrm{L}^{-1}$ & 4,0 \\
Dureza total $(\mathrm{CaCO}$ & $\mathrm{mg} \cdot \mathrm{L}^{-1}$ & 61,8 \\
\hline
\end{tabular}


O Índice de Saturação de Langelier calculado para a água de irrigação do experimento foi negativo; portando, não houve tendência de precipitação de $\mathrm{CaCO}_{3}$.

Com relação aos outros parâmetros, pode-se afirmar de acordo com Nakayama \& Bucks (1986) que: (a) os sólidos em suspensão não apresentam risco ao entupimento, (b) o ferro também não apresenta risco ao entupimento; (c) o pH apresenta valor de moderado risco ao entupimento.

\subsection{Manejo da Irrigação}

O efeito dos tratamentos secos pode ser visualmente observado na Figura 8.
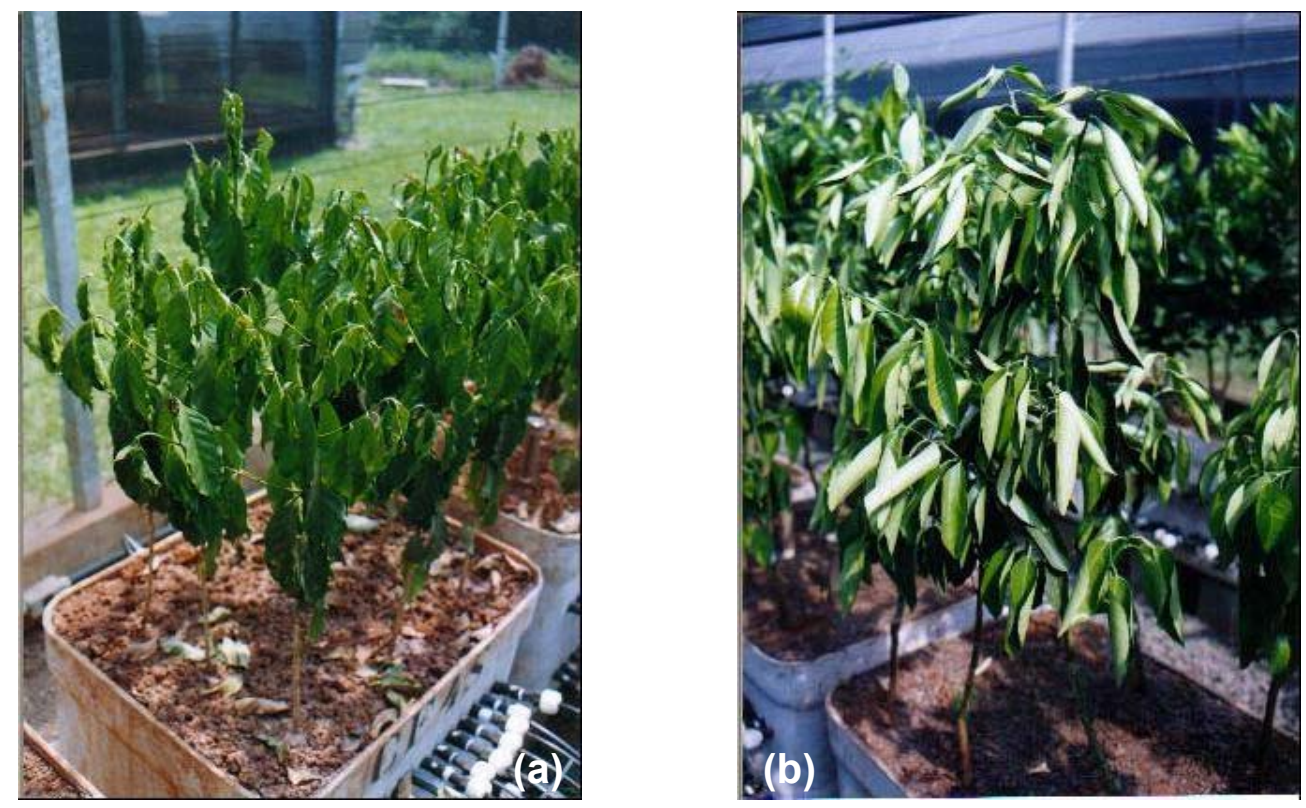

Figura 8 - Sintomas de déficit hídrico das plantas no tratamento seco: (a) café seco e (b) citros seco. 
Na Figura 9 (a) é apresenta a variação da umidade no solo para a cultura do café. Nota-se que a umidade mínima apresentada nos gráficos refere-se à ao potencial de $-80 \mathrm{kPa}$, tensão máxima possível de ser registrada por tensiometria nas condições experimentais. A Figura 9 (b), apresenta a variação da umidade do solo ao longo do ensaio para a cultura do citros.
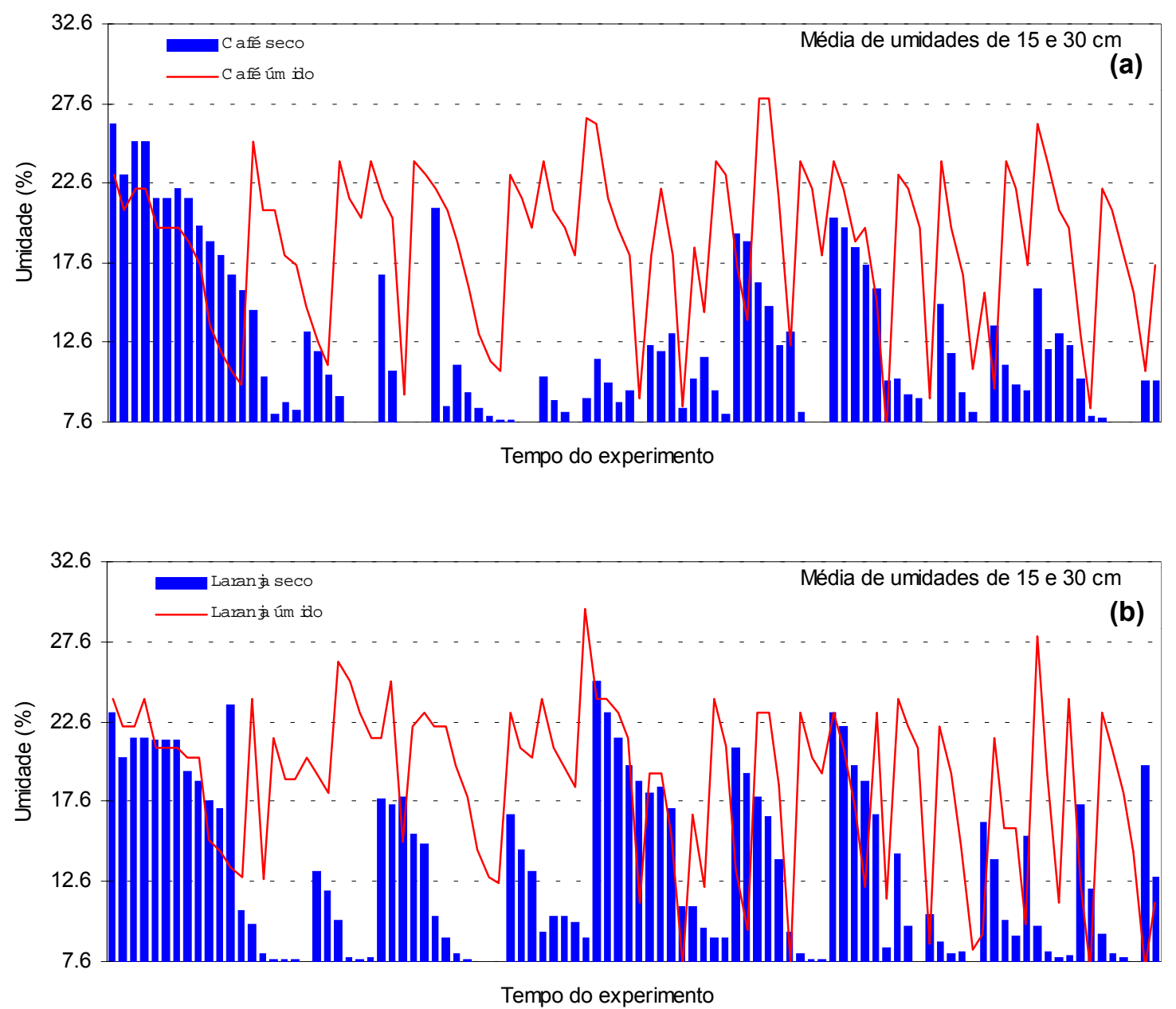

Figura 9 - Umidade do solo ao longo do tempo nas culturas: (a) café e (b) citros. 
Tanto para a cultura do café, quanto para a cultura do citros, observam-se picos de umidade nos tratamentos secos. Esses picos se devem às ocasiões em que se realizaram as leituras, pois, ao se determinar a vazão dos emissores, praticava-se indiretamente a rega do solo. Essas regas elevaram a umidade do solo até a saturação. Como a freqüência de leitura era mensal, uma vez por mês, o solo dos vasos com tratamento seco era saturado.

Observa-se também que, inicialmente, os valores de umidade tanto para os tratamentos secos como para os úmidos apresentaram-se semelhantes, para promover o "pegamento" das mudas. Esta estratégia foi promovida por 30 dias. Encerrado esse período, iniciaram-se os tratamentos.

\subsection{Desenvolvimento radicular}

Foi realizada entre os dias 28 e 31 de janeiro de 2002 a abertura de quatro vasos, através da destruição destes, sendo um vaso para cada tratamento (café seco, café úmido, citrus seco e citrus úmido). A intenção da abertura desses vasos foi verificar se o crescimento do sistema radicular havia sido uniforme dentro do vaso, e inspecionar intrusão radicular nos emissores. Não foram abertos todos os vasos, pois o experimento continua a ser conduzido.

A Figura 10 apresenta o desenvolvimento radicular para o cafeeiro e para a laranjeira. Observa-se que, para as quatro situações apresentadas, houve um desenvolvimento radicular que transpassou tanto a primeira linha de emissores quanto a segunda linha. O desenvolvimento radicular foi mais denso nos tratamentos úmidos tanto para o cafeeiro quanto para a laranjeira. 

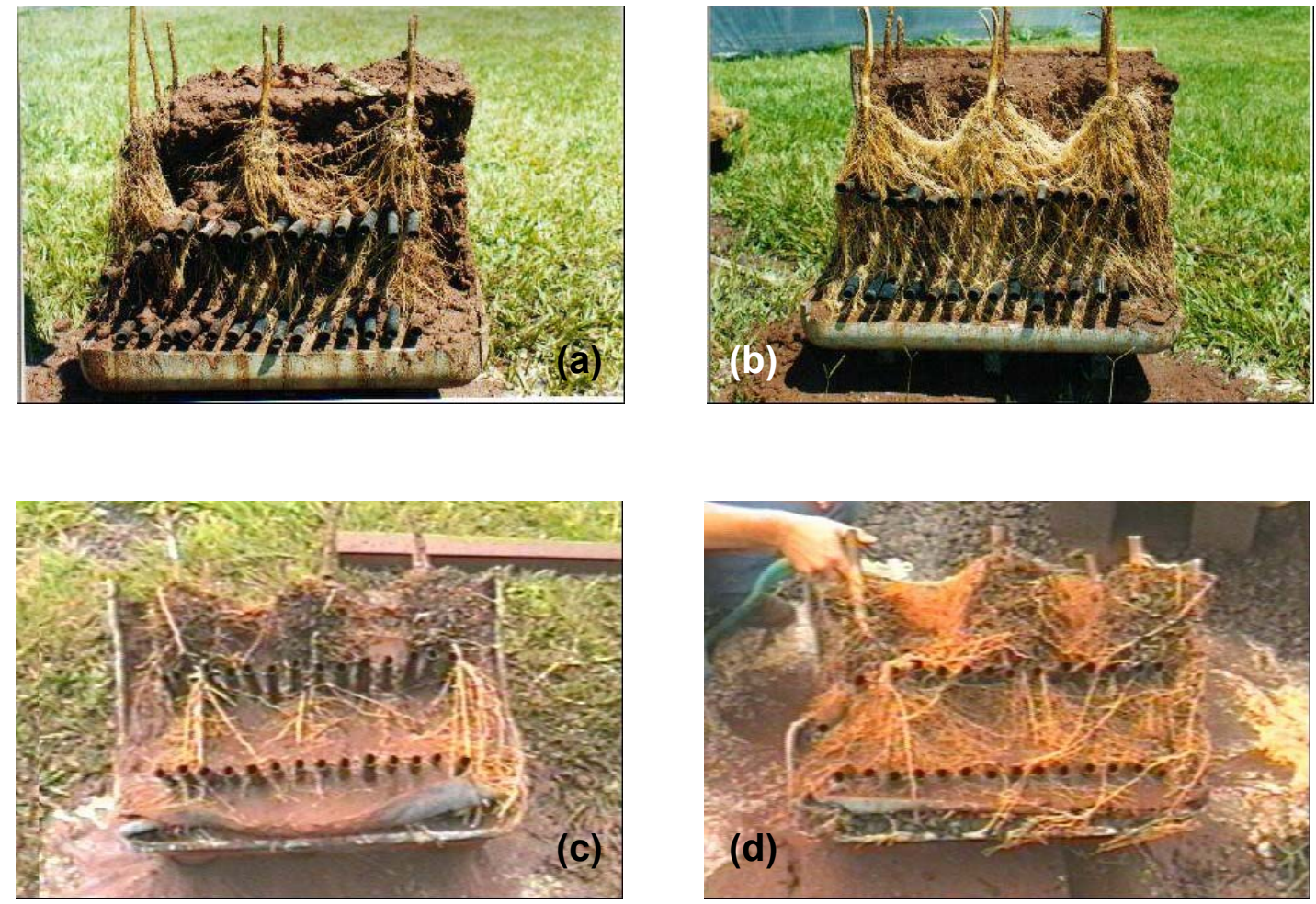

Figura 10 - Desenvolvimento radicular: (a) desenvolvimento radicular do cafeeiro no tratamento seco; (b) desenvolvimento radicular do cafeeiro no tratamento úmido; (c) desenvolvimento radicular da laranjeira no tratamento seco; (d) desenvolvimento radicular da laranjeira no tratamento úmido.

Observa-se nos tratamentos secos (citros e café) um desenvolvimento mais intenso do sistema radicular em profundidade no vaso, sendo que na camada superior mais exposta ao déficit hídrico, o crescimento radicular foi mais discreto.

\subsection{Vazão relativa e coeficiente de variação de vazão}

Foram utilizados os índices vazão relativa $(Q R)$ e coeficiente de variação de vazão (CVQ). A vazão relativa foi obtida a partir da média de dez emissores em cada leitura do tratamento. Os valores das médias em cada leitura foram divididos pelo valor da média da primeira leitura. Assim, os valores obtidos para todas as leituras são percentuais da vazão média da 
leitura inicial, indicando aumento de vazão para valores acima de 1 e redução de vazão para valores abaixo de 1 . Já o coeficiente de variação de vazão foi também calculado para cada leitura, a partir de uma amostra de 10 emissores, utilizando-se a mesma equação empregada no cálculo do coeficiente de variação de fabricação (CVF). A diferença entre estes dois índices deve-se ao fato de o CVF ser empregado apenas para amostras de emissores novos e o CVQ ter sido utilizado para os dados de emissores novos e para os demais dados das leituras subseqüentes.

Apesar de ter havido planejamento para a realização da tradicional análise de variância (delineamento estatístico), optou-se por explorar de maneira mais qualitativa a discussão dos resultados enfocando principalmente os valores extremos observados, que são mais sensitivos à influência do sistema radicular através do coeficiente de variação de vazão (CVQ), uma vez que o curto período do experimento (seis meses), assim como, a ausência total de referência na literatura não garantiram que o efeito dos tratamentos pudesse ter tido oportunidade de manifestação plena no experimento idealizado, que estará sendo conduzido por pelo menos mais três anos.

\subsubsection{Emissor modelo A}

Na Figura 11 são apresentados os gráficos de QR e CVQ para o emissor modelo A, para as cinco determinações de vazões. Nos gráficos as colunas indicam a vazão relativa $(\mathrm{QR} \%)$ e as linhas o coeficiente de variação de vazão (CVQ\%). A Tabela 4 apresenta os dados de vazão para o emissor $A$, com suas 10 repetições ( $R 1, R 2, \ldots, R 10)$, para as 5 determinações de vazão $(1 \mathrm{~L}, 2 \mathrm{~L}, \ldots, 5 \mathrm{~L})$, para todos os tratamentos e testemunhas. Os valores ausentes indicam problemas técnicos de amostragem (vazamentos etc). As 
Figuras de 11 até 24 e as Tabelas de 4 até 17, seguem o mesmo esquema anteriormente apresentados.
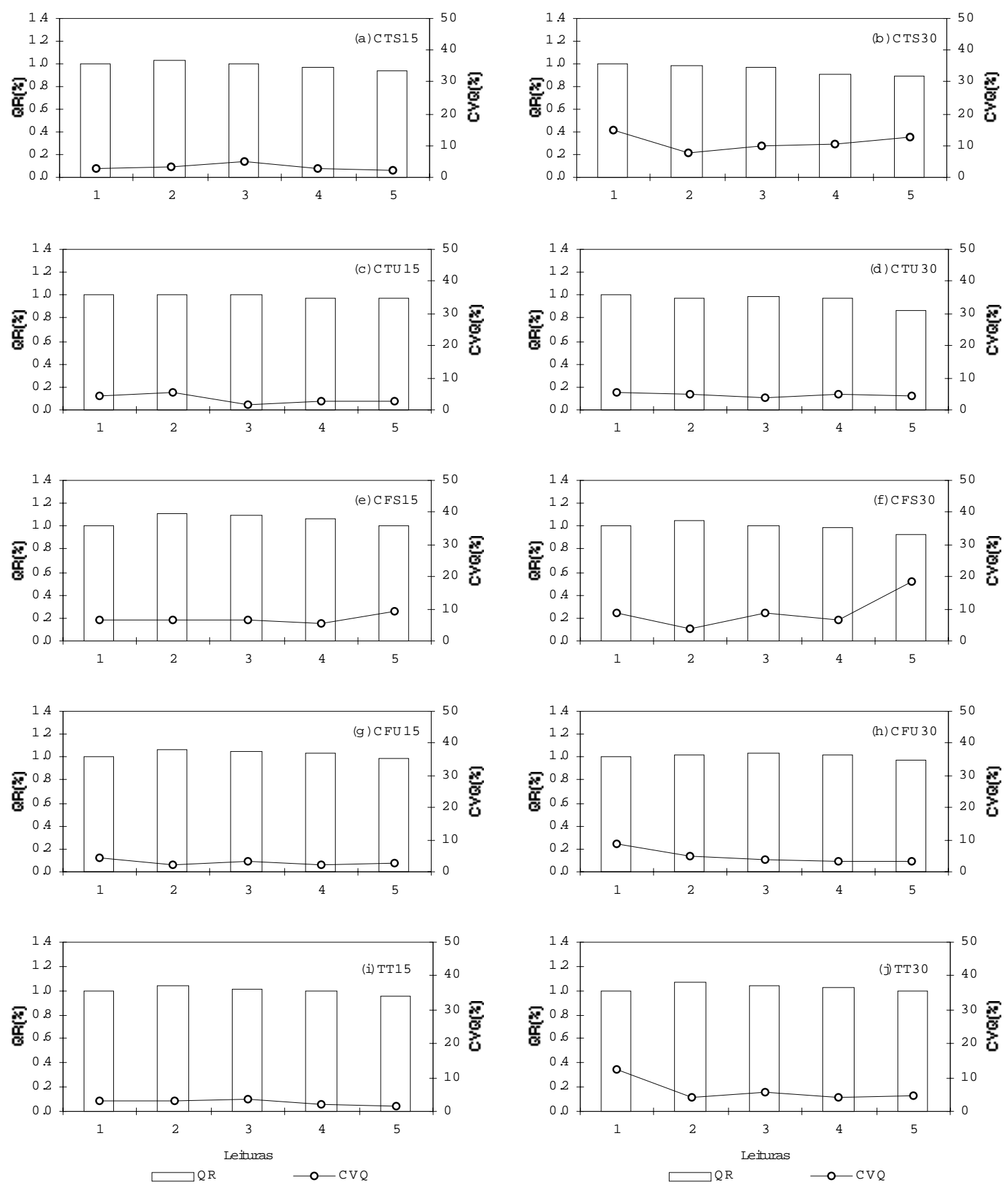

Figura 11- QR e CVQ para o emissor modelo A: (a) citros seco $15 \mathrm{~cm}$; (b) citros seco $30 \mathrm{~cm}$; (c) citros úmido $15 \mathrm{~cm}$; (d) citros úmido $30 \mathrm{~cm}$; (e) café seco $15 \mathrm{~cm}$, (f) café seco $30 \mathrm{~cm}$; (g) café úmido $15 \mathrm{~cm}$; (h) café úmido $30 \mathrm{~cm}$; (i) testemunha $15 \mathrm{~cm}$; (j) testemunha $30 \mathrm{~cm}$. 
Tabela 4. Vazões do emissor modelo $A$ em $L . h^{-1}$ para as cinco leituras realizadas (1L até $5 \mathrm{~L}$ ), dez repetições (R1 até $\left.R 10\right)$ para todos os tratamentos (CTS15, CTS30, CTU15, CTU30, CFS15, CFS30, CFU15, CFU30, TT15 e TT30).

\begin{tabular}{|c|c|c|c|c|c|c|c|c|c|c|c|c|c|c|c|c|c|c|c|c|c|c|c|}
\hline & & R1 & $\bar{R} 2$ & R3 & R4 & R5 & $\mathrm{R} 6$ & R7 & $\overline{R 8}$ & R9 & R10 & & & R1 & $\overline{\mathrm{R} 2}$ & R3 & R4 & R5 & R6 & R7 & R8 & $\mathrm{R9}$ & R10 \\
\hline \multirow[t]{5}{*}{ CTS15 } & $1 \mathrm{~L}$ & & 2.28 & 2.37 & & 2.33 & 2.21 & & 2.27 & 2.31 & 2.41 & S30 & $1 \mathrm{~L}$ & 1.94 & 3.17 & & 2.13 & 2.41 & 2.26 & 2.06 & 2.27 & 2.38 & 2.34 \\
\hline & $2 \mathrm{~L}$ & & 2.48 & 2.38 & & 2.34 & 2.48 & & 2.38 & 2.35 & 2.26 & & $2 \mathrm{~L}$ & 2.06 & 2.34 & & 1.98 & 2.47 & 2.56 & 2.28 & 2.32 & 2.23 & 2.27 \\
\hline & $3 \mathrm{~L}$ & 2.35 & 2.33 & 2.47 & 2.42 & 2.42 & 2.20 & 2.18 & 2.14 & 2.26 & 2.24 & & 3L & 1.75 & 2.38 & 2.38 & 2.16 & 2.37 & 2.62 & 2.15 & 2.18 & 2.26 & 2.18 \\
\hline & $4 \mathrm{~L}$ & 2.34 & 2.23 & 24 & 2.20 & 2.27 & 2.13 & 2.18 & 2.17 & 2.27 & 2.23 & & $4 \mathrm{~L}$ & 1.52 & 2.15 & 2.25 & 2.02 & 2.25 & 2.25 & 2.10 & 2.15 & 2.17 & 2.18 \\
\hline & $5 \mathrm{~L}$ & 2.26 & 2.18 & .15 & 12 & 18 & .08 & 2.12 & 2.12 & 2.17 & 2.14 & & $5 \mathrm{~L}$ & 1.36 & 2.14 & 2.15 & 2.26 & 2.16 & 2.04 & 2.13 & 2.24 & 2.18 & 2.14 \\
\hline \multirow[t]{5}{*}{ CTU15 } & $1 \mathrm{~L}$ & 2.08 & & 2.25 & 2.20 & 2.26 & 2.34 & 2.34 & 2.36 & 2.32 & 2.12 & 30 & $1 \mathrm{~L}$ & 2.08 & 2.25 & 2.06 & 2.15 & 2.26 & 2.35 & 2.41 & 2.32 & 2.35 & 2.40 \\
\hline & $2 \mathrm{~L}$ & 16 & 2.16 & 14 & 25 & 26 & 53 & 34 & 37 & 16 & 24 & & $2 \mathrm{~L}$ & 2.05 & 2.18 & 2.12 & 2.18 & 2.24 & 2.37 & 2.36 & 2.17 & .32 & \\
\hline & $3 \mathrm{~L}$ & 2.28 & 2.25 & 2.24 & 2.25 & 2.25 & 2.33 & 25 & 2.32 & 2.26 & 2.34 & & $3 \mathrm{~L}$ & 2.26 & 2.32 & 2.13 & 2.23 & 2.14 & 2.20 & 2.27 & 2.35 & 2.36 & \\
\hline & $4 \mathrm{~L}$ & 2.15 & 19 & 2.17 & 2.20 & 2.27 & 2.28 & 10 & 2.14 & 2.16 & 2.18 & & $4 \mathrm{~L}$ & 2.08 & 2.28 & 2.02 & 2.28 & 2.30 & 2.32 & 2.17 & 2.18 & .15 & \\
\hline & $5 \mathrm{~L}$ & 2.13 & 2.21 & 2.17 & 2.32 & 2.14 & 2.23 & 2.12 & 2.16 & 2.18 & 2.17 & & $5 \mathrm{~L}$ & 2.08 & 2.26 & 1.98 & 2.30 & 2.17 & 2.25 & 2.21 & 2.23 & 2.18 & \\
\hline \multirow[t]{5}{*}{ CFS15 } & $1 \mathrm{~L}$ & 07 & 2.05 & 15 & .10 & 1.96 & 1.76 & & 1.98 & & 2.16 & & 1L & 2.48 & 2.16 & 2.12 & 2.10 & 2.67 & 2.04 & 2.16 & 2.16 & 2.23 & 2.31 \\
\hline & $2 \mathrm{~L}$ & 95 & 30 & 27 & 40 & .28 & 11 & 2.24 & 2.46 & & 2.23 & & $2 \mathrm{~L}$ & & 2.32 & 2.45 & 2.46 & & 2.20 & 2.30 & 2.32 & 2.37 & \\
\hline & $3 \mathrm{~L}$ & 1.82 & 2.30 & 32 & .24 & .30 & .25 & 2.26 & 2.20 & 2.32 & 2.23 & & $3 \mathrm{~L}$ & 1.74 & 2.32 & 2.31 & 2.25 & 2.34 & 2.30 & 2.31 & 2.37 & 2.22 & 2.45 \\
\hline & $4 \mathrm{~L}$ & 1.86 & 2.20 & 25 & .26 & .17 & .18 & 2.21 & 2.08 & 2.22 & 2.16 & & $4 \mathrm{~L}$ & 1.85 & 2.32 & 2.34 & 2.36 & 2.26 & 2.22 & 2.24 & 2.23 & 2.15 & 2.32 \\
\hline & $5 \mathrm{~L}$ & 1.54 & 2.02 & 2.10 & 2.12 & 2.18 & 2.05 & 2.13 & 2.02 & 2.18 & 2.00 & & $5 \mathrm{~L}$ & 1.02 & 2.14 & 2.14 & 2.42 & 2.22 & 2.21 & 2.20 & 2.08 & 2.08 & 2.18 \\
\hline \multirow[t]{5}{*}{ CFU15 } & $1 \mathrm{~L}$ & 2.11 & 2.18 & 2.09 & 2.20 & 2.21 & 2.34 & 2.18 & 2.16 & .01 & 2.04 & CFU30 & $1 \mathrm{~L}$ & 2.11 & 2.18 & 2.09 & 2.20 & 2.21 & 2.34 & 2.18 & 2.16 & 2.01 & 2.04 \\
\hline & $2 \mathrm{~L}$ & 2.37 & 2.32 & 2.28 & & 2.24 & 2.25 & 2.30 & 2.36 & & 2.23 & & $2 \mathrm{~L}$ & 2.38 & 2.26 & 2.35 & 2.34 & 14 & 26 & 2.38 & & 28 & 2.06 \\
\hline & $3 \mathrm{~L}$ & 2.19 & 2.24 & 2.16 & 2.20 & 2.30 & 38 & 32 & 2.32 & 2.35 & 2.26 & & $3 \mathrm{~L}$ & 2.20 & 2.12 & 2.24 & 2.44 & 2.33 & 2.27 & 2.30 & 2.36 & 34 & 2.30 \\
\hline & $4 \mathrm{~L}$ & 2.23 & .19 & 2.14 & 2.24 & 2.23 & 2.32 & 18 & 2.24 & 2.22 & 2.25 & & $4 \mathrm{~L}$ & 2.21 & 2.20 & 2.25 & 2.43 & 2.26 & 2.20 & 2.21 & 2.30 & 2.37 & 2.31 \\
\hline & $5 \mathrm{~L}$ & 2.08 & 2.15 & 2.08 & 2.14 & 2.14 & 2.01 & 2.18 & 2.21 & 2.11 & 2.18 & & $5 \mathrm{~L}$ & 2.13 & 2.06 & 2.12 & 2.26 & 2.16 & 2.04 & 2.13 & 2.24 & 2.18 & 2.14 \\
\hline \multirow[t]{5}{*}{ TT15 } & $1 \mathrm{~L}$ & 2.25 & 2.19 & 2.28 & 2.26 & 2.15 & 2.13 & 2.24 & 2.33 & 2.34 & 2.26 & TT30 & $1 \mathrm{~L}$ & 2.13 & 1.45 & 2.25 & 2.18 & 2.07 & 2.40 & 2.23 & 2.22 & 2.32 & 2.27 \\
\hline & $2 \mathrm{~L}$ & 2.32 & 2.32 & 2.46 & 2.42 & 2.42 & 2.32 & 2.23 & 2.26 & 2.29 & 2.33 & & $2 \mathrm{~L}$ & 2.13 & 2.38 & 2.36 & 2.34 & 2.38 & & 2.24 & 2.17 & 2.33 & 2.31 \\
\hline & $3 \mathrm{~L}$ & 2.23 & 2.13 & 2.20 & 2.32 & 2.28 & 2.21 & 2.35 & 2.35 & 2.28 & 2.16 & & $3 \mathrm{~L}$ & 1.96 & 2.26 & 2.16 & 2.17 & 2.38 & & 2.36 & 2.33 & 2.18 & 2.20 \\
\hline & $4 \mathrm{~L}$ & 2.20 & 2.20 & 2.28 & 2.19 & 2.18 & 2.23 & 2.21 & 2.28 & 2.28 & 2.27 & & $4 \mathrm{~L}$ & 2.02 & 2.32 & 2.16 & 2.21 & 2.15 & & 2.27 & 2.30 & 2.24 & 2.28 \\
\hline & $5 \mathrm{~L}$ & 2.12 & 2.15 & 2.15 & 2.15 & 2.17 & 2.08 & 2.12 & 2.19 & 2.14 & 2.17 & & $5 \mathrm{~L}$ & 1.88 & 2.25 & 2.10 & 2.10 & 2.10 & 2.23 & 2.15 & 2.16 & 2.15 & 2.20 \\
\hline
\end{tabular}


Observa-se que o desempenho do emissor $A$, no que se refere ao coeficiente de variação de vazão (CVQ) inicial, apresentou boa uniformidade geral. No tratamento citros seco $30 \mathrm{~cm}$ (CTS30), Figura 11(b), CFS30, Figura 11(f) e Testemunha $30 \mathrm{~cm}$, Figura 11(j), ocorreu CVQ inicial superior ao demais. Este fato pode ser compreendido analisando a Tabela 4, onde, no caso do CTS30, um emissor apresentou vazão inicial reduzida. O CVQ inicial de todos os emissores deste modelo para todos os tratamentos (amostras com 100 indivíduos) foi de 8,6\%.

Analisando a Figura 11, nota-se que houve ligeira queda de vazão na quinta leitura, comparando-a com as leituras anteriores. Observa-se também que o CVQ geral apresentou pior desempenho no tratamento CFS30, com pico na quinta leitura $(5 \mathrm{~L})$.

Não se observa, até a realização da última leitura, efeito pronunciado dos tratamentos.

O comportamento das testemunhas no que se refere à redução de vazão e CVQ foi normal.

Não houve emissor que se destacasse quanto aos parâmetros analisados, não tendo ocorrido redução total de vazão até a realização da última leitura.

O emissor modelo A não possui mecanismo de regulação de vazão, não estando sujeito ao envelhecimento da membrana compensadora de pressão. Sua vazão real manteve-se próxima a vazão nominal fornecida pelo fabricante. 


\subsubsection{Emissor modelo B}

Esse modelo de emissor apresentou CVQ inicial geral igual a 7,3\%, para todos os emissores em todos os tratamentos. O comportamento do $C V Q$ inicial para os tratamentos foi normal, não tendo ocorrido tratamento que se destacasse no que refere-se à esse parâmetro.

A tendência geral foi de redução de vazão, e não havendo vazão nula para nenhuma repetição. Observa-se uma grande quantidade de vazões não determinadas (células vazias). Esse fato reflete à dificuldade da montagem das conexões utilizadas na alimentação e no final das linhas desse emissor, o que muitas vezes levou ao rompimento dos conectores, provocando vazamento. Os conectores utilizados para essa finalidade não eram específicos para os tubos.

O valor máximo do CVQ ocorreu na quinta leitura no tratamento CFU15, pois alguns emissores apresentaram redução de vazão superior aos demais, como pode ser observado na Tabela 5.

Pode-se inferir que o tratamento CFU15 apresentou destaque no que se refere ao efeito dos tratamentos, pois nesse caso ocorreu a maior redução de vazão e o pior desempenho quanto ao parâmetro CVQ.

As testemunhas apresentaram desempenho normal, não tendo ocorrido redução de vazão considerável e CVQ uniforme.

Os emissores do tratamento CFU15, das repetições R1, R5 e R6, destacaram-se quanto a redução de vazão, pois apresentaram maior redução.

A vazão nominal desse emissor, fornecida pelo fabricante, apresentou-se aquém da vazão real. Analisando-se a Tabela 5, nota-se que houve elevada variação de vazão. Tal fato, como no modelo $A$, não pode ser atribuído à presença da membrana compensadora de pressão, pois este emissor não possui mecanismo de autocompensação. 

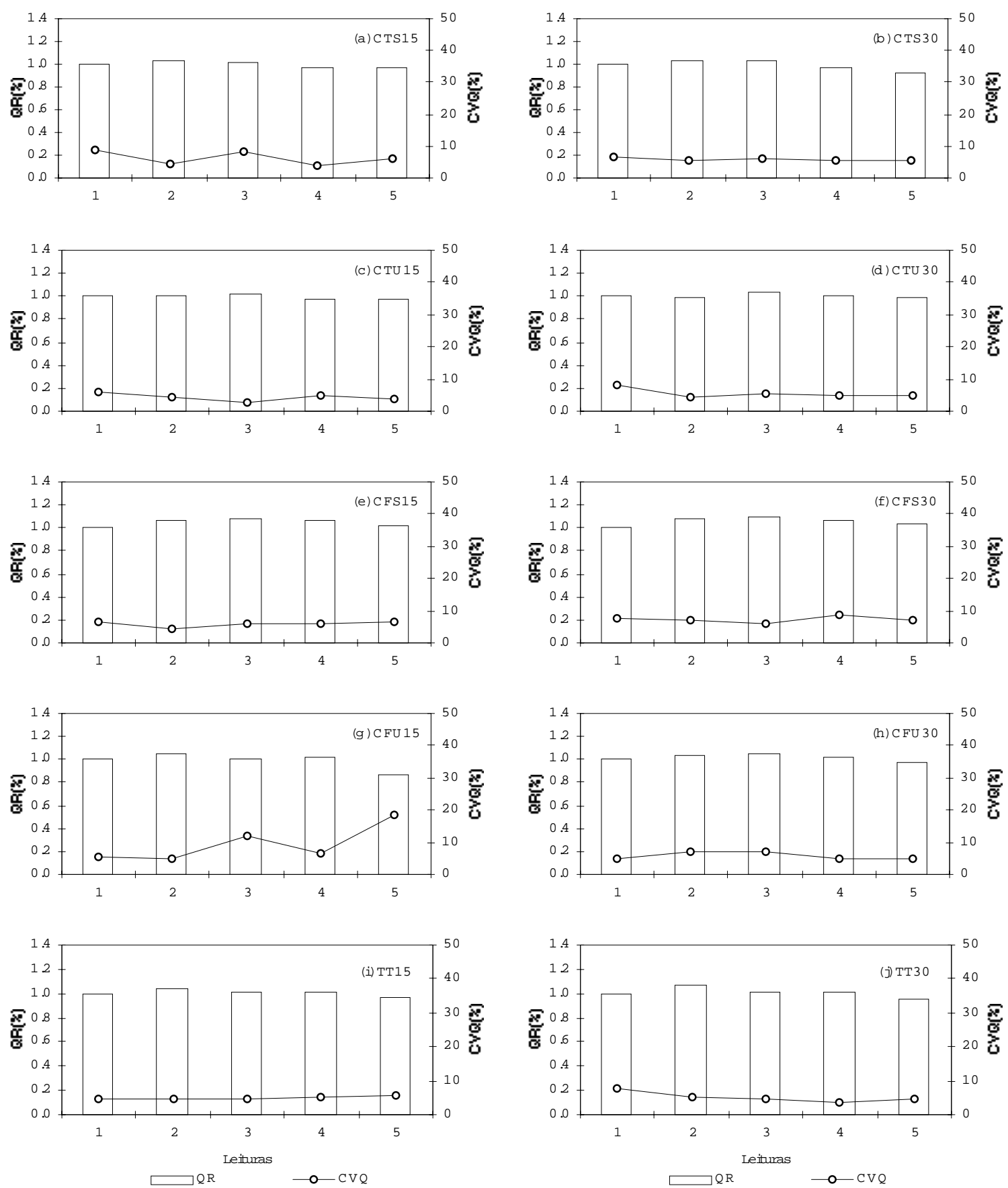

Figura 12 - QR e CVQ para o emissor modelo B: (a) citros seco $15 \mathrm{~cm}$; (b) citros seco $30 \mathrm{~cm}$; (c) citros úmido $15 \mathrm{~cm}$; (d) citros úmido $30 \mathrm{~cm}$; (e) café seco $15 \mathrm{~cm}$, (f) café seco $30 \mathrm{~cm}$; $(\mathrm{g})$ café úmido $15 \mathrm{~cm}$; (h) café úmido $30 \mathrm{~cm}$; (i) testemunha $15 \mathrm{~cm}$; (j) testemunha $30 \mathrm{~cm}$. 
Tabela 5. Vazões do emissor modelo $B$ em $L . h^{-1}$ para as cinco leituras realizadas (1L até $5 \mathrm{~L}$ ), dez repetições (R1 até $\left.R 10\right)$ para todos os tratamentos (CTS15, CTS30, CTU15, CTU30, CFS15, CFS30, CFU15, CFU30, TT15 e TT30).

\begin{tabular}{|c|c|c|c|c|c|c|c|c|c|c|c|c|c|c|c|c|c|c|c|c|c|c|c|}
\hline & & R1 & R2 & R3 & R4 & R5 & R6 & R7 & R8 & R9 & R10 & & & R1 & $\mathrm{R} 2$ & R3 & R4 & R5 & R6 & R7 & R8 & R9 & R10 \\
\hline \multirow[t]{5}{*}{ CTS15 } & $1 \mathrm{~L}$ & 1.56 & 1.63 & 1.81 & 1.93 & 1.78 & 1.65 & 1.38 & 1.73 & 1.64 & 1.67 & CTS30 & $1 \mathrm{~L}$ & 1.53 & 1.71 & 1.78 & 1.84 & 1.53 & 1.69 & 1.71 & 1.64 & 1.72 & 1.83 \\
\hline & $2 \mathrm{~L}$ & 1.64 & 1.76 & 1.72 & 1.84 & 1.76 & & & 1.82 & 76 & 1.62 & & $2 \mathrm{~L}$ & & 1.78 & 1.85 & 1.78 & 1.77 & & 1.87 & 1.72 & 1.56 & 1.68 \\
\hline & $3 \mathrm{~L}$ & 58 & 64 & 82 & 88 & 78 & 1.58 & 1.54 & 72 & 93 & 1.57 & & $3 \mathrm{~L}$ & 1.66 & 1.76 & 1.85 & 1.87 & 1.63 & 1.78 & 1.72 & 63 & 93 & 70 \\
\hline & $4 \mathrm{~L}$ & 56 & 62 & 66 & 67 & 72 & 65 & 54 & 1.68 & 58 & 1.56 & & $4 \mathrm{~L}$ & 1.62 & 1.60 & 1.66 & 1.78 & 1.54 & 1.74 & 1.72 & 66 & 48 & 1.70 \\
\hline & $5 \mathrm{~L}$ & 1.58 & 60 & 1.60 & 1.74 & 1.65 & 1.58 & 1.47 & 1.67 & 1.80 & 1.55 & & $5 \mathrm{~L}$ & 1.60 & 1.64 & 1.72 & 1.46 & 1.49 & 1.58 & & 1.62 & 1.63 & 1.47 \\
\hline \multirow[t]{5}{*}{ CTU15 } & $1 \mathrm{~L}$ & 1.50 & 67 & 69 & 1.63 & 1.62 & 1.72 & 1.73 & 1.69 & 1.87 & 1.57 & & $1 \mathrm{~L}$ & 1.61 & 1.41 & 1.72 & 1.52 & & 1.64 & & 1.75 & 1.75 & 1.48 \\
\hline & $2 \mathrm{~L}$ & 1.58 & 62 & 72 & .72 & 1.67 & 1.78 & 1.73 & 1.76 & 1.62 & & & $2 \mathrm{~L}$ & 1.52 & & 1.62 & 1.66 & & & & .54 & & \\
\hline & $3 \mathrm{~L}$ & 1.68 & 68 & .76 & 1.72 & 1.65 & 1.68 & 1.64 & 1.72 & 1.78 & 1.76 & & $3 \mathrm{~L}$ & 1.64 & 1.60 & 1.58 & 1.70 & 1.74 & 1.58 & 86 & 1.74 & 72 & 1.62 \\
\hline & $4 \mathrm{~L}$ & 1.56 & 62 & 75 & .72 & 63 & 1.77 & 1.56 & 1.54 & 1.62 & 1.58 & & $4 \mathrm{~L}$ & 1.52 & 1.53 & 1.56 & 1.72 & 73 & 1.66 & 68 & 53 & 65 & 1.60 \\
\hline & $5 \mathrm{~L}$ & 1.55 & 57 & 72 & 67 & 63 & 67 & 58 & .57 & 1.67 & 1.58 & & $5 \mathrm{~L}$ & 1.48 & 1.50 & 1.53 & 1.64 & 62 & 62 & 1.74 & .56 & 60 & .54 \\
\hline \multirow[t]{5}{*}{ CFS15 } & $1 \mathrm{~L}$ & 1.54 & 1.61 & 1.70 & 1.55 & 1.46 & 1.51 & 1.48 & 1.76 & 1.65 & 1.66 & & $1 \mathrm{~L}$ & 1.69 & 1.62 & 1.46 & 1.37 & 1.37 & 1.49 & 1.37 & 1.56 & 1.62 & 1.49 \\
\hline & $2 \mathrm{~L}$ & 1.86 & 1.76 & & & 1.68 & 1.65 & 1.63 & 1.66 & 1.68 & 1.70 & & $2 \mathrm{~L}$ & 1.73 & 1.72 & & 1.53 & 1.64 & 1.57 & 1.42 & 1.66 & 1.76 & 1.53 \\
\hline & $3 \mathrm{~L}$ & 1.53 & 1.80 & 1.65 & 1.67 & 1.67 & 1.76 & 1.65 & 1.86 & 1.76 & 1.87 & & $3 \mathrm{~L}$ & 1.66 & 1.74 & 1.65 & 1.55 & 1.60 & 1.65 & 1.44 & 1.65 & 1.80 & 1.74 \\
\hline & $4 \mathrm{~L}$ & 1.52 & 1.64 & 1.63 & 1.72 & 1.72 & 1.72 & 1.66 & 1.86 & 1.67 & 1.87 & & $4 \mathrm{~L}$ & 1.72 & 1.70 & 1.60 & & 1.54 & 1.64 & 1.28 & 1.55 & 1.72 & 1.63 \\
\hline & $5 \mathrm{~L}$ & 1.44 & 1.52 & & 1.66 & 1.58 & 1.68 & 1.60 & 1.77 & 1.72 & 1.57 & & $5 \mathrm{~L}$ & 1.60 & 1.60 & 1.47 & & 1.52 & 1.65 & & 1.40 & 1.76 & 1.49 \\
\hline \multirow[t]{5}{*}{ CFU15 } & $1 \mathrm{~L}$ & 1.53 & 1.57 & 1.53 & 1.65 & 1.57 & 1.72 & 1.69 & .61 & 1.61 & .41 & & $1 \mathrm{~L}$ & 1.46 & 1.52 & 1.48 & 1.52 & 1.52 & 1.64 & 1.58 & 1.71 & 1.56 & 1.58 \\
\hline & $2 \mathrm{~L}$ & 1.74 & & 1.73 & 1.72 & 1.63 & & & 1.66 & & 1.52 & & $2 \mathrm{~L}$ & 1.55 & 1.64 & & 1.52 & 1.53 & & 1.78 & 1.72 & .72 & 1.49 \\
\hline & $3 \mathrm{~L}$ & 1.60 & 1.56 & 1.64 & 1.66 & 1.13 & 1.77 & 1.70 & 1.67 & 1.82 & 1.48 & & $3 \mathrm{~L}$ & 1.48 & 1.52 & 1.56 & 1.57 & 1.60 & 1.60 & 1.72 & 1.73 & 1.88 & 1.66 \\
\hline & $4 \mathrm{~L}$ & 1.65 & 1.57 & 1.63 & 1.67 & 1.36 & 1.72 & 1.62 & 1.64 & 1.72 & 1.52 & & $4 \mathrm{~L}$ & 1.52 & 1.55 & 1.60 & 1.55 & 1.58 & 1.53 & 1.68 & 1.65 & 1.75 & 1.54 \\
\hline & $5 \mathrm{~L}$ & 1.20 & 1.46 & 1.52 & 1.55 & 1.13 & 0.82 & 1.58 & 1.57 & 1.64 & 1.40 & & $5 \mathrm{~L}$ & 1.45 & 1.47 & 1.48 & 1.46 & 1.49 & 1.58 & & 1.62 & 1.63 & 1.47 \\
\hline \multirow[t]{5}{*}{ TT15 } & $1 \mathrm{~L}$ & 1.62 & 1.65 & 1.62 & 1.61 & 56 & 1.48 & 1.58 & .69 & 1.75 & 1.62 & 0 & $1 \mathrm{~L}$ & 1.74 & 1.49 & 1.68 & 1.73 & 1.35 & 1.61 & 1.54 & 1.64 & 1.61 & 1.74 \\
\hline & $2 \mathrm{~L}$ & 54 & 76 & 67 & .66 & & .74 & & 1.68 & 75 & .60 & & & 1.76 & .72 & 1.82 & .80 & 1.58 & 1.63 & & & .64 & \\
\hline & $3 \mathrm{~L}$ & 1.56 & 1.66 & 1.56 & 1.52 & & 1.67 & & 1.76 & 1.67 & 1.60 & & $3 \mathrm{~L}$ & 1.60 & 1.48 & 1.65 & 1.68 & 1.70 & 1.72 & .54 & & 1.58 & 1.66 \\
\hline & $4 \mathrm{~L}$ & 1.56 & 1.73 & 1.55 & 1.57 & 1.55 & 1.63 & 1.65 & 1.75 & 1.78 & 1.62 & & $4 \mathrm{~L}$ & 1.70 & 1.58 & 1.68 & 1.64 & 1.50 & 1.68 & 1.60 & 1.58 & 1.65 & 1.65 \\
\hline & $5 \mathrm{~L}$ & 1.46 & 1.65 & 1.72 & 1.48 & 1.48 & 1.50 & 1.56 & 1.60 & 1.62 & 1.48 & & $5 \mathrm{~L}$ & 1.62 & 1.50 & 1.60 & 1.62 & 1.42 & 1.57 & 1.46 & 1.47 & 1.53 & \\
\hline
\end{tabular}




\subsubsection{Emissor modelo C}

Esse modelo de emissor não apresentou uniformidade do CVQ para leitura inicial, como pode ser observado analisando-se a Figura 13. O CVQ inicial geral para todos os emissores presentes em todos os tratamentos foi de $12,2 \%$.

Ocorreu tendência geral de aumento de vazão, como pode ser verificado na Tabela 6 , onde se observa, na quinta leitura, emissores com vazão na quinta leitura, com acréscimo superior a $20 \%$ de vazão, quando comparado às vazões ocorridas na leitura inicial.

Observam-se picos do CVQ nos tratamentos CFS15 e CFU15, pois os emissores apresentaram elevada vazão na quinta leitura, comparada a vazões observadas nas leituras anteriores.

Pode-se inferir que ocorreu efeito realçado dos tratamentos CFS15 e CFU15, quando comparados aos demais tratamentos na profundidade de 30 $\mathrm{cm}$.

A testemunha apresentou pior desempenho no tratamento a $15 \mathrm{~cm}$, comparado ao tratamento de $30 \mathrm{~cm}$.

$O$ fato de ter sido observado um desempenho ruim quanto aos parâmetros analisados, pode ser explicado pelo fato desse emissor ser autocompensante. Entretanto, o aumento de vazão poderia impossibilitar a pressurização das parcelas em campo, mesmo para o sistema novo, desequilibrando a hidráulica do projeto. 

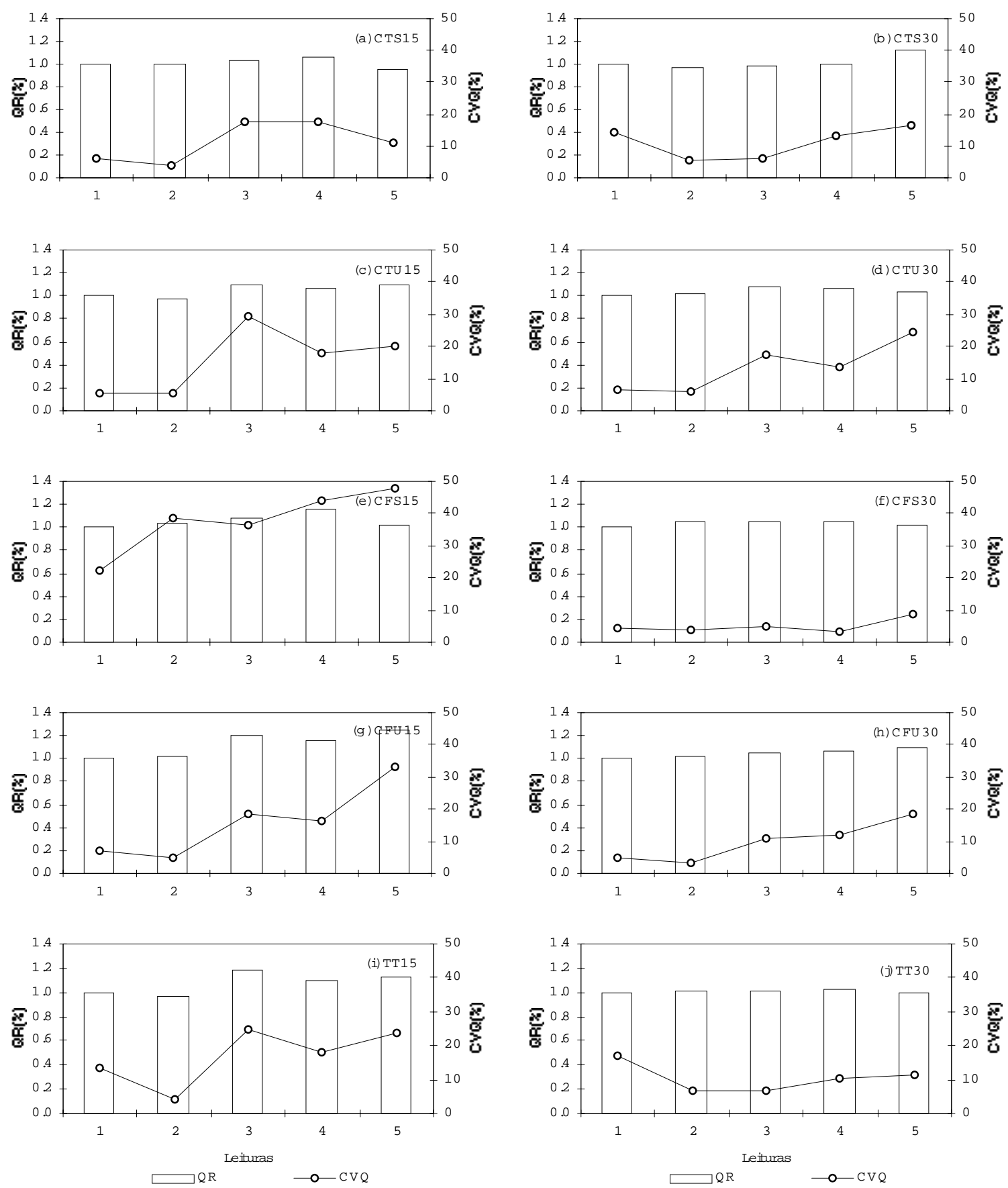

Figura 13 - QR e CVQ para o emissor modelo C: (a) citros seco $15 \mathrm{~cm}$; (b) citros seco $30 \mathrm{~cm}$; (c) citros úmido $15 \mathrm{~cm}$; (d) citros úmido $30 \mathrm{~cm}$; (e) café seco $15 \mathrm{~cm}$, (f) café seco $30 \mathrm{~cm}$; (g) café úmido $15 \mathrm{~cm}$; (h) café úmido $30 \mathrm{~cm}$; (i) testemunha $15 \mathrm{~cm}$; (j) testemunha $30 \mathrm{~cm}$. 
Tabela 6. Vazões do emissor modelo $C$ em $L . h^{-1}$ para as cinco leituras realizadas (1L até $5 \mathrm{~L}$ ), dez repetições (R1 até $\left.R 10\right)$ para todos os tratamentos (CTS15, CTS30, CTU15, CTU30, CFS15, CFS30, CFU15, CFU30, TT15 e TT30).

\begin{tabular}{|c|c|c|c|c|c|c|c|c|c|c|c|c|c|c|c|c|c|c|c|c|c|c|c|}
\hline & & $\mathrm{R} 1$ & R2 & R3 & R4 & R5 & $\mathrm{R} 6$ & R7 & $\overline{R 8}$ & R9 & R10 & & & R1 & $\overline{\mathrm{R} 2}$ & R3 & R4 & R5 & R6 & R7 & R8 & $\mathrm{R9}$ & R10 \\
\hline \multirow[t]{5}{*}{ CTS15 } & $1 \mathrm{~L}$ & & 3.89 & & 3.82 & & 3.44 & 3.33 & 3.86 & 3.65 & 3.78 & \multirow[t]{5}{*}{ CTS30 } & $1 \mathrm{~L}$ & 3.78 & 3.63 & 3.88 & 5.08 & 3.37 & 3.73 & 3.29 & 3.42 & 3.67 & \\
\hline & $2 \mathrm{~L}$ & 3.44 & 3.87 & & 3.62 & 3.65 & 3.65 & 3.60 & 3.92 & 3.72 & 3.77 & & $2 \mathrm{~L}$ & 3.76 & 3.68 & 3.63 & 3.96 & 3.45 & 3.86 & 3.42 & 3.52 & 3.47 & 3.9 \\
\hline & $3 \mathrm{~L}$ & 3.30 & 3.85 & 5.62 & 3.62 & 3.38 & 3.52 & 3.36 & 3.88 & 3.63 & 3.75 & & $3 \mathrm{~L}$ & 3.74 & 3.63 & 3.66 & 3.92 & 3.37 & 3.97 & 3.46 & 3.45 & 3.63 & 3.94 \\
\hline & $4 \mathrm{~L}$ & 3.55 & 84 & 5.72 & 3.60 & 3.63 & 3.48 & 3.36 & 4.23 & 3.70 & 3.74 & & $4 \mathrm{~L}$ & 3.82 & 5.06 & 3.52 & 3.86 & 3.42 & 3.88 & 3.45 & 3.38 & 3.47 & .96 \\
\hline & $5 \mathrm{~L}$ & 3.46 & 84 & 2.52 & .58 & 3.52 & 3.48 & .24 & 3.86 & 3.76 & 3.70 & & $5 \mathrm{~L}$ & 3.92 & 4.97 & 3.76 & 4.58 & 4.05 & 3.68 & 5.23 & 3.50 & 5.24 & 3.50 \\
\hline \multirow[t]{5}{*}{ CTU15 } & $1 \mathrm{~L}$ & 4.06 & .96 & 3.59 & 3.57 & 3.47 & 3.96 & 3.84 & 3.64 & 3.69 & & \multirow[t]{5}{*}{ CTU30 } & $1 \mathrm{~L}$ & 3.42 & 3.35 & 3.60 & 3.54 & 3.76 & 4.08 & 3.37 & 3.49 & 3.54 & 3.33 \\
\hline & $2 \mathrm{~L}$ & 12 & 76 & 3.53 & 61 & 46 & 3.62 & 78 & 3.65 & 3.48 & 3.46 & & $2 \mathrm{~L}$ & 3.48 & 3.36 & 3.66 & 3.68 & 3.78 & 4.08 & 3.57 & 3.62 & .52 & .38 \\
\hline & $3 \mathrm{~L}$ & 4.68 & 36 & 3.62 & .60 & .40 & 3.85 & .52 & 3.66 & 3.73 & 3.50 & & $3 \mathrm{~L}$ & 3.58 & 3.40 & 5.62 & 3.62 & 3.78 & 4.18 & 3.46 & 3.65 & 3.58 & 3.53 \\
\hline & $4 \mathrm{~L}$ & 4.90 & 46 & 3.58 & 3.60 & 3.92 & 4.38 & 3.57 & 3.48 & 3.50 & 3.43 & & $4 \mathrm{~L}$ & 3.54 & 3.74 & 5.13 & 3.74 & 3.82 & 3.97 & 3.42 & 3.48 & 3.45 & .38 \\
\hline & $5 \mathrm{~L}$ & 4.43 & .93 & 3.54 & 3.54 & 4.67 & 4.74 & 3.53 & 3.56 & 3.58 & 3.42 & & $5 \mathrm{~L}$ & 3.52 & 3.64 & 6.08 & 2.67 & 3.74 & 3.93 & 3.12 & 3.48 & 3.41 & 3.35 \\
\hline \multirow[t]{5}{*}{ CFS15 } & $1 \mathrm{~L}$ & 3.33 & 05 & 3.45 & .48 & .49 & 3.72 & .69 & 3.91 & 2.13 & 4.82 & \multirow[t]{5}{*}{ CFS30 } & 1L & 3.47 & 3.31 & 3.43 & 3.43 & 3.37 & 3.85 & 3.45 & 3.54 & 3.39 & 3.47 \\
\hline & $2 \mathrm{~L}$ & 3.52 & 56 & 3.58 & .17 & .72 & .30 & .87 & .66 & .38 & .78 & & $2 \mathrm{~L}$ & 3.68 & 3.65 & 3.70 & 3.56 & 3.53 & 3.96 & 3.58 & 3.66 & 3.65 & 3.46 \\
\hline & $3 \mathrm{~L}$ & 3.53 & 62 & 3.63 & .16 & 4.20 & 7.13 & 4.06 & 4.22 & 3.42 & 4.96 & & $3 \mathrm{~L}$ & 3.66 & 3.60 & 3.66 & 3.62 & 3.50 & 4.12 & 3.60 & 3.57 & 3.65 & 3.52 \\
\hline & $4 \mathrm{~L}$ & 3.38 & & 3.64 & & 4.08 & 7.34 & .16 & .78 & .28 & 4.42 & & $4 \mathrm{~L}$ & 3.72 & 3.57 & 3.68 & 3.77 & 3.45 & 3.88 & 3.58 & 3.53 & 3.65 & 3.70 \\
\hline & $5 \mathrm{~L}$ & 3.36 & .46 & 3.56 & 0.13 & 3.88 & 7.82 & .95 & .23 & .15 & 4.22 & & $5 \mathrm{~L}$ & 3.58 & 3.26 & 3.45 & 3.72 & 3.46 & 3.83 & 3.92 & 2.84 & .54 & .55 \\
\hline \multirow{5}{*}{ CFU15 } & $1 \mathrm{~L}$ & 3.38 & 15 & 3.47 & 3.74 & 3.88 & 3.34 & 3.49 & 3.24 & 3.21 & 3.32 & \multirow[t]{5}{*}{ CFU30 } & $1 \mathrm{~L}$ & 3.44 & & 3.53 & 3.77 & 4.02 & 3.70 & 3.60 & 3.66 & 3.51 & 3.70 \\
\hline & $2 \mathrm{~L}$ & 3.48 & 34 & 3.68 & & 3.58 & 3.38 & 45 & 32 & 86 & 3.43 & & $2 \mathrm{~L}$ & 3.53 & 3.65 & 3.72 & 78 & 3.98 & 3.74 & & & 76 & 3.7 \\
\hline & $3 \mathrm{~L}$ & 3.50 & .34 & 3.60 & 4.43 & 4.77 & 5.18 & .52 & 3.57 & 5.34 & 3.65 & & $3 \mathrm{~L}$ & 3.47 & 3.55 & 3.63 & 4.25 & 4.06 & 3.67 & 3.82 & 3.54 & 86 & 3.8 \\
\hline & $4 \mathrm{~L}$ & 3.52 & 30 & 3.57 & 4.18 & 4.05 & 5.28 & 3.53 & 3.76 & 4.85 & 3.57 & & $4 \mathrm{~L}$ & 3.51 & 3.54 & 3.63 & 3.75 & 4.04 & 3.84 & 4.18 & 3.52 & 5.00 & 3.73 \\
\hline & $5 \mathrm{~L}$ & 3.44 & 3.28 & 3.45 & 7.94 & 4.95 & 4.93 & 3.47 & 3.51 & 4.42 & 3.55 & & $5 \mathrm{~L}$ & 3.42 & 3.47 & 3.43 & 4.58 & 4.05 & 3.68 & 5.23 & 3.50 & 5.24 & 3.58 \\
\hline \multirow[t]{5}{*}{ TT15 } & $1 \mathrm{~L}$ & 3.60 & 3.52 & 4.35 & 3.70 & 3.64 & 5.12 & 3.62 & 3.64 & & 3.88 & \multirow[t]{5}{*}{ TT30 } & $1 \mathrm{~L}$ & 3.40 & 3.39 & 3.70 & 3.49 & 2.27 & 4.25 & 3.52 & 4.57 & 3.87 & 4.02 \\
\hline & $2 \mathrm{~L}$ & 3.72 & 3.63 & 3.93 & & 3.94 & & 3.56 & 3.64 & 3.80 & 3.95 & & $2 \mathrm{~L}$ & 3.53 & 4.23 & 3.76 & 3.54 & 3.65 & 3.67 & 3.42 & 3.52 & 4.02 & 3.59 \\
\hline & $3 \mathrm{~L}$ & 3.73 & 4.54 & 6.48 & 6.52 & 3.98 & 5.38 & 3.56 & 3.80 & 3.74 & 4.26 & & $3 \mathrm{~L}$ & 3.37 & 4.08 & 3.66 & 3.53 & 3.62 & & 3.58 & 3.58 & 4.05 & 3.48 \\
\hline & $4 \mathrm{~L}$ & 3.84 & 3.65 & 5.76 & 5.48 & 3.93 & 4.38 & 3.67 & 3.74 & 3.75 & 4.3 & & $4 \mathrm{~L}$ & 3.52 & & 3.74 & 3.48 & 3.47 & 4.64 & 3.52 & 3.56 & 4.02 & 3.5 \\
\hline & $5 \mathrm{~L}$ & 3.75 & 3.54 & 5.69 & 5.64 & 3.92 & 6.22 & 3.67 & 3.56 & 3.71 & 4.26 & & $5 \mathrm{~L}$ & 3.41 & 3.62 & 3.78 & 3.38 & 3.38 & 4.63 & 3.37 & 3.44 & 4.10 & 3.42 \\
\hline
\end{tabular}




\subsubsection{Emissor modelo D}

O coeficiente de variação de vazão inicial médio para esse modelo de emissor foi em torno de 16,4\%. O CVQ inicial para os tratamentos mostrou-se elevado e desuniforme.

A vazão apresentou ligeira queda com o passar do tempo como pode ser confirmado, analisando-se os dados de vazão na Tabela 7.

Os valores extremos do CVQ, como observa-se na Figura 14, ocorreram na leitura inicial do tratamento CFS15 e CTS30. Para o primeiro caso, o emissor da sexta repetição (R6) apresentou vazão inicial reduzida; entretanto, nas leituras seguintes, houve recuperação de vazão. No segundo caso, o emissor da oitava repetição (R8) apresentou redução total de vazão na quinta leitura. O CVQ na última leitura apresentou-se uniforme, desconsiderando-se apenas o ocorrido no tratamento CTS30.

Não se observou efeito dos tratamentos para esse modelo de emissor, pois comparando-se os tratamentos entre si e também com as testemunhas não ocorreu discrepância.

O desempenho das testemunhas às duas profundidades mostrou-se normal quanto aos parâmetros analisados.

O fato de se observar na Tabela 7 a presença de células vazias, como no tratamento CF30 (R1 e R8), deveu-se à desuniformidade dos emissores novos, gerando vazões excessivamente altas, fora da faixa de leitura do medidor magnético de vazão.

Este modelo de emissor possui mecanismo de autocompensação; entretanto, esse fato não apresentou efeito quanto à desuniformidade de vazão para a maior parte dos emissores. 

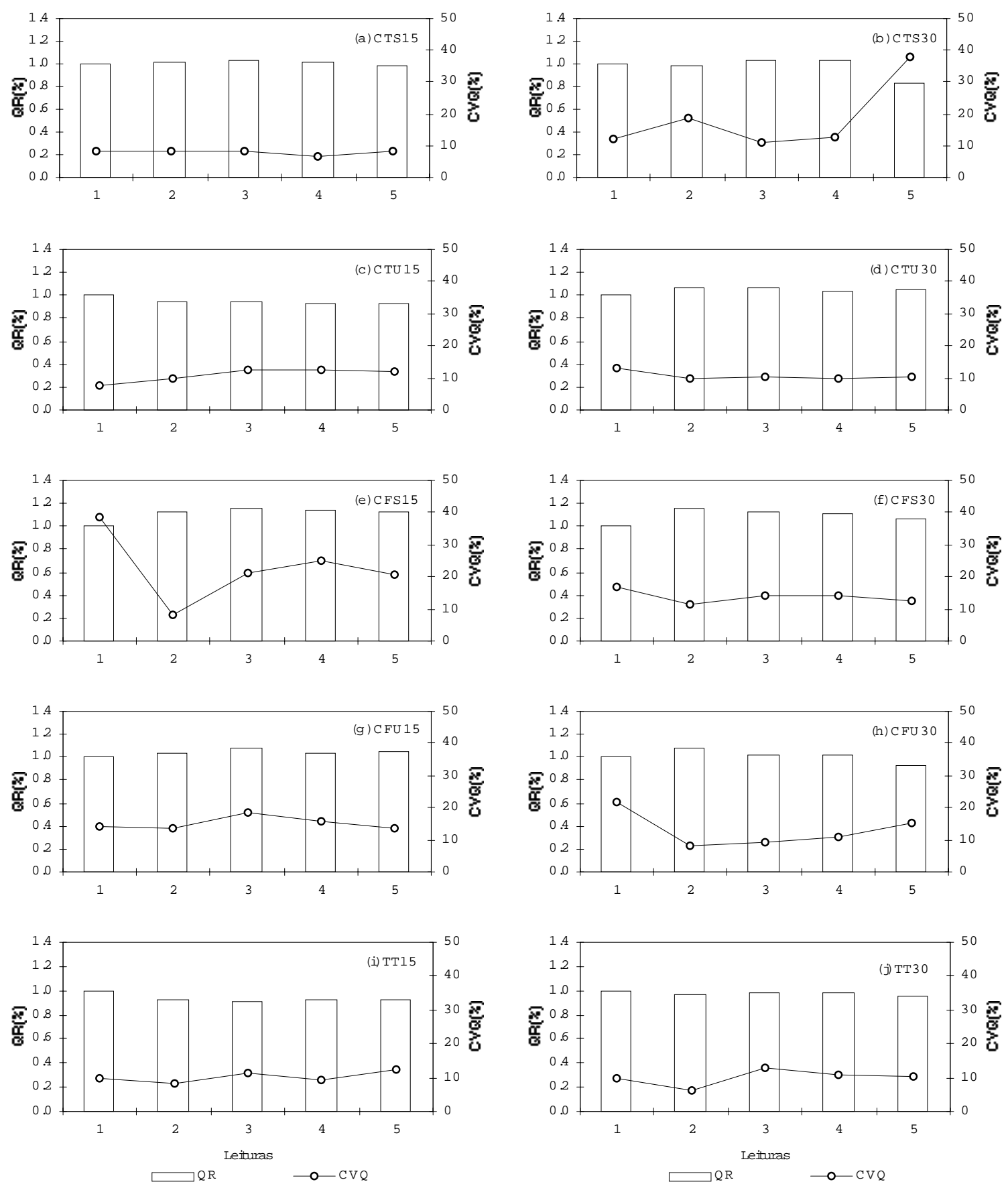

Figura 14 - QR e CVQ para o emissor modelo D: (a) citros seco $15 \mathrm{~cm}$; (b) citros seco $30 \mathrm{~cm}$; (c) citros úmido $15 \mathrm{~cm}$; (d) citros úmido $30 \mathrm{~cm}$; (e) café seco $15 \mathrm{~cm}$, (f) café seco $30 \mathrm{~cm}$; $(\mathrm{g})$ café úmido $15 \mathrm{~cm}$; (h) café úmido $30 \mathrm{~cm}$; (i) testemunha $15 \mathrm{~cm}$; (j) testemunha $30 \mathrm{~cm}$. 
Tabela 7. Vazões do emissor modelo $D$ em $L . h^{-1}$ para as cinco leituras realizadas (1L até $5 \mathrm{~L}$ ), dez repetições (R1 até $\left.R 10\right)$ para todos os tratamentos (CTS15, CTS30, CTU15, CTU30, CFS15, CFS30, CFU15, CFU30, TT15 e TT30).

\begin{tabular}{|c|c|c|c|c|c|c|c|c|c|c|c|c|c|c|c|c|c|c|c|c|c|c|c|}
\hline & & R1 & R2 & R3 & R4 & R5 & $\mathrm{R} 6$ & R7 & R8 & R9 & R10 & & & R1 & R2 & R3 & R4 & R5 & R6 & R7 & R8 & $\mathrm{R9}$ & R10 \\
\hline \multirow[t]{5}{*}{ CTS15 } & $1 \mathrm{~L}$ & 3.50 & 3.41 & & 3.27 & 3.73 & 3.48 & 3.18 & 3.08 & 3.97 & 3.64 & TS30 & $1 \mathrm{~L}$ & 3.02 & 3.17 & 3.09 & 3.89 & 4.19 & 3.28 & 3.28 & 2.95 & & 3.41 \\
\hline & $2 \mathrm{~L}$ & 3.43 & 3.34 & & 3.19 & 3.68 & 4.02 & 3.46 & 3.28 & 3.93 & 3.48 & & $2 \mathrm{~L}$ & 2.17 & 3.16 & 3.38 & 3.94 & 4.44 & 3.43 & 3.38 & 3.10 & 2.78 & 6 \\
\hline & $3 \mathrm{~L}$ & 3.46 & 3.74 & 22 & 3.22 & 3.68 & 3.66 & 3.30 & 4.06 & 3.93 & 3.45 & & $3 \mathrm{~L}$ & 3.10 & 3.47 & 3.35 & 3.86 & 3.98 & 3.56 & 2.82 & 3.26 & .93 & 3.16 \\
\hline & $4 \mathrm{~L}$ & 3.42 & 3.78 & 62 & 3.14 & 3.64 & 3.68 & 3.33 & 3.34 & 3.87 & 3.34 & & $4 \mathrm{~L}$ & 3.18 & 3.14 & 3.34 & 4.17 & 4.36 & 3.46 & 3.04 & 3.36 & 30 & 3.22 \\
\hline & $5 \mathrm{~L}$ & 4.04 & 3.47 & 15 & 3.08 & 3.55 & 3.63 & 3.27 & 3.18 & 3.64 & 3.34 & & $5 \mathrm{~L}$ & 3.04 & 3.12 & 3.50 & 2.16 & 3.07 & 3.04 & 3.31 & 0.00 & 2.93 & 3.58 \\
\hline \multirow[t]{5}{*}{ CTU15 } & $1 \mathrm{~L}$ & 3.54 & 41 & 28 & 48 & 3.87 & 3.54 & 3.38 & 3.31 & 3.89 & 2.98 & & $1 \mathrm{~L}$ & 2.82 & 3.18 & 2.84 & 2.52 & 3.80 & 3.53 & 3.19 & 3.33 & 3.55 & 2.75 \\
\hline & $2 \mathrm{~L}$ & 43 & 24 & 32 & 48 & 23 & 14 & 34 & 3.26 & 72 & 62 & & $2 \mathrm{~L}$ & 2.83 & 2.92 & 3.56 & & 45 & 3.67 & 3.13 & 3.28 & 3.52 & 3.74 \\
\hline & $3 \mathrm{~L}$ & 3.38 & 33 & 78 & 42 & 92 & 28 & 58 & 3.46 & 3.86 & 2.48 & & $3 \mathrm{~L}$ & 3.18 & 2.82 & 2.85 & 3.42 & 3.15 & 3.43 & 3.96 & 3.40 & 3.62 & 3.53 \\
\hline & $4 \mathrm{~L}$ & 3.46 & 36 & 78 & 48 & .03 & 3.42 & 3.46 & 3.16 & 3.68 & 2.33 & & $4 \mathrm{~L}$ & 3.08 & 3.07 & 2.92 & 3.28 & 3.26 & 3.63 & 2.95 & 3.18 & 56 & 3.87 \\
\hline & $5 \mathrm{~L}$ & 3.34 & .27 & 96 & 3.58 & 10 & 3.27 & 36 & 3.18 & 3.73 & 2.30 & & $5 \mathrm{~L}$ & 2.63 & 2.94 & 3.54 & 3.38 & 3.08 & 3.57 & 3.34 & 3.20 & 3.72 & 3.50 \\
\hline \multirow{5}{*}{ CFS15 } & $1 \mathrm{~L}$ & 3.48 & .92 & 2.86 & & 3.45 & 0.30 & 3.06 & & 4.06 & 3.80 & & $1 \mathrm{~L}$ & 3.71 & 3.81 & 3.07 & 3.86 & 2.67 & 2.88 & & 2.41 & 2.87 & 3.08 \\
\hline & $2 \mathrm{~L}$ & 3.74 & 52 & 13 & 24 & 3.58 & 47 & 3.15 & & 3.86 & 3.86 & & $2 \mathrm{~L}$ & 3.72 & 3.86 & 4.12 & 4.09 & 3.85 & 2.94 & & & 3.18 & 3.57 \\
\hline & $3 \mathrm{~L}$ & 3.68 & 77 & 18 & 02 & 2.46 & 3.67 & 3.15 & 5.36 & 3.88 & 3.92 & & $3 \mathrm{~L}$ & 4.22 & 4.13 & 3.25 & 4.02 & 2.84 & 3.00 & 3.73 & & 3.45 & 3.28 \\
\hline & $4 \mathrm{~L}$ & 3.66 & 3.48 & 13 & 15 & 2.00 & .55 & .14 & 5.53 & 3.92 & 3.78 & & $4 \mathrm{~L}$ & 3.82 & 4.12 & 3.38 & 4.02 & 2.68 & 2.98 & 3.73 & & 3.64 & 3.18 \\
\hline & $5 \mathrm{~L}$ & 3.67 & 3.28 & 3.08 & 3.17 & 2.88 & 3.56 & 3.12 & 5.45 & 3.76 & 3.25 & & $5 \mathrm{~L}$ & 3.56 & 3.87 & 3.07 & 3.84 & 2.65 & 2.97 & 3.55 & & 3.37 & 3.12 \\
\hline \multirow[t]{5}{*}{ CFU1 } & $1 \mathrm{~L}$ & & 4.03 & 97 & 3.39 & 2.93 & 3.65 & 2.94 & 3.00 & 2.58 & 3.55 & CFU30 & $1 \mathrm{~L}$ & & 3.98 & 4.01 & 3.50 & 3.43 & 3.13 & 3.28 & & 1.71 & 3.72 \\
\hline & $2 \mathrm{~L}$ & & 4.23 & .74 & 3.32 & 3.07 & 3.48 & 3.07 & 3.00 & 2.72 & 36 & & $2 \mathrm{~L}$ & & 3.02 & 3.70 & 3.54 & 3.48 & 3.76 & 3.57 & & 3.65 & 4.03 \\
\hline & $3 \mathrm{~L}$ & 4.68 & 4.20 & 3.12 & 4.04 & 2.78 & 56 & 3.08 & 3.04 & 2.78 & 3.46 & & $3 \mathrm{~L}$ & & 3.06 & 3.68 & 3.94 & 3.18 & 3.17 & 3.64 & & 3.23 & 3.27 \\
\hline & $4 \mathrm{~L}$ & & 4.11 & 15 & 4.12 & 2.84 & 3.54 & 3.00 & 3.04 & 2.68 & 3.66 & & $4 \mathrm{~L}$ & & 3.06 & 3.72 & 3.92 & 3.30 & 3.14 & 3.26 & & 3.00 & 3.83 \\
\hline & $5 \mathrm{~L}$ & 3.90 & 3.84 & 3.80 & 3.86 & 3.25 & 3.46 & 2.98 & 96 & 2.56 & 35 & & $5 \mathrm{~L}$ & & 3.23 & 3.68 & 2.16 & 3.07 & 3.04 & 3.31 & & 2.93 & .58 \\
\hline \multirow[t]{5}{*}{ TT15 } & $1 \mathrm{~L}$ & 3.50 & 3.85 & .06 & 3.66 & 3.45 & 3.84 & 3.31 & 4.04 & 4.27 & 3.98 & ТT30 & $1 \mathrm{~L}$ & 3.60 & 4.06 & 3.02 & 3.75 & 3.70 & 3.34 & 3.81 & 3.03 & 3.92 & 3.72 \\
\hline & $2 \mathrm{~L}$ & 3.55 & 3.12 & 3.24 & 3.60 & & & 3.0 & 3.83 & 3.66 & 3.28 & & $2 \mathrm{~L}$ & 3.82 & 3.57 & 3.35 & 3.18 & 3.45 & 3.36 & 3.66 & 3.13 & 3.52 & 3.5 \\
\hline & $3 \mathrm{~L}$ & 3.45 & 2.96 & 3.15 & 3.96 & 3.28 & & 3.12 & 3.92 & 3.53 & 2.98 & & $3 \mathrm{~L}$ & 3.65 & 3.36 & 3.10 & 3.02 & 4.46 & 3.52 & 3.38 & 3.12 & 3.44 & 4.08 \\
\hline & $4 \mathrm{~L}$ & 3.60 & 3.04 & 3.12 & 3.54 & 3.43 & & 3.02 & 3.87 & 3.77 & 3.19 & & $4 \mathrm{~L}$ & 3.73 & 4.25 & 3.07 & 3.10 & 3.40 & 3.40 & 3.32 & 3.44 & 3.60 & 4.08 \\
\hline & $5 \mathrm{~L}$ & 3.48 & 3.18 & 2.83 & 3.53 & 3.82 & 4.14 & 2.94 & 3.73 & 3.58 & 3.05 & & $5 \mathrm{~L}$ & 3.58 & 3.83 & 3.09 & 3.02 & 3.42 & 3.31 & 3.36 & 2.90 & 3.48 & 4.02 \\
\hline
\end{tabular}




\subsubsection{Emissor modelo $\mathrm{E}$}

Quanto ao parâmetro CVQ inicial, esse modelo de emissor apresentou desempenho normal. Apenas no tratamento CTS30, como se observa na Figura 15, seu comportamento foi anormal, apresentando CVQ elevado inicialmente. O valor do CVQ inicial geral foi de $16,9 \%$, ficando abaixo do aceitável.

O emissor modelo $E$ não apresentou uma clara tendência de comportamento de vazão. Nos tratamentos CTS15, CTS30, CFS30, CFU30 e testemunha 15 e $30 \mathrm{~cm}$ houve redução de vazão. Nos demais tratamentos, o comportamento foi de aumento de vazão.

Observam-se picos elevados de QR e CVQ. A QR, como em CTU15, que chegou a apresentar valor de $2,4 \%$, ou seja, $240 \%$ de aumento de vazão em relação à vazão inicial. Quanto ao CVQ, este chegou a $130 \%$ para o mesmo caso. Tais valores ocorreram, pois alguns emissores apresentaram vazões elevadas, chegando a mais de 20 L.h ${ }^{-1}$, conforme Tabela 8.

Quanto aos efeitos dos tratamentos, observa-se que nos ensaios CTU15, CTU30, CFS15, CFU15, ocorreu um aumento significativo do CVQ a partir das leituras 3, 4 e 5, o que não ocorreu nas testemunhas, indicando distúrbios de vazão por interferência radicular.

O desempenho das testemunhas às duas profundidades foi normal, não tendo havido redução elevada de vazão nem aumento do CVQ.

Particularmente, chamou a atenção o desempenho dos emissores nas repetições R1 e R2 do CTU15, R4 e R6 do CFU15 e R6 do CTU30. Estes apresentaram elevação extrema de vazão e, caso tal fato ocorresse em campo de maneira generalizada, causaria desequilíbrio hidráulico no sistema. 

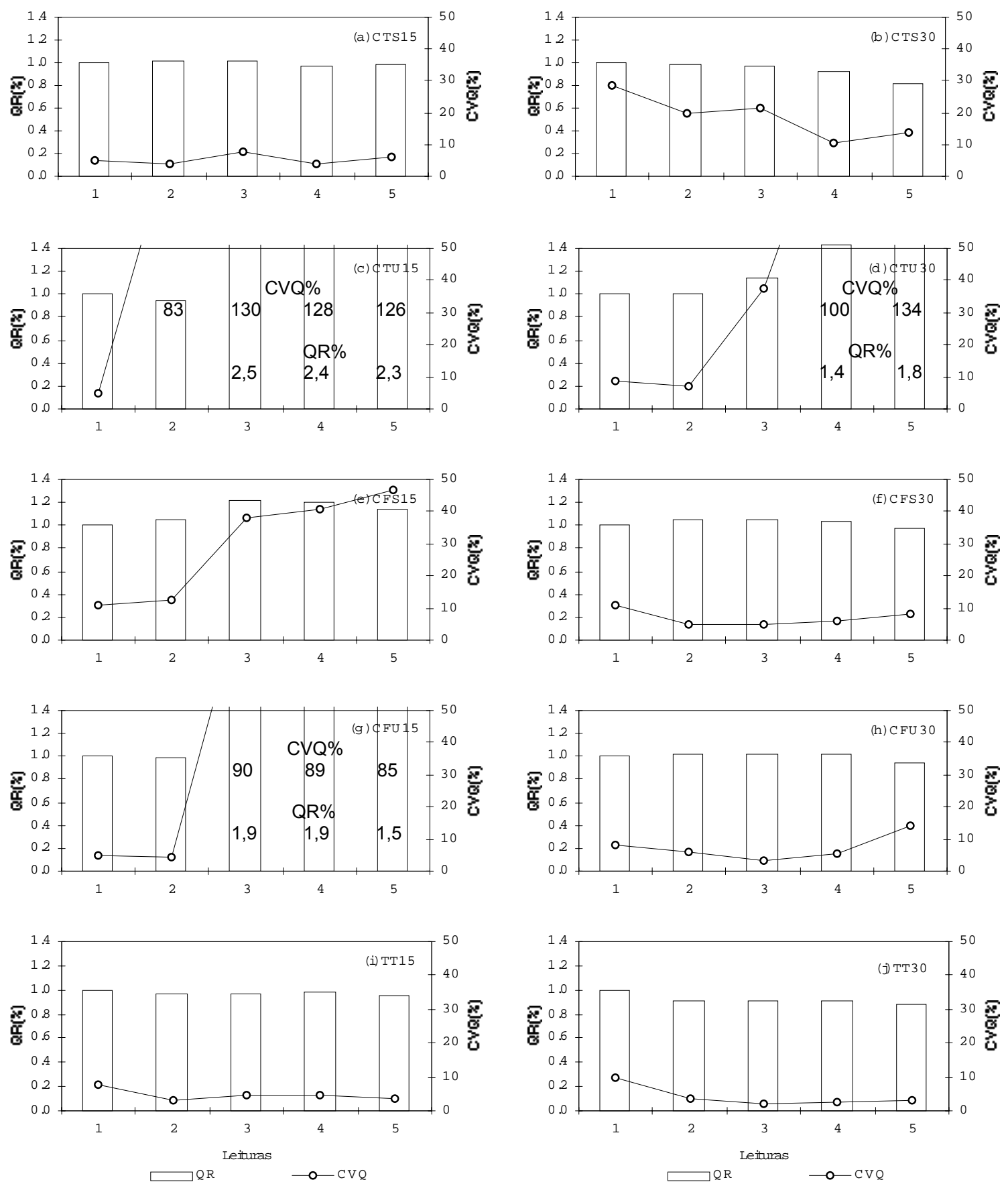

Figura 15 - QR e CVQ para o emissor modelo E: (a) citros seco $15 \mathrm{~cm}$; (b) citros seco $30 \mathrm{~cm}$; (c) citros úmido $15 \mathrm{~cm}$; (d) citros úmido $30 \mathrm{~cm}$; (e) café seco $15 \mathrm{~cm}$, (f) café seco $30 \mathrm{~cm}$; $(\mathrm{g})$ café úmido $15 \mathrm{~cm}$; (h) café úmido $30 \mathrm{~cm}$; (i) testemunha $15 \mathrm{~cm}$; (j) testemunha $30 \mathrm{~cm}$. 
Tabela 8. Vazões do emissor modelo $E$ em $L . h^{-1}$ para as cinco leituras realizadas (1L até $5 \mathrm{~L}$ ), dez repetições (R1 até $\left.R 10\right)$ para todos os tratamentos (CTS15, CTS30, CTU15, CTU30, CFS15, CFS30, CFU15, CFU30, TT15 e TT30).

\begin{tabular}{|c|c|c|c|c|c|c|c|c|c|c|c|c|c|c|c|c|c|c|c|c|c|c|c|}
\hline & & R1 & R2 & R3 & R4 & R5 & R6 & R7 & R8 & R9 & R10 & & & R1 & R2 & R3 & R4 & R5 & R6 & R7 & R8 & R9 & R10 \\
\hline \multirow{5}{*}{ CTS15 } & $1 \mathrm{~L}$ & 2.45 & 2.26 & 2.23 & 2.25 & 2.23 & 2.03 & 2.19 & 2.29 & 2.21 & & \multirow[t]{5}{*}{ CTS30 } & $1 \mathrm{~L}$ & 2.14 & 2.18 & 2.27 & 2.37 & 2.32 & 2.06 & 4.26 & 2.13 & 2.21 & \\
\hline & $2 \mathrm{~L}$ & 2.36 & 2.26 & 2.34 & 2.26 & & 2.23 & 2.13 & 2.42 & 2.25 & 2.23 & & $2 \mathrm{~L}$ & 2.23 & 2.15 & 2.20 & 2.36 & & & 3.43 & 2.16 & 2.17 & \\
\hline & $3 \mathrm{~L}$ & 2.73 & 28 & 12 & 2.27 & 2.24 & 2.14 & 2.12 & 2.33 & 2.25 & 2.20 & & $3 \mathrm{~L}$ & 2.18 & 2.16 & 2.17 & 2.43 & 2.18 & 2.05 & 3.74 & 2.12 & 2.25 & \\
\hline & $4 \mathrm{~L}$ & 14 & 24 & 16 & 15 & 2.16 & 2.08 & 2.10 & 2.38 & 2.13 & 2.23 & & $4 \mathrm{~L}$ & 2.05 & 2.10 & 2.16 & 2.30 & 2.26 & 2.10 & 2.88 & 2.16 & 12 & \\
\hline & $5 \mathrm{~L}$ & 2.48 & 2.23 & 2.23 & 2.15 & 2.05 & 2.07 & 2.05 & 2.30 & 2.26 & 2.23 & & $5 \mathrm{~L}$ & 2.04 & 2.07 & 2.27 & 2.07 & 2.09 & 2.05 & 2.03 & 2.07 & 1.24 & 2.10 \\
\hline \multirow[t]{5}{*}{ CTU15 } & $1 \mathrm{~L}$ & & & 2.27 & 2.26 & 2.40 & & 2.23 & 11 & 2.26 & 2.45 & \multirow[t]{5}{*}{ CTU30 } & $1 \mathrm{~L}$ & 2.28 & 2.26 & 2.04 & 2.26 & 2.09 & 2.03 & 2.69 & 2.19 & 2.38 & 2.12 \\
\hline & $2 \mathrm{~L}$ & 2.23 & 9.43 & 2.15 & .17 & 2.08 & & 2.25 & 2.15 & 2.05 & & & $2 \mathrm{~L}$ & 2.10 & 2.28 & 2.23 & 2.24 & 2.11 & 2.10 & 2.32 & 2.42 & 2.15 & 2.58 \\
\hline & $3 \mathrm{~L}$ & 17.68 & 21.65 & 2.13 & 2.26 & 2.18 & 2.14 & 2.15 & 2.03 & 2.25 & 2.28 & & $3 \mathrm{~L}$ & 2.16 & 2.16 & 2.24 & 2.32 & 1.95 & 5.18 & 2.26 & 2.84 & 2.14 & 2.22 \\
\hline & $4 \mathrm{~L}$ & 17.05 & 20.50 & 14 & .26 & 2.16 & 2.15 & 2.23 & 2.08 & 2.21 & 2.22 & & $4 \mathrm{~L}$ & 2.20 & 2.22 & 2.18 & 2.24 & 1.94 & 12.30 & 2.38 & 2.10 & 2.16 & 2.20 \\
\hline & $5 \mathrm{~L}$ & 16.32 & 20.00 & 2.15 & 17 & 2.20 & 2.19 & 2.16 & 08 & 2.19 & 2.24 & & $5 \mathrm{~L}$ & 2.18 & 2.24 & 2.16 & 2.25 & .63 & 20.00 & 2.36 & 2.43 & 4.12 & 2.28 \\
\hline \multirow[t]{5}{*}{ CFS15 } & $1 \mathrm{~L}$ & 2.22 & 2.41 & 2.09 & 2.33 & 2.11 & 1.61 & 1.98 & 2.23 & 2.21 & 2.36 & \multirow[t]{5}{*}{ CFS30 } & $1 \mathrm{~L}$ & 1.59 & 2.16 & 2.22 & 2.34 & 2.07 & 2.38 & 2.12 & 2.00 & 2.35 & 2.16 \\
\hline & $2 \mathrm{~L}$ & 2.95 & 2.36 & 2.24 & 2.38 & 2.32 & 1.96 & 2.04 & 2.03 & 2.21 & 2.25 & & $2 \mathrm{~L}$ & 2.42 & 2.26 & 2.27 & 2.23 & 2.20 & 2.23 & 2.25 & 2.03 & 2.41 & 2.18 \\
\hline & $3 \mathrm{~L}$ & 2.78 & 2.16 & 5.40 & 2.32 & 2.28 & 2.06 & 2.16 & 2.38 & 2.24 & 2.37 & & $3 \mathrm{~L}$ & 2.18 & 2.22 & 2.24 & 2.27 & 2.37 & 2.08 & 2.30 & 2.14 & 2.47 & 2.20 \\
\hline & $4 \mathrm{~L}$ & 2.63 & 2.35 & .50 & 2.39 & 2.26 & 1.95 & 1.98 & 2.32 & 2.16 & 2.23 & & $4 \mathrm{~L}$ & 2.45 & 2.23 & 2.24 & 2.28 & 2.18 & 2.03 & 2.21 & 2.03 & 2.42 & 2.22 \\
\hline & $5 \mathrm{~L}$ & 2.24 & 2.25 & 5.65 & 2.20 & 2.22 & 1.54 & 1.98 & 2.16 & 2.14 & 2.18 & & $5 \mathrm{~L}$ & 1.73 & 2.15 & 2.17 & 2.26 & 2.20 & 1.86 & 2.22 & 2.02 & 2.23 & 2.10 \\
\hline \multirow[t]{5}{*}{ CFU15 } & $1 \mathrm{~L}$ & .94 & 2.28 & .16 & .18 & 2.18 & 2.24 & 2.26 & 2.20 & & & \multirow[t]{5}{*}{ CFU30 } & $1 \mathrm{~L}$ & 1.96 & 2.18 & 2.15 & 2.16 & 2.24 & & 2.38 & 2.28 & 1.83 & 2.02 \\
\hline & $2 \mathrm{~L}$ & 2.06 & 2.28 & 2.23 & 2.10 & 2.04 & 2.16 & & 2.21 & & & & $2 \mathrm{~L}$ & 2.18 & 2.38 & 2.33 & 2.21 & 2.15 & & 2.10 & 2.23 & 1.94 & 2.12 \\
\hline & $3 \mathrm{~L}$ & 2.00 & 2.28 & 2.25 & 10.43 & 2.14 & 10.50 & 2.25 & 2.22 & & & & $3 \mathrm{~L}$ & 2.12 & 2.22 & 2.22 & 2.10 & 2.12 & 2.08 & 2.18 & 2.23 & 2.18 & 2.28 \\
\hline & $4 \mathrm{~L}$ & 2.03 & 2.38 & 2.22 & 10.48 & 2.08 & 10.00 & 2.23 & 2.16 & & & & $4 \mathrm{~L}$ & 2.12 & 2.28 & 2.24 & 2.15 & 2.15 & 2.10 & 2.45 & 2.17 & 2.10 & 2.05 \\
\hline & $5 \mathrm{~L}$ & 1.96 & 2.25 & 2.14 & 3.35 & 2.00 & 10.08 & 2.27 & 2.16 & & & & $5 \mathrm{~L}$ & 2.03 & 2.20 & 2.24 & 2.07 & 2.09 & 2.05 & 2.03 & 2.07 & 1.24 & 2.10 \\
\hline \multirow[t]{5}{*}{ TT15 } & $1 \mathrm{~L}$ & 2.11 & 10 & 2.55 & 06 & .19 & 2.18 & .20 & 2.49 & 2.18 & .08 & \multirow[t]{5}{*}{ TT30 } & $1 \mathrm{~L}$ & 2.07 & 2.15 & 2.19 & 2.10 & 1.99 & 2.03 & 2.75 & 2.18 & 2.12 & 2. \\
\hline & $2 \mathrm{~L}$ & 23 & 08 & 14 & 06 & 22 & 21 & 20 & 16 & .09 & .10 & & $2 \mathrm{~L}$ & 2.11 & & 2.15 & 2.14 & 2.12 & & 2.20 & 2.14 & .05 & 2.3 \\
\hline & $3 \mathrm{~L}$ & 2.16 & 2.08 & 2.06 & 2.08 & 2.16 & 2.14 & 2.24 & 2.38 & 2.13 & 2.06 & & $3 \mathrm{~L}$ & 2.12 & & 2.10 & 2.12 & 2.16 & & 2.24 & 2.18 & 2.12 & 2.19 \\
\hline & $4 \mathrm{~L}$ & 2.26 & 2.10 & 2.12 & 2.02 & 2.23 & 2.08 & 2.20 & 2.37 & 2.24 & 2.10 & & $4 \mathrm{~L}$ & 2.13 & 2.14 & 2.17 & 2.14 & 2.08 & 2.23 & 2.28 & 2.16 & 2.12 & 2.22 \\
\hline & $5 \mathrm{~L}$ & 2.20 & .10 & .08 & .96 & 2.16 & 2.15 & 2.12 & 2.26 & .10 & 2.07 & & $5 \mathrm{~L}$ & 2.02 & 2.08 & 2.13 & 2.12 & 2.06 & 2.13 & 2.20 & 2.00 & 2.05 & 2. \\
\hline
\end{tabular}




\subsubsection{Emissor modelo $F$}

Esse emissor apresentou CVQ inicial geral de $8,7 \%$, e os valores desse parâmetro para os tratamentos foram uniformes. Apenas no tratamento CFU15, devido ao valor de vazão do emissor na repetição R10, o CVQ foi elevado, quando comparado com os outros tratamentos e com as testemunhas, como pode ser observado na Tabela 9 e na Figura 16 (g).

A vazão na última leitura apresentou tendência discreta de queda para todos os tratamentos e para as testemunhas.

Foram observados dois picos discretos nos valores do CVQ, em CFS15 e TT30. Esses picos são explicados por emissores que, na terceira determinação de vazão, apresentaram vazão reduzida. Esses emissores recuperaram sua vazão normal, fazendo com que o CVQ nas leituras subseqüentes se apresentasse dentro da normalidade.

Não foi observada evidência dos efeitos dos tratamentos, e o desempenho desse modelo de emissor nas testemunhas foi normal e uniforme.

O desempenho geral desse modelo de emissor demonstrou elevada uniformidade quando comparado como os outros modelos ensaiados; não apresentou redução total de vazão bem como valores extremos nesse parâmetro. Seu comportamento surpreendeu pelo fato de possuir mecanismo de compensação, pois, para os outros modelos de emissor autocompensantes ensaiados, o desempenho foi aquém das expectativas. Ressalta-se também o fato de a vazão desse emissor ser a mais elevada dos ensaiados, e que a vazão real ficou próxima da nominal fornecida pelo fabricante. 

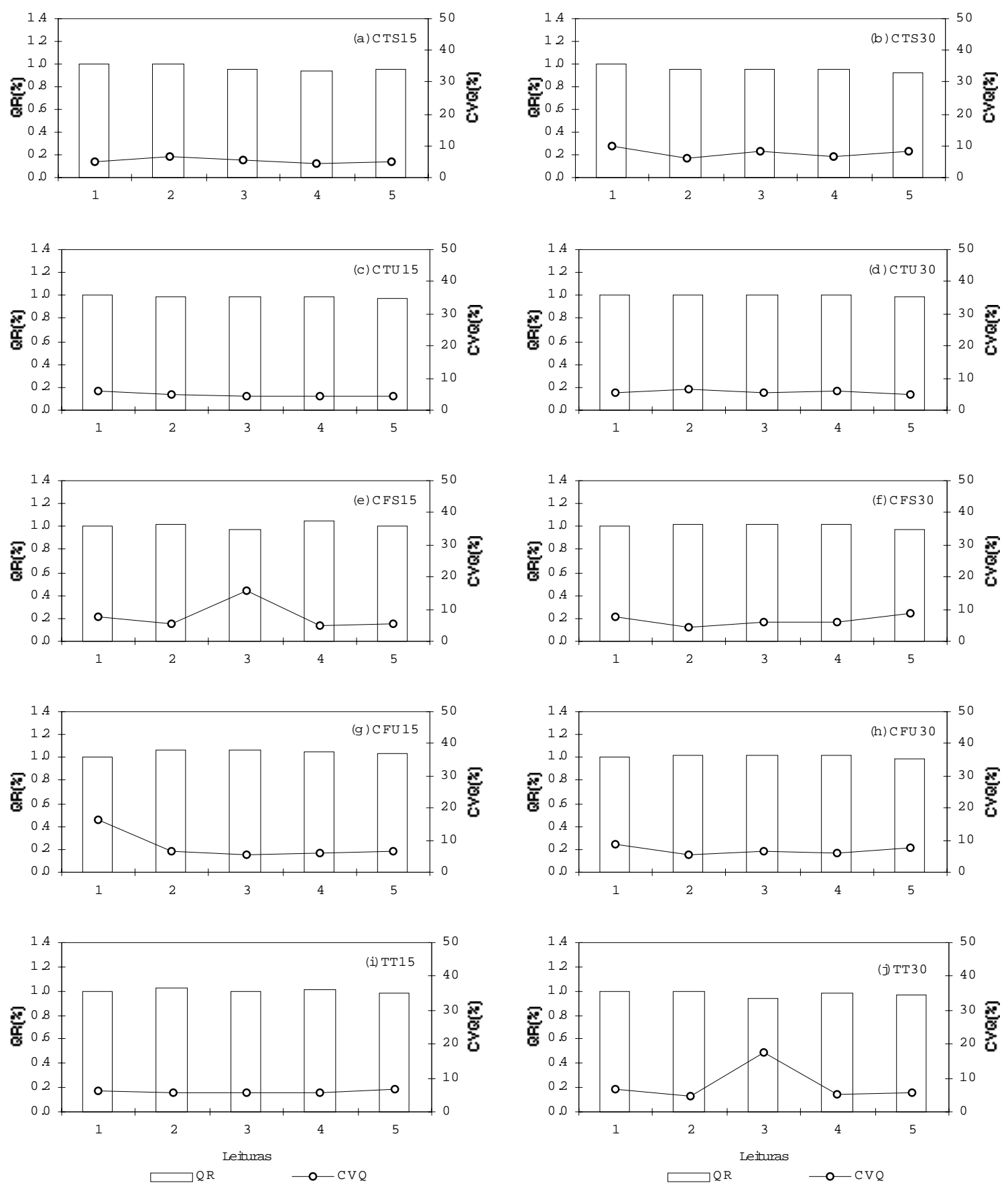

Figura 16 - QR e CVQ para o emissor modelo F: (a) citros seco $15 \mathrm{~cm}$; (b) citros seco $30 \mathrm{~cm}$; (c) citros úmido $15 \mathrm{~cm}$; (d) citros úmido $30 \mathrm{~cm}$; (e) café seco $15 \mathrm{~cm}$, (f) café seco $30 \mathrm{~cm}$; $(\mathrm{g})$ café úmido $15 \mathrm{~cm}$; (h) café úmido $30 \mathrm{~cm}$; (i) testemunha $15 \mathrm{~cm}$; (j) testemunha $30 \mathrm{~cm}$. 
Tabela 9. Vazões do emissor modelo $F$ em L.h ${ }^{-1}$ para as cinco leituras realizadas (1L até $5 \mathrm{~L}$ ), dez repetições (R1 até $\left.R 10\right)$ para todos os tratamentos (CTS15, CTS30, CTU15, CTU30, CFS15, CFS30, CFU15, CFU30, TT15 e TT30).

\begin{tabular}{|c|c|c|c|c|c|c|c|c|c|c|c|c|c|c|c|c|c|c|c|c|c|c|c|}
\hline & $1 \mathrm{~L}$ & $\frac{\mathrm{R} 1}{4.41}$ & $\begin{array}{l}\mathrm{R} 2 \\
453\end{array}$ & R3 & $\begin{array}{l}\mathrm{R} 4 \\
453\end{array}$ & $\begin{array}{l}\mathrm{R} 5 \\
438\end{array}$ & $\begin{array}{l}\mathrm{R} 6 \\
456\end{array}$ & $\begin{array}{c}\mathrm{R} 7 \\
387\end{array}$ & $\begin{array}{l}\mathrm{R} 8 \\
4.29\end{array}$ & $\begin{array}{l}\text { R99 } \\
4.37\end{array}$ & R10 & & 1L & $\begin{array}{l}\text { R1 } \\
372\end{array}$ & $\begin{array}{l}\mathrm{R} 2 \\
4.18\end{array}$ & R3 & $\begin{array}{l}\text { R4 } \\
481\end{array}$ & $\begin{array}{l}\text { R5 } \\
4.03\end{array}$ & $\begin{array}{l}\mathrm{R} 6 \\
457\end{array}$ & $\frac{\mathrm{R} 7}{4.63}$ & $\begin{array}{c}\mathrm{R} 8 \\
383\end{array}$ & $\begin{array}{l}\mathrm{R} 9 \\
4.42\end{array}$ & $\frac{\mathrm{R} 10}{492}$ \\
\hline \multirow{4}{*}{ CTS15 } & $2 \mathrm{~L}$ & 4.20 & 4.43 & & 4.75 & & 4.56 & 3.93 & 4.32 & & & \multirow{4}{*}{ CTS30 } & $2 \mathrm{~L}$ & 4.05 & 4.14 & & 4.56 & 3.95 & & 4.47 & 3.87 & 4.26 & 3.90 \\
\hline & $3 \mathrm{~L}$ & 4.17 & 4.46 & 4.23 & .15 & 4.08 & 4.56 & 3.98 & 4.28 & 3.84 & 96 & & $3 \mathrm{~L}$ & 3.82 & 4.12 & 4.52 & 4.25 & 4.05 & 4.62 & 4.72 & 3.85 & 3.84 & 3.92 \\
\hline & $4 \mathrm{~L}$ & 4.15 & 32 & 12 & .06 & 4.10 & 4.32 & 3.90 & 3.94 & 3.84 & & & $4 \mathrm{~L}$ & 3.74 & 4.04 & 4.38 & 4.43 & 4.02 & 4.54 & 4.42 & 3.86 & 4.10 & 3.92 \\
\hline & $5 \mathrm{~L}$ & 4.17 & 32 & 22 & 43 & 4.12 & 34 & 3.90 & 4.32 & 3.85 & 3.94 & & SL & 3.65 & 4.05 & 18 & 4.28 & 42 & 52 & 4.42 & .77 & 14 & U. \\
\hline \multirow[t]{5}{*}{ CTU15 } & $1 \mathrm{~L}$ & 3.91 & 83 & 53 & 4.00 & 4.29 & 4.01 & 4.25 & & 4.52 & 4.06 & \multirow[t]{5}{*}{ CTU30 } & $1 \mathrm{~L}$ & 4.02 & 4.16 & 4.32 & 4.35 & 3.99 & 4.24 & 4.64 & 4.12 & 3.83 & 3.98 \\
\hline & $2 \mathrm{~L}$ & 3.94 & 85 & 50 & .03 & 4.18 & 4.06 & & & 4.18 & & & $2 \mathrm{~L}$ & 4.02 & 4.48 & 4.28 & & 4.05 & 4.34 & 4.54 & 3.92 & 76 & .0 \\
\hline & $3 \mathrm{~L}$ & 4.05 & .85 & 4.46 & 3.98 & 4.16 & 3.96 & 4.24 & 4.03 & 4.34 & 4.20 & & $3 \mathrm{~L}$ & 4.18 & 4.14 & 4.26 & 4.30 & 4.08 & 4.10 & 4.65 & 3.98 & .86 & 4.02 \\
\hline & $4 \mathrm{~L}$ & 3.92 & 82 & 46 & 4.12 & 4.20 & 4.07 & 4.15 & 4.03 & 4.26 & 4.06 & & $4 \mathrm{~L}$ & 4.14 & 4.48 & 4.27 & 4.35 & 3.95 & 4.35 & 4.53 & 3.95 & .78 & 4.05 \\
\hline & $5 \mathrm{~L}$ & 3.88 & 3.78 & 36 & 3.98 & 4.06 & 4.05 & 4.17 & 4.00 & 4.25 & 4.06 & & $5 \mathrm{~L}$ & 4.22 & 12 & 26 & 34 & 93 & 15 & 47 & .94 & .78 & .03 \\
\hline \multirow[t]{5}{*}{ CFS15 } & $1 \mathrm{~L}$ & 3.63 & .35 & 4.52 & 17 & 4.55 & 3.72 & .35 & 4.36 & 3.93 & 4.12 & \multirow[t]{5}{*}{ CFS30 } & $1 \mathrm{~L}$ & 4.36 & 3.98 & 3.88 & 3.58 & 4.23 & 3.88 & 3.82 & 3.72 & .5 & 4.2 \\
\hline & $2 \mathrm{~L}$ & 4.16 & & & 31 & 54 & .43 & .56 & .92 & 4.13 & .12 & & $2 \mathrm{~L}$ & 4.46 & 4.06 & 93 & 3.96 & 4.14 & 4.03 & 4.05 & 92 & 34 & .13 \\
\hline & $3 \mathrm{~L}$ & 4.02 & 4.35 & 4.55 & 4.17 & & 2.48 & .67 & 4.17 & 4.08 & 3.98 & & $3 \mathrm{~L}$ & 4.46 & 3.98 & 4.00 & 3.80 & 4.24 & 4.05 & 4.03 & 3.90 & 62 & 4.20 \\
\hline & $4 \mathrm{~L}$ & 4.16 & .36 & 4.62 & .23 & 4.64 & 4.52 & .35 & 4.58 & 4.06 & 4.15 & & $\mathrm{H} \mathrm{L}$ & 4.50 & 4.04 & 95 & 3.78 & 4.26 & 4.05 & 3.92 & .74 & .37 & 4.20 \\
\hline & $5 \mathrm{~L}$ & 4.03 & 20 & .46 & 87 & 4.46 & 4.34 & .52 & 18 & .02 & .03 & & $5 \mathrm{~L}$ & 4.36 & 3.72 & 83 & 3.53 & 25 & 00 & 18 & .45 & 43 & 14 \\
\hline \multirow[t]{5}{*}{ CFU15 } & $1 \mathrm{~L}$ & 4.06 & 44 & 23 & 32 & 3.89 & 4.48 & .69 & 13 & 4.15 & 2.27 & \multirow[t]{5}{*}{ CFU30 } & $1 \mathrm{~L}$ & 3.93 & 4.29 & 3.87 & 4.36 & 4.42 & 3.74 & 4.70 & 3.95 & 3.61 & 3.7 \\
\hline & $2 \mathrm{~L}$ & 32 & 3 & 52 & 30 & 87 & 46 & 76 & 11 & & .08 & & $2 \mathrm{~L}$ & 4.15 & 4.47 & 10 & 4.28 & 4.38 & 34 & & 02 & 0 & $3 . \varepsilon$ \\
\hline & $3 \mathrm{~L}$ & 4.22 & .48 & 4.32 & .30 & 3.90 & 4.52 & 4.80 & 4.18 & 4.25 & 4.16 & & $\dot{L}$ & 4.05 & 4.36 & 3.93 & 4.16 & 4.52 & 3.83 & 4.52 & 4.08 & 3.75 & 3.92 \\
\hline & $4 \mathrm{~L}$ & 4.08 & 4.56 & 4.36 & .32 & 3.85 & 4.46 & 4.73 & 4.18 & 4.32 & 4.13 & & $4 \mathrm{~L}$ & 4.08 & 4.24 & 3.94 & 4.34 & 4.48 & 3.82 & 4.44 & 3.97 & 3.84 & 4.36 \\
\hline & $5 \mathrm{~L}$ & 4.13 & 4.46 & 4.26 & 4.20 & 3.75 & 4.33 & 4.72 & 4.06 & 4.17 & 4.00 & & $5 \mathrm{~L}$ & 3.98 & 4.07 & 3.82 & 4.28 & 4.42 & 3.52 & 4.42 & 3.77 & 3.74 & 4.02 \\
\hline \multirow[t]{5}{*}{ TT15 } & $1 \mathrm{~L}$ & 3.72 & 4.40 & 4.31 & 4.40 & 4.16 & 3.98 & 4.46 & 3.76 & 4.14 & 4.32 & \multirow[t]{5}{*}{ TT30 } & $1 \mathrm{~L}$ & 3.73 & 4.00 & & 4.23 & 4.55 & 3.94 & 4.23 & 4.48 & & .9 \\
\hline & $2 \mathrm{~L}$ & & 4.32 & & 4.42 & 13 & & 4.45 & 3.80 & 18 & 4.41 & & $2 \mathrm{~L}$ & 3.86 & 4.00 & 4.17 & 4.30 & & & .13 & 38 & 30 & .02 \\
\hline & $3 \mathrm{~L}$ & 3.85 & 4.18 & 3 & 4.36 & 4.16 & & 4.46 & 3.80 & 4.03 & 4.3 & & $3 \mathrm{~L}$ & 3.78 & 3.94 & 4.16 & 4.20 & 61 & & 2.23 & 4.46 & 85 & 3.97 \\
\hline & $4 \mathrm{~L}$ & 85 & 32 & 32 & .35 & 4.15 & .98 & 4.47 & .84 & 4.08 & 4.4 & & 4L & 3.72 & 3.95 & 4.18 & 4.24 & 4.47 & 4.06 & 4.12 & 4.20 & 3.90 & 4.05 \\
\hline & $5 \mathrm{~L}$ & 3.66 & 4.32 & 4.17 & .28 & .17 & .87 & 4.44 & .75 & 1.02 & 4.35 & & $5 \mathrm{~L}$ & 3.64 & 3.92 & 4.06 & 4.06 & 4.45 & 3.90 & 3.94 & 4.25 & 3.78 & 3.94 \\
\hline
\end{tabular}




\subsubsection{Emissor modelo G}

O valor do CVQ inicial geral para esse modelo de emissor foi de $8,4 \%$. Os valores de CVQ inicial nos tratamentos e nas testemunhas não apresentaram-se baixos e uniformes com exceção dos tratamentos CFS15, CFS30 e CFU30 que apresentaram ligeira desuniformidade inicial.

Houve tendência de redução de vazão desse emissor. As vazões médias para todos os tratamentos apresentaram uniformidade, como pode ser observado na Figura 17.

Não ocorreram picos nos valores do CVQ, demonstrando estabilidade de vazão. Tal fato pode ser explicado por se tratar de emissor sem mecanismo de compensação de pressão.

Observam-se maiores valores de CVQ para o tratamento café seco $30 \mathrm{~cm}$; porém o valor do CVQ para a primeira leitura já se apresentava elevado. Ressalta-se o fato de ter sido encontrado por ocasião da abertura dos vasos, um emissor desse modelo com intrusão radicular (CFS30 na repetição R1) cuja foto pode ser observada na Figura 25 (d).

Quanto aos parâmetros analisados, o desempenho das testemunhas foi uniforme e normal.

Esse modelo de emissor apresentou, de forma geral, bom desempenho até a determinação da última vazão, e sua vazão real esteve sempre próxima da nominal. 

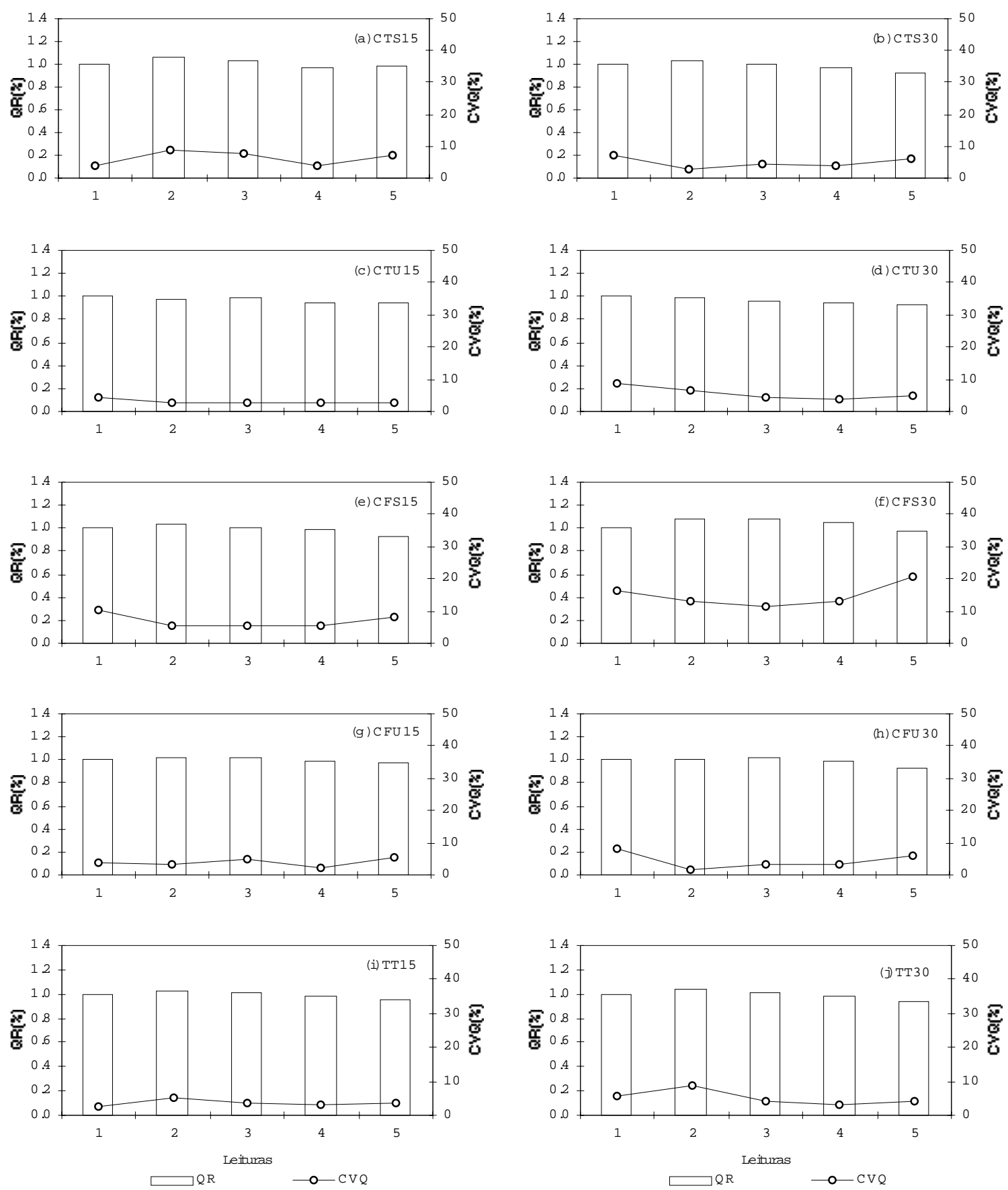

Figura 17 - QR e CVQ para o emissor modelo G: (a) citros seco $15 \mathrm{~cm}$; (b) citros seco $30 \mathrm{~cm}$; (c) citros úmido $15 \mathrm{~cm}$; (d) citros úmido $30 \mathrm{~cm}$; (e) café seco $15 \mathrm{~cm}$, (f) café seco $30 \mathrm{~cm}$; (g) café úmido $15 \mathrm{~cm}$; (h) café úmido $30 \mathrm{~cm}$; (i) testemunha $15 \mathrm{~cm}$; (j) testemunha $30 \mathrm{~cm}$. 
Tabela 10. Vazões do emissor modelo $G$ em $L . h^{-1}$ para as cinco leituras realizadas (1L até $5 \mathrm{~L}$ ), dez repetições (R1 até $\left.R 10\right)$ para todos os tratamentos (CTS15, CTS30, CTU15, CTU30, CFS15, CFS30, CFU15, CFU30, TT15 e TT30).

\begin{tabular}{|c|c|c|c|c|c|c|c|c|c|c|c|c|c|c|c|c|c|c|c|c|c|c|c|}
\hline & & R1 & $\mathrm{R} 2$ & R3 & R4 & R5 & R6 & R7 & $\mathrm{R} 8$ & R9 & R10 & & & R1 & R2 & R3 & R4 & R5 & R6 & R7 & R8 & R9 & R10 \\
\hline \multirow[t]{5}{*}{ CTS15 } & $1 \mathrm{~L}$ & 2.08 & & & & & 1.97 & & & & 2.12 & 530 & $1 \mathrm{~L}$ & 2.02 & 2.07 & 2.14 & 2.24 & 1.96 & 1.74 & 1.99 & 1.96 & 2.23 & 2.13 \\
\hline & $2 \mathrm{~L}$ & 2.16 & 2.10 & & & & & & & 2.46 & 2.04 & & $2 \mathrm{~L}$ & 2.18 & 2.08 & 2.02 & 2.22 & 2.15 & 2.08 & 2.13 & 2.07 & 2.10 & 2.04 \\
\hline & $3 \mathrm{~L}$ & 2.08 & 2.02 & 2.15 & 18 & 2.14 & 1.97 & 2.54 & 2.13 & 2.02 & 1.97 & & 3L & 2.00 & 2.07 & 2.12 & 2.24 & 2.02 & 1.93 & 2.03 & 2.02 & 2.02 & 1.94 \\
\hline & $4 \mathrm{~L}$ & 2.02 & 98 & 96 & 95 & 2.12 & 1.87 & 07 & 2.01 & 2.08 & 1.98 & & $4 \mathrm{~L}$ & 1.98 & 1.95 & 2.00 & 2.05 & 2.10 & 1.84 & 1.98 & 2.00 & .04 & 1.92 \\
\hline & $5 \mathrm{~L}$ & 2.04 & .92 & 94 & 2.02 & 03 & 1.92 & 38 & 02 & 2.03 & 1.88 & & $5 \mathrm{~L}$ & 1.90 & 2.02 & 2.00 & 1.98 & 1.68 & 1.74 & 1.90 & 1.88 & 1.98 & 1.90 \\
\hline \multirow[t]{5}{*}{ CTU15 } & $1 \mathrm{~L}$ & 2.08 & 2.22 & .11 & 96 & .09 & 2.13 & 2.14 & 2.24 & 2.17 & 1.98 & & $1 \mathrm{~L}$ & 2.29 & 1.86 & 1.77 & 2.18 & 2.03 & 2.20 & 2.24 & 2.14 & 2.03 & 1.89 \\
\hline & $2 \mathrm{~L}$ & 06 & 04 & 33 & 02 & 5 & 14 & 07 & 19 & 2.03 & 98 & & $2 \mathrm{~L}$ & 2.08 & 1.85 & 1.84 & 2.16 & 2.06 & 2.25 & 2.16 & 2.00 & 2.04 & \\
\hline & $3 \mathrm{~L}$ & 2.18 & 2.02 & 08 & 06 & 02 & 2.02 & 2.03 & 10 & 2.14 & 2.16 & & $3 \mathrm{~L}$ & 2.05 & 1.93 & 1.85 & 1.92 & 1.93 & 2.04 & 2.07 & 2.12 & 2.05 & 1.96 \\
\hline & $4 \mathrm{~L}$ & 2.07 & 2.00 & 00 & 00 & 06 & 2.08 & 1.92 & 98 & 2.00 & 1.95 & & $4 \mathrm{~L}$ & 2.02 & 1.82 & 1.88 & 2.02 & 1.98 & 2.05 & 2.02 & 1.95 & .96 & 1.90 \\
\hline & $5 \mathrm{~L}$ & 2.11 & 1.90 & .95 & 1.94 & 2.00 & 1.97 & 1.95 & 2.00 & 2.02 & 1.98 & & $5 \mathrm{~L}$ & 2.03 & 1.76 & 1.82 & 1.98 & 1.84 & 2.00 & 1.95 & 1.94 & 2.00 & 1.95 \\
\hline \multirow[t]{5}{*}{ CFS15 } & $1 \mathrm{~L}$ & 1.86 & 01 & .01 & 99 & .86 & 1.84 & 1.96 & 2.54 & & 2.01 & & 1L & 1.60 & 1.98 & 1.13 & 1.91 & 1.94 & 1.76 & 2.13 & 1.82 & 2.05 & 2.10 \\
\hline & $2 \mathrm{~L}$ & .08 & 16 & 27 & 13 & 06 & 02 & 6 & 4 & 2.10 & 13 & & $2 \mathrm{~L}$ & 2.06 & 2.10 & 1.34 & & 2.05 & 1.98 & 2.26 & 1.94 & .14 & 1.94 \\
\hline & $3 \mathrm{~L}$ & 2.02 & 16 & .20 & 2.06 & .84 & 2.00 & 1.93 & 8 & 1.98 & 2.13 & & $3 \mathrm{~L}$ & 1.96 & 2.08 & 1.45 & 1.93 & 2.05 & 2.03 & 2.36 & 1.97 & 1.96 & 2.11 \\
\hline & $4 \mathrm{~L}$ & 1.92 & 2.16 & 16 & 03 & .93 & 2.00 & 1.82 & 1.92 & 1.90 & 2.00 & & $4 \mathrm{~L}$ & 2.03 & 2.04 & 1.26 & 1.96 & 1.94 & 2.00 & 2.01 & 2.23 & 1.89 & 2.03 \\
\hline & $5 \mathrm{~L}$ & 1.80 & 2.04 & 2.03 & 92 & 1.57 & 1.94 & 1.64 & 82 & 1.93 & 1.88 & & $5 \mathrm{~L}$ & 1.87 & 1.92 & 0.80 & 1.78 & 1.85 & 1.90 & 2.22 & 2.01 & 1.73 & 1.84 \\
\hline \multirow[t]{5}{*}{ CFU15 } & $1 \mathrm{~L}$ & 2.01 & .92 & 98 & 07 & 12 & 2.02 & 2.05 & 15 & 1.93 & 2.01 & & $1 \mathrm{~L}$ & & 1.95 & & 2.04 & 2.21 & 2.05 & 2.30 & 2.01 & 1.78 & 1.92 \\
\hline & $2 \mathrm{~L}$ & 2.12 & 04 & 02 & 22 & 03 & 92 & 2.08 & 12 & 15 & 2.07 & & $2 \mathrm{~L}$ & & 2.04 & & 01 & 2.07 & 2.06 & & & 08 & 2.02 \\
\hline & $3 \mathrm{~L}$ & 2.02 & 94 & 2.00 & 97 & 2.10 & 2.07 & 2.28 & 07 & 2.14 & 2.12 & & $3 \mathrm{~L}$ & 1.97 & 1.96 & 2.12 & 2.05 & 2.13 & 2.10 & 2.10 & 2.03 & 15 & 2.02 \\
\hline & $4 \mathrm{~L}$ & 2.00 & .95 & .96 & 1.9 & 1.96 & 2.00 & 2.00 & 2.06 & 2.07 & 2.06 & & $4 \mathrm{~L}$ & 1.98 & 2.00 & 2.07 & 2.10 & 2.14 & 2.02 & 1.94 & 1.96 & 2.00 & 1.97 \\
\hline & $5 \mathrm{~L}$ & 1.95 & 1.84 & 1.95 & 1.82 & 1.93 & 1.90 & 2.22 & .02 & 2.00 & 1.99 & & $5 \mathrm{~L}$ & 1.88 & 1.90 & 2.04 & 1.98 & 1.68 & 1.74 & 1.90 & 1.88 & 1.98 & 1.90 \\
\hline \multirow[t]{5}{*}{ TT15 } & $1 \mathrm{~L}$ & 1.95 & 2.07 & 2.02 & 13 & 05 & 2.02 & 2.10 & .07 & 2.06 & 2.07 & TT30 & $1 \mathrm{~L}$ & 1.85 & & 2.03 & 2.15 & 2.03 & 2.01 & 1.99 & 2.02 & 2.28 & 2.02 \\
\hline & $2 \mathrm{~L}$ & 2.00 & 2.07 & 2.23 & 22 & 2.20 & 2.14 & 2.08 & 94 & 1.97 & 2.08 & & $2 \mathrm{~L}$ & 1.98 & 2.17 & 2.12 & 2.24 & 2.16 & 2.06 & 1.92 & 2.00 & 2.60 & 2.09 \\
\hline & $3 \mathrm{~L}$ & 1.95 & 2.00 & 2.04 & 2.10 & 2.18 & 2.12 & 2.18 & 2.05 & 2.12 & 2.07 & & $3 \mathrm{~L}$ & 1.90 & 2.00 & & 2.06 & 2.20 & 2.12 & 2.06 & 2.11 & & 2.03 \\
\hline & $4 \mathrm{~L}$ & 1.86 & 2.04 & 2.03 & 2.10 & 2.03 & 1.98 & 2.03 & 1.98 & 1.96 & 2.06 & & $4 \mathrm{~L}$ & 1.88 & 2.00 & 2.00 & 2.10 & 2.02 & 2.04 & 1.94 & 2.00 & 2.08 & 2.04 \\
\hline & $5 \mathrm{~L}$ & 1.82 & 1.97 & 1.93 & 2.02 & 1.98 & 1.98 & 2.02 & 1.87 & 2.03 & 1.95 & & $5 \mathrm{~L}$ & 1.76 & 1.88 & 1.95 & 2.02 & 2.00 & 1.95 & 1.85 & 1.88 & 1.92 & 1.94 \\
\hline
\end{tabular}




\subsubsection{Emissor modelo $\mathrm{H}$}

O emissor modelo $\mathrm{H}$ apresentou CVQ inicial geral de 27,2\%, valor este considerado elevado para uma amostra de emissores novos. Os valores do CVQ inicial para os tratamentos e testemunhas apresentaram elevada desuniformidade, principalmente para os tratamentos CTS30, CFU15, CTS15 e CFU30 como pode ser observado na Figura 18. Pode-se melhor entender as causas de elevada variação analisando-se os valores individuais de vazão na Tabela 11, onde se notam emissores desse modelo apresentando vazão real de $340 \%$ da vazão nominal.

Não ocorreu tendência geral no comportamento da vazão. Para os tratamentos CFU15, CTS30 e CTU30 ocorreu elevação de vazão; para os demais tratamentos e testemunhas, observa-se o inverso.

Observam-se picos elevados tanto para vazão relativa como para coeficiente de variação de vazão, como na Figura 18 (b). Nesse caso, dois emissores apresentaram vazões extremamente altas, fazendo com que os parâmetros QR e CVQ resultassem em valores extremos.

Os efeitos dos tratamentos não foram conclusivos, porém existe uma tendência do sistema radicular a $15 \mathrm{~cm}$ úmido ser tão agressivo quanto a 30 cm seco.

O fato deste modelo de emissor apresentar alta variabilidade de vazão e vazões extremas muito elevadas faz com que, caso tais fatos se repetiam em campo de maneira generalizada, problemas de desequilíbrio hidráulico ocorram, tornando o sistema inoperante, além de tornar a aplicação de água desuniforme, prejudicando o rendimento dos cultivos e o retorno econômico do empreendimento. 

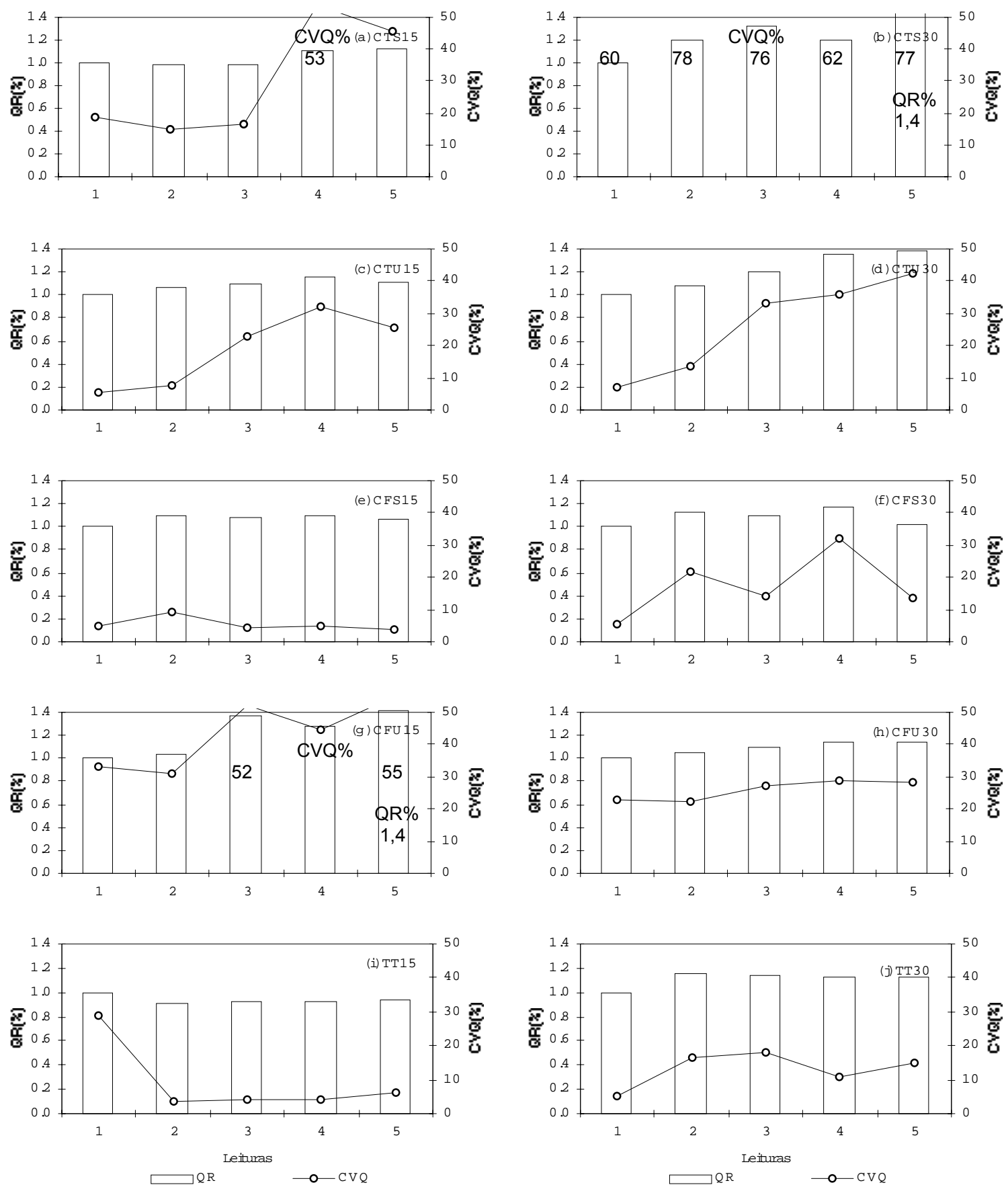

Figura 18 - QR e CVQ para o emissor modelo H: (a) citros seco $15 \mathrm{~cm}$; (b) citros seco $30 \mathrm{~cm}$; (c) citros úmido $15 \mathrm{~cm}$; (d) citros úmido $30 \mathrm{~cm}$; (e) café seco $15 \mathrm{~cm}$, (f) café seco $30 \mathrm{~cm}$; (g) café úmido $15 \mathrm{~cm}$; (h) café úmido $30 \mathrm{~cm}$; (i) testemunha $15 \mathrm{~cm}$; (j) testemunha $30 \mathrm{~cm}$. 
Tabela 11. Vazões do emissor modelo $\mathrm{H}$ em $\mathrm{L} \cdot \mathrm{h}^{-1}$ para as cinco leituras realizadas (1L até $5 \mathrm{~L}$ ), dez repetições (R1 até $\left.\mathrm{R} 10\right)$ para todos os tratamentos (CTS15, CTS30, CTU15, CTU30, CFS15, CFS30, CFU15, CFU30, TT15 e TT30).

\begin{tabular}{|c|c|c|c|c|c|c|c|c|c|c|c|c|c|c|c|c|c|c|c|c|c|c|c|}
\hline & & R1 & $\mathrm{R} 2$ & R3 & R4 & R5 & R6 & R7 & R8 & R9 & R10 & & & R1 & R2 & R3 & R4 & R5 & $\mathrm{R} 6$ & R7 & R8 & R9 & R10 \\
\hline \multirow[t]{5}{*}{ CTS15 } & $1 \mathrm{~L}$ & 1.84 & 2.88 & 1.83 & 1.78 & 1.87 & 1.87 & 1.99 & 1.72 & 2.51 & 1.83 & \multirow[t]{5}{*}{ CTS30 } & $1 \mathrm{~L}$ & 1.67 & 5.56 & & 1.74 & 1.71 & \multirow{2}{*}{\multicolumn{2}{|c|}{1.71}} & 1.72 & 2.03 & 1.83 \\
\hline & $2 \mathrm{~L}$ & 2.16 & & 1.83 & 1.74 & 1.88 & 1.92 & 2.58 & 1.74 & 2.26 & 1.76 & & $2 \mathrm{~L}$ & & 7.27 & 2.18 & 1.83 & 1.76 & & & 1.75 & 2.05 & 1.92 \\
\hline & $3 \mathrm{~L}$ & 1.82 & 2.54 & 1.78 & 1.82 & 1.80 & 1.76 & 2.20 & 1.76 & 2.52 & 1.72 & & $3 \mathrm{~L}$ & 2.08 & 7.87 & 6.52 & 1.84 & 1.70 & 1.76 & 2.08 & 1.78 & 2.26 & 1.78 \\
\hline & $4 \mathrm{~L}$ & 1.96 & 2.15 & 1.82 & 1.78 & 1.75 & 1.76 & 2.18 & 1.68 & 5.63 & 1.73 & & $4 \mathrm{~L}$ & 2.02 & 4.08 & 6.95 & 1.87 & 1.72 & 1.75 & 2.63 & 2.26 & .85 & 1.72 \\
\hline & $5 \mathrm{~L}$ & 1.88 & 34 & 1.87 & 1.83 & 1.78 & 1.82 & 2.46 & 1.83 & 5.12 & 1.73 & & $5 \mathrm{~L}$ & 1.76 & 6.05 & 9.18 & 2.83 & 1.70 & 1.78 & 1.86 & 1.73 & 3.46 & 2.06 \\
\hline \multirow[t]{5}{*}{ CTU15 } & $1 \mathrm{~L}$ & 1.78 & 1.78 & 1.68 & 1.80 & 1.91 & .01 & 1.71 & 1.78 & 1.76 & 1.78 & \multirow[t]{5}{*}{ CTU30 } & $1 \mathrm{~L}$ & 1.68 & 1.76 & 1.66 & 1.76 & 1.73 & 1.76 & 1.79 & 2.12 & 1.86 & 1.86 \\
\hline & $2 \mathrm{~L}$ & 76 & 89 & & 78 & 13 & & 1.83 & 1.87 & & 2.07 & & $2 \mathrm{~L}$ & 1.64 & 1.74 & 2.23 & 1.89 & 1.76 & 2.38 & & 2.13 & 1.78 & \\
\hline & $3 \mathrm{~L}$ & 1.73 & .88 & 1.83 & 1.74 & 1.86 & 3.26 & 1.90 & 1.82 & 1.84 & 1.96 & & $3 \mathrm{~L}$ & 1.70 & 1.86 & 1.83 & 2.16 & 1.83 & 2.18 & 4.12 & 2.34 & 1.83 & 1.84 \\
\hline & $4 \mathrm{~L}$ & 1.80 & .94 & 1.87 & 1.98 & 2.02 & 3.95 & 1.78 & 1.77 & 1.68 & 1.97 & & $4 \mathrm{~L}$ & 1.77 & 3.07 & 1.74 & 2.34 & 1.95 & 2.27 & 4.46 & 3.06 & 1.86 & 1.84 \\
\hline & $5 \mathrm{~L}$ & 1.68 & 1.87 & 1.87 & 2.08 & 1.83 & 3.43 & 1.83 & 1.78 & 1.70 & 1.95 & & $5 \mathrm{~L}$ & 1.76 & 1.77 & 2.06 & 2.43 & 2.23 & 2.12 & 4.37 & 4.47 & 1.77 & 1.80 \\
\hline \multirow[t]{5}{*}{ CFS15 } & $1 \mathrm{~L}$ & 1.56 & 64 & .68 & 1.68 & 1.81 & 1.78 & 1.78 & 1.67 & 1.78 & 1.82 & \multirow[t]{5}{*}{ CFS30 } & $1 \mathrm{~L}$ & 1.76 & 1.56 & 1.72 & 1.85 & 1.80 & 1.70 & 1.63 & 1.76 & 1.62 & 1.82 \\
\hline & $2 \mathrm{~L}$ & .85 & 8 & 92 & 77 & 76 & 86 & 82 & 88 & .34 & 1.83 & & $2 \mathrm{~L}$ & & 1.74 & 1.72 & 1.87 & 1.86 & 1.72 & 3.03 & 1.88 & 1.68 & 1.87 \\
\hline & $3 \mathrm{~L}$ & 1.78 & .84 & 1.93 & .78 & 1.78 & 1.97 & 1.94 & 1.88 & 1.95 & 1.78 & & $3 \mathrm{~L}$ & 1.78 & 1.86 & 1.70 & 1.98 & 1.88 & 1.73 & 2.62 & 1.76 & 1.73 & 1.90 \\
\hline & $4 \mathrm{~L}$ & 1.85 & 82 & 1.84 & 1.86 & 1.75 & 1.96 & 1.94 & 1.82 & 2.06 & 1.85 & & $4 \mathrm{~L}$ & & 1.78 & 1.76 & 1.95 & 1.82 & 1.76 & 3.76 & 1.88 & 1.68 & 1.87 \\
\hline & $5 \mathrm{~L}$ & 1.82 & 1.78 & 1.74 & .83 & .79 & 1.92 & .94 & 1.93 & 1.86 & 1.78 & & $5 \mathrm{~L}$ & 1.80 & 1.88 & 1.13 & 1.94 & 1.98 & 1.76 & 1.88 & 1.83 & 1.68 & 1.76 \\
\hline \multirow{5}{*}{ CFU15 } & $1 \mathrm{~L}$ & 1.63 & .88 & 1.70 & 3.74 & 1.66 & 1.74 & 1.72 & 1.75 & 1.71 & 1.78 & \multirow{5}{*}{ CFU30 } & $1 \mathrm{~L}$ & 1.59 & 1.68 & 1.66 & 2.92 & 1.88 & 1.68 & & 1.63 & 1.78 & 1.71 \\
\hline & $2 \mathrm{~L}$ & 1.80 & 96 & 85 & 76 & 74 & 78 & 74 & 1.87 & 86 & 1.74 & & $2 \mathrm{~L}$ & 1.62 & 2.53 & 78 & 2.82 & 68 & 1.78 & 1.73 & 1.68 & & 1.76 \\
\hline & $3 \mathrm{~L}$ & 3.42 & 78 & 84 & 4.82 & 68 & 1.80 & 5.36 & 1.78 & 1.90 & 2.20 & & $3 \mathrm{~L}$ & 1.72 & 1.82 & 1.72 & 3.34 & 1.75 & 1.76 & 1.72 & 1.77 & 1.94 & 2.65 \\
\hline & $4 \mathrm{~L}$ & 2.97 & 1.83 & 1.82 & 3.35 & 1.76 & 1.76 & 2.22 & 1.83 & 2.02 & 5.17 & & $4 \mathrm{~L}$ & 1.67 & 1.88 & 2.18 & 3.54 & 1.73 & 1.75 & 1.68 & 1.76 & 2.70 & 2.04 \\
\hline & $5 \mathrm{~L}$ & 3.14 & 1.84 & 1.75 & 6.13 & 1.76 & 2.12 & 2.24 & 1.84 & 1.85 & 4.65 & & $5 \mathrm{~L}$ & 1.67 & 2.28 & 1.72 & 2.83 & 1.70 & 1.78 & 1.86 & 1.73 & 3.46 & 2.06 \\
\hline \multirow[t]{5}{*}{ TT15 } & $1 \mathrm{~L}$ & 3.52 & 1.85 & 1.87 & 1.75 & 1.70 & 1.71 & 1.68 & 1.87 & 1.69 & 1.80 & \multirow[t]{5}{*}{ TT30 } & $1 \mathrm{~L}$ & 1.70 & 1.68 & 1.68 & 1.58 & 1.62 & 1.78 & 1.56 & 1.66 & 1.80 & 1.58 \\
\hline & $2 \mathrm{~L}$ & 1.76 & 1.74 & 1.87 & 1.82 & 1.74 & 1.78 & 1.72 & 1.70 & 1.66 & 1.80 & & $2 \mathrm{~L}$ & 1.78 & 1.85 & 1.78 & 1.75 & 1.92 & 1.76 & 1.76 & 1.68 & 2.74 & 2.14 \\
\hline & $3 \mathrm{~L}$ & 1.78 & 1.76 & 1.88 & 1.68 & 1.73 & 1.90 & 1.74 & 1.85 & 1.70 & 1.82 & & $3 \mathrm{~L}$ & 1.66 & 1.73 & 1.73 & 1.70 & & 1.82 & 1.76 & 1.77 & 2.70 & 2.23 \\
\hline & $4 \mathrm{~L}$ & 1.78 & 1.84 & 1.95 & 1.69 & 1.76 & 1.70 & 1.74 & 1.84 & 1.76 & 1.8 & & $4 \mathrm{~L}$ & 1.73 & 1.83 & 1.79 & 1.75 & 1.73 & 2.07 & 1.72 & 1.77 & 2.28 & 2.16 \\
\hline & $5 \mathrm{~L}$ & 1.76 & 1.78 & 1.95 & 1.76 & 1.72 & 1.76 & 1.85 & 1.76 & 1.72 & 2.06 & & $5 \mathrm{~L}$ & 1.72 & 1.80 & 1.77 & 1.73 & 1.70 & 1.74 & 1.76 & 1.70 & 2.36 & 2.45 \\
\hline
\end{tabular}




\subsubsection{Emissor modelo I}

Os valores de CVQ inicial geral e inicial dos tratamentos e testemunhas apresentaram-se uniformes. O valor do CVQ inicial geral foi de 6,2\% e, de maneira geral, o CVQ dos tratamentos apresentaram-se próximos desse valor, demonstrando variabilidade reduzida.

Analisando-se a Figura 19, observa-se moderada tendência de redução de vazão para todos os tratamentos e testemunhas, assemelhandose ao desempenho do emissor modelo $\mathrm{G}$.

Observam-se picos no CVQ nos tratamentos CFU30 e CFU30, como pode ser visto na Figura 19 (h). Isso se deveu à redução total de vazão do emissor da quinta repetição, que inicialmente apresentava vazão normal e posteriormente sofreu redução de vazão, chegando à obstrução total.

Assim como no emissor modelo $G$, aparentemente ocorreu evidência de tratamento para CFS30; entretanto, a diferença entre os valores do CVQ inicial e final foi reduzida. Poder-se-ia sugerir que, devido ao fato de ser tratar de tratamento com déficit de água, o sistema radicular da cultura poderia ter apresentado maior desenvolvimento radicular em profundidade $\mathrm{e}$ conseqüentemente ter penetrado nos emissores, provocando obstrução.

O desempenho das testemunhas quanto aos parâmetros analisados foi uniforme e normal, como pode ser observado na Figura 19 (i) e (j).

De maneira geral, esse modelo de emissor apresentou estabilidade, uniformidade e baixa variância. Ressalta-se o fato de este modelo de emissor não possuir mecanismos de compensação de pressão. A vazão real manteve-se próxima da vazão nominal fornecida pelo fabricante, demonstrando elevado padrão de fabricação. 

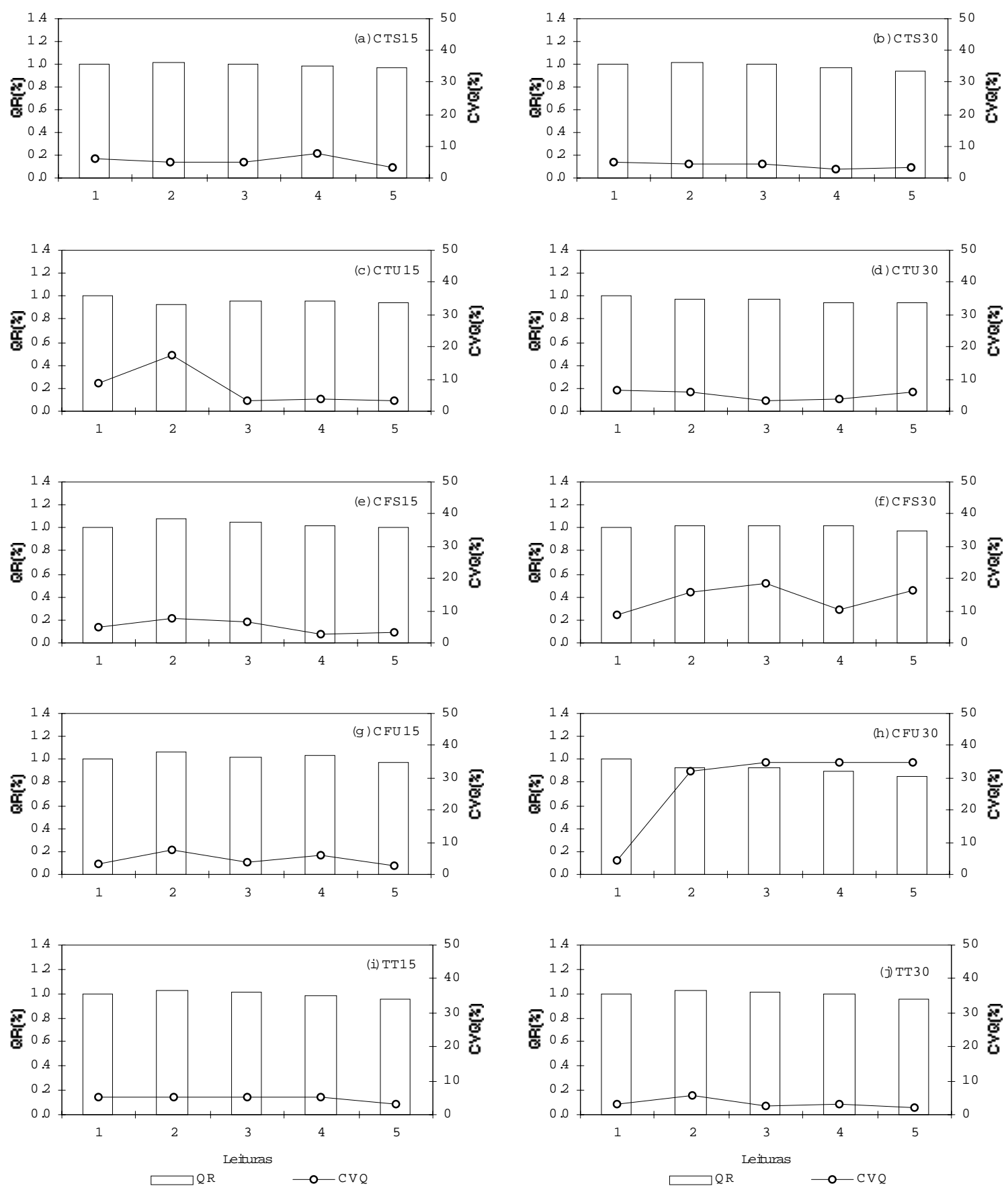

Figura 19 - QR e CVQ para o emissor modelo I: (a) citros seco $15 \mathrm{~cm}$; (b) citros seco $30 \mathrm{~cm}$; (c) citros úmido $15 \mathrm{~cm}$; (d) citros úmido $30 \mathrm{~cm}$; (e) café seco $15 \mathrm{~cm}$, (f) café seco $30 \mathrm{~cm}$; $(\mathrm{g})$ café úmido $15 \mathrm{~cm}$; (h) café úmido $30 \mathrm{~cm}$; (i) testemunha $15 \mathrm{~cm}$; (j) testemunha $30 \mathrm{~cm}$. 
Tabela 12. Vazões do emissor modelo I em $L . h^{-1}$ para as cinco leituras realizadas (1L até $5 \mathrm{~L}$ ), dez repetições (R1 até $\left.R 10\right)$ para todos os tratamentos (CTS15, CTS30, CTU15, CTU30, CFS15, CFS30, CFU15, CFU30, TT15 e TT30).

\begin{tabular}{|c|c|c|c|c|c|c|c|c|c|c|c|c|c|c|c|c|c|c|c|c|c|c|c|}
\hline & & R1 & R2 & R3 & R4 & R5 & $\mathrm{R6}$ & R7 & R8 & R9 & R10 & & & R1 & $\mathrm{R} 2$ & R3 & R4 & R5 & $\mathrm{R} 6$ & R7 & R8 & $\mathrm{R9}$ & R1 \\
\hline \multirow[t]{5}{*}{ CTS15 } & $1 \mathrm{~L}$ & 1.98 & 2.12 & 2.13 & 2.11 & 2.19 & 1.89 & & 1.98 & 1.86 & 2.21 & SS30 & $1 \mathrm{~L}$ & 1.98 & 2.18 & 2.08 & 2.01 & 1.99 & 1.90 & 1.94 & 2.07 & 2.11 & 2.18 \\
\hline & $2 \mathrm{~L}$ & 2.18 & 2.24 & 2.02 & 2.02 & & & & 2.06 & 1.96 & 2.06 & & $2 \mathrm{~L}$ & 2.20 & & 2.04 & 1.98 & 2.12 & 2.24 & 2.07 & 2.13 & 1.94 & 2.07 \\
\hline & $3 \mathrm{~L}$ & 1.98 & 2.10 & 2.14 & 2.10 & 2.18 & 2.03 & 2.06 & 2.00 & 1.82 & 2.00 & & $3 \mathrm{~L}$ & 2.03 & 2.12 & 2.11 & 2.08 & 2.06 & 1.98 & 2.06 & 2.12 & 1.82 & 2.00 \\
\hline & $4 \mathrm{~L}$ & 1.98 & 2.43 & 1.98 & 1.98 & 2.10 & 1.96 & 2.00 & 1.98 & 1.82 & 2.00 & & $4 \mathrm{~L}$ & 2.08 & 1.94 & 2.02 & 1.94 & 1.95 & 1.97 & 1.96 & 2.00 & 1.90 & 2.06 \\
\hline & $5 \mathrm{~L}$ & 1.98 & 2.08 & 2.00 & 2.05 & 2.03 & 1.97 & 1.95 & 1.98 & 1.87 & 2.05 & & $5 \mathrm{~L}$ & 2.04 & 1.95 & 2.02 & 1.90 & 1.90 & 1.82 & 1.98 & 1.98 & 1.93 & 1.86 \\
\hline \multirow[t]{5}{*}{ CTU15 } & $1 \mathrm{~L}$ & 1.98 & & .95 & 38 & 2.09 & 2.21 & 2.32 & 2.37 & & 1.97 & & $1 \mathrm{~L}$ & 2.26 & 2.06 & 2.00 & 1.88 & 2.23 & 1.98 & 2.27 & 2.14 & 1.98 & 2.04 \\
\hline & $2 \mathrm{~L}$ & 1.98 & 2.04 & 88 & 23 & .05 & 28 & 14 & 2.26 & & 5 & & $2 \mathrm{~L}$ & 2.03 & 2.06 & 2.04 & 1.94 & 2.25 & & & 97 & 87 & 2.2 \\
\hline & $3 \mathrm{~L}$ & 2.04 & 2.04 & 94 & 12 & .03 & 10 & 2.12 & 2.16 & 2.08 & 2.15 & & $3 \mathrm{~L}$ & 2.02 & 2.13 & 2.04 & 1.95 & 1.98 & 1.96 & 2.15 & 2.03 & 2.03 & 2.07 \\
\hline & $4 \mathrm{~L}$ & 2.00 & 2.20 & .00 & 2.18 & 12 & .06 & 03 & 2.05 & 1.96 & 2.00 & & $4 \mathrm{~L}$ & 2.05 & 2.10 & 2.05 & 1.95 & 1.97 & 1.93 & 1.98 & 1.92 & 1.84 & 2.00 \\
\hline & $5 \mathrm{~L}$ & 2.05 & 2.20 & .05 & .06 & 2.02 & 12 & 03 & 03 & 1.97 & 1.98 & & $5 \mathrm{~L}$ & 2.10 & 2.04 & 1.72 & 1.95 & 1.88 & 1.87 & 2.00 & 2.08 & 1.88 & 2.02 \\
\hline \multirow{5}{*}{ CFS15 } & $1 \mathrm{~L}$ & 2.00 & .90 & .98 & 2.08 & 1.82 & 1.84 & 2.07 & 2.01 & 1.97 & 2.12 & & $1 \mathrm{~L}$ & 1.80 & 1.92 & 1.94 & 1.97 & 1.93 & 1.90 & 1.90 & 2.43 & 2.08 & 2.00 \\
\hline & $2 \mathrm{~L}$ & 2.12 & 03 & 15 & 08 & 22 & 97 & 2.08 & .56 & 2.04 & 2.19 & & $2 \mathrm{~L}$ & 1.28 & 2.08 & 96 & 09 & 2.25 & 2.00 & 2.01 & 2.56 & 2.06 & 2.04 \\
\hline & $3 \mathrm{~L}$ & 2.03 & 00 & 04 & 02 & 12 & 00 & 18 & .07 & 02 & 2.43 & & $3 \mathrm{~L}$ & 1.41 & 2.07 & 1.08 & 2.10 & 2.16 & 2.10 & 2.09 & 2.48 & 2.08 & 2.15 \\
\hline & $4 \mathrm{~L}$ & 2.08 & .00 & 06 & .02 & 00 & 95 & 2.08 & 2.04 & 1.93 & 2.00 & & $4 \mathrm{~L}$ & 1.54 & 2.04 & 2.11 & 2.04 & 1.90 & 2.02 & 1.97 & 2.38 & 2.02 & 2.13 \\
\hline & $5 \mathrm{~L}$ & 1.98 & 93 & 97 & 1.97 & 1.98 & 1.88 & 2.07 & 2.00 & 1.87 & 2.08 & & $5 \mathrm{~L}$ & 1.15 & 1.92 & 2.00 & 1.93 & 2.06 & 2.01 & 1.96 & 2.46 & 1.92 & 2.05 \\
\hline \multirow{5}{*}{ CFU15 } & $1 \mathrm{~L}$ & 1.90 & 98 & 82 & .98 & 2.02 & 1.96 & 1.98 & 2.00 & & 1.88 & & $1 \mathrm{~L}$ & 1.97 & 1.94 & 1.99 & 2.02 & 2.20 & 2.09 & 2.05 & 2.05 & 1.96 & 1.88 \\
\hline & $2 \mathrm{~L}$ & 2.05 & 06 & 95 & .45 & 95 & 95 & 2.02 & 2.14 & & 1.96 & & $2 \mathrm{~L}$ & 2.03 & 2.07 & 2.09 & 2.08 & 0.16 & 2.06 & 2.18 & 2.16 & 2.06 & 1.92 \\
\hline & $3 \mathrm{~L}$ & 1.95 & 1.88 & 90 & 2.05 & 2.00 & 06 & 2.08 & 2.05 & & 2.00 & & $3 \mathrm{~L}$ & 1.97 & 2.00 & 2.04 & 2.14 & 0.00 & 2.12 & 2.14 & 2.12 & 2.15 & 1.97 \\
\hline & $4 \mathrm{~L}$ & 1.97 & 1.88 & 1.85 & 2.27 & 1.96 & 2.00 & 2.04 & 2.03 & & 2.00 & & $4 \mathrm{~L}$ & 2.00 & 2.05 & 2.08 & 2.08 & 0.00 & 2.03 & 2.08 & 2.02 & 2.02 & 1.92 \\
\hline & $5 \mathrm{~L}$ & 1.90 & 1.86 & 82 & .91 & 1.90 & 1.88 & 97 & 2.00 & & 1.90 & & $5 \mathrm{~L}$ & 1.85 & 1.96 & 1.97 & 1.90 & 0.00 & 1.82 & 1.98 & 1.98 & 1.93 & 86 \\
\hline \multirow[t]{5}{*}{ TT15 } & $1 \mathrm{~L}$ & 181 & 2.01 & .05 & .05 & & 2.02 & 03 & 05 & 2.03 & 2.22 & ТT30 & $1 \mathrm{~L}$ & 2.03 & 2.02 & 2.11 & 2.01 & 2.05 & 1.92 & 1.95 & 1.99 & 2.10 & 2.08 \\
\hline & $2 \mathrm{~L}$ & 97 & .98 & .23 & .17 & 08 & 2.18 & 2.0 & 2.02 & 1.5 & 2.23 & & $2 \mathrm{~L}$ & 2.0 & 2.23 & 2.23 & $2.1 \varepsilon$ & 2.1 & 1.87 & 1.98 & 1.97 & 2.08 & 2.08 \\
\hline & $3 \mathrm{~L}$ & 1.90 & 1.93 & 2.00 & 2.10 & 1.98 & 2.16 & 2.20 & 2.07 & 1.98 & 2.14 & & $3 \mathrm{~L}$ & 2.02 & 1.97 & 2.12 & 2.03 & 2.13 & 2.03 & 2.08 & 2.04 & 2.02 & 1.98 \\
\hline & $4 \mathrm{~L}$ & 1.88 & 1.92 & 2.12 & 2.09 & 1.88 & 1.98 & 2.00 & 2.00 & 1.95 & 2.17 & & $4 \mathrm{~L}$ & 2.00 & 2.02 & 2.08 & 2.04 & 2.02 & 1.90 & 2.00 & 2.02 & 2.12 & 2.00 \\
\hline & $5 \mathrm{~L}$ & 1.85 & 1.85 & 1.93 & 1.98 & 1.85 & 1.98 & 1.95 & 1.94 & 1.90 & 1.98 & & $5 \mathrm{~L}$ & 1.96 & 1.92 & 2.00 & 1.96 & 1.95 & 1.88 & 1.87 & 1.92 & 1.96 & 1.94 \\
\hline
\end{tabular}




\subsubsection{Emissor modelo $\mathrm{J}$}

O desempenho desse modelo de emissor quanto ao parâmetro CVQ inicial, como se observa na Figura 20, apresentou desuniformidade entre tratamentos. O CVQ inicial geral foi de $14,8 \%$.

Observa-se, para todos os tratamentos, tendência inicial de aumento de vazão e posteriormente de redução de vazão, pouco evidente nas testemunhas.

Quanto à evidência dos tratamentos, pode-se afirmar que os tratamentos citros úmido para as duas profundidades ensaiadas aparentemente demonstraram interferência radicular, pois o CVQ para a última leitura sofreu elevação provocada por queda brusca de vazão de alguns emissores.

O desempenho das testemunhas para os dois parâmetros estudados apresentou-se normal, como se observa na Figura 20 (i) e (j).

Esse modelo de emissor, como se observa na Tabela 13, apresentou elevada quantidade de dados não coletados devido a vazamentos nos conectores. Tal fato explica-se por se tratar de um tubo gotejador de parede delgada, dificultando a vedação em uniões, até mesmo para as conexões específicas para esse modelo.

A elevação do CVQ no tratamento CFU15, Figura 20 (g), para as vazões da terceira leitura, deveu-se ao fato de um emissor (R7), que não havia tido sua vazão determinada em razão de vazamentos, ter apresentado vazão reduzida. Nas determinações de vazão seguintes (4L e 5L), ocorreu recuperação de vazão, fazendo com que o CVQ sofresse queda.

Esse modelo de emissor destacou-se pela dificuldade de vedação nas conexões, fato que, se ocorresse de maneira generalizada em campo, provocaria desequilíbrio hidráulico no sistema de irrigação. 

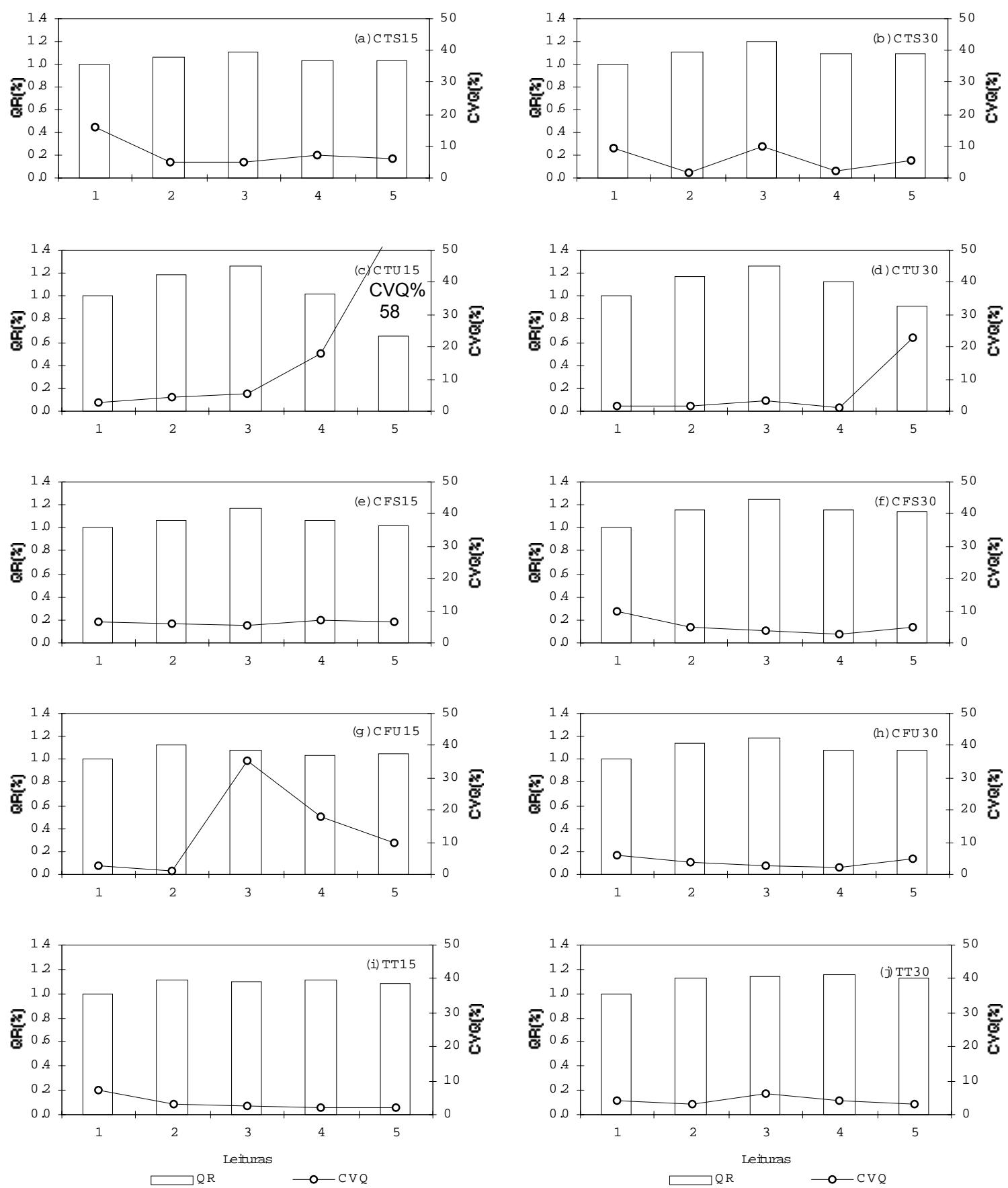

Figura 20 - QR e CVQ para o emissor modelo J: (a) citros seco $15 \mathrm{~cm}$; (b) citros seco $30 \mathrm{~cm}$; (c) citros úmido $15 \mathrm{~cm}$; (d) citros úmido $30 \mathrm{~cm}$; (e) café seco $15 \mathrm{~cm}$, (f) café seco $30 \mathrm{~cm}$; (g) café úmido $15 \mathrm{~cm}$; (h) café úmido $30 \mathrm{~cm}$; (i) testemunha $15 \mathrm{~cm}$; (j) testemunha $30 \mathrm{~cm}$. 
Tabela 13. Vazões do emissor modelo I em $L \cdot h^{-1}$ para as cinco leituras realizadas (1L até $5 \mathrm{~L}$ ), dez repetições (R1 até $\left.R 10\right)$ para todos os tratamentos (CTS15, CTS30, CTU15, CTU30, CFS15, CFS30, CFU15, CFU30, TT15 e TT30).

\begin{tabular}{|c|c|c|c|c|c|c|c|c|c|c|c|c|c|c|c|c|c|c|c|c|c|c|c|}
\hline & & R1 & R2 & R3 & $\mathrm{R} 4$ & R5 & R6 & R7 & R8 & R9 & R10 & & & R1 & R2 & R3 & R4 & R5 & R6 & R7 & R8 & R9 & R10 \\
\hline \multirow[t]{5}{*}{ CTS15 } & $1 \mathrm{~L}$ & & & 1.30 & & 1.72 & 1.36 & & & & & \multirow[t]{5}{*}{ CTS30 } & $1 \mathrm{~L}$ & 1.27 & 1.27 & & 1.53 & & & & & & 1.32 \\
\hline & $2 \mathrm{~L}$ & 1.48 & & 1.54 & & 1.68 & 1.54 & & 1.56 & & & & $2 \mathrm{~L}$ & & 1.48 & & 1.52 & & & 1.48 & & & 1.53 \\
\hline & $3 \mathrm{~L}$ & 1.53 & 1.63 & 1.56 & 1.55 & 1.72 & 1.63 & 1.65 & 1.67 & 1.56 & 1.76 & & $3 \mathrm{~L}$ & 1.57 & 1.52 & 1.58 & 2.06 & 1.60 & 1.50 & 1.62 & 1.60 & 1.56 & 1.59 \\
\hline & $4 \mathrm{~L}$ & 1.47 & 1.48 & 1.46 & 1.42 & 1.76 & 1.45 & 1.64 & 1.44 & 1.46 & 1.45 & & $4 \mathrm{~L}$ & 1.52 & 1.48 & 1.50 & 1.49 & 1.43 & 1.47 & 1.43 & 1.42 & 1.47 & 1.45 \\
\hline & $5 \mathrm{~L}$ & 1.43 & .48 & 1.64 & 1.43 & 1.62 & 1.47 & 1.65 & 1.42 & 1.52 & 1.48 & & $5 \mathrm{~L}$ & 1.54 & 1.52 & 1.50 & 1.33 & 1.38 & 1.52 & 1.45 & 1.56 & 1.48 & 1.37 \\
\hline \multirow[t]{5}{*}{ CTU15 } & $1 \mathrm{~L}$ & 1.24 & & & 1.29 & & 1.24 & & 1.27 & 1.30 & 1.32 & \multirow[t]{5}{*}{ CTU30 } & $1 \mathrm{~L}$ & & & & 1.28 & & & & & & 1.31 \\
\hline & $2 \mathrm{~L}$ & 1.58 & & & 1.46 & 1.53 & 45 & & 1.47 & 1.52 & 1.62 & & $2 \mathrm{~L}$ & & & & 1.52 & 1.47 & & 1.50 & 1.52 & 1.54 & 1.53 \\
\hline & $3 \mathrm{~L}$ & 1.57 & 1.52 & 1.50 & 1.60 & 65 & 1.62 & 1.57 & 1.63 & 1.68 & 1.82 & & $3 \mathrm{~L}$ & 1.53 & 1.68 & 1.64 & 1.57 & 1.67 & 1.64 & 1.65 & 1.58 & .65 & 1.65 \\
\hline & $4 \mathrm{~L}$ & 1.42 & 85 & 1.45 & 1.40 & 0.86 & 1.38 & 1.24 & 1.47 & 1.50 & 1.38 & & $4 \mathrm{~L}$ & 1.47 & 1.48 & 1.46 & 1.45 & 1.44 & 1.44 & 1.45 & 1.45 & 1.45 & 1.47 \\
\hline & $5 \mathrm{~L}$ & 0.65 & 18 & 0.72 & 0.84 & 0.50 & 1.34 & 1.26 & 1.38 & 1.32 & 0.12 & & $5 \mathrm{~L}$ & 0.82 & 0.97 & 0.66 & 1.33 & 1.46 & 1.23 & 1.38 & 1.18 & 1.41 & 1.44 \\
\hline \multirow{5}{*}{ CFS15 } & $1 \mathrm{~L}$ & 1.31 & .43 & 1.35 & 1.31 & 1.46 & 1.24 & 1.46 & 1.30 & 1.39 & 1.50 & \multirow[t]{5}{*}{ CFS30 } & $1 \mathrm{~L}$ & 1.41 & 1.40 & 1.36 & 1.45 & 1.40 & 1.38 & 1.48 & 1.32 & & 1.75 \\
\hline & $2 \mathrm{~L}$ & 1.52 & 36 & 1.43 & 42 & 1.45 & 1.42 & 1.64 & & 1.38 & 1.50 & & $2 \mathrm{~L}$ & 1.43 & 1.57 & 52 & 1.48 & 1.45 & & 1.44 & 1.63 & & 1.45 \\
\hline & $3 \mathrm{~L}$ & 1.64 & 42 & 1.48 & 1.68 & 1.60 & 67 & 1.65 & 1.66 & 1.60 & 1.64 & & $3 \mathrm{~L}$ & 1.58 & 1.53 & 1.55 & 1.63 & 1.63 & 1.57 & 1.70 & 1.68 & 1.64 & 1.68 \\
\hline & $4 \mathrm{~L}$ & 1.46 & 1.26 & 1.44 & 1.44 & 1.49 & 1.47 & 1.67 & 1.50 & 1.40 & 1.47 & & $4 \mathrm{~L}$ & 1.44 & 1.47 & 1.53 & 1.49 & 1.52 & 1.55 & 1.45 & 1.48 & 1.43 & 1.54 \\
\hline & $5 \mathrm{~L}$ & 1.38 & 1.26 & 1.28 & 1.40 & 1.44 & 1.42 & 1.58 & 1.42 & 1.33 & 1.40 & & $5 \mathrm{~L}$ & 1.42 & 1.46 & 1.48 & 1.45 & 1.46 & 1.62 & 1.42 & 1.54 & 1.38 & 1.42 \\
\hline \multirow[t]{5}{*}{ CFU15 } & $1 \mathrm{~L}$ & 1.31 & & & 1.39 & 1.32 & & & & 1.31 & 1.32 & \multirow[t]{5}{*}{ CFU30 } & $1 \mathrm{~L}$ & 1.37 & 1.23 & 1.40 & 1.26 & & & 1.37 & 1.43 & & \\
\hline & $2 \mathrm{~L}$ & & & & 1.47 & 1.50 & & & & & 1.48 & & $2 \mathrm{~L}$ & & & 1.54 & 1.45 & & & 1.58 & 1.56 & & \\
\hline & $3 \mathrm{~L}$ & & 1.66 & 1.63 & 1.64 & 1.62 & 1.63 & 0.08 & 1.54 & 1.60 & 1.50 & & $3 \mathrm{~L}$ & 1.64 & 1.66 & 1.60 & 1.52 & 1.58 & 1.60 & 1.56 & 1.62 & 1.57 & 1.52 \\
\hline & $4 \mathrm{~L}$ & & 1.46 & 1.44 & 1.45 & 1.45 & 1.48 & 0.72 & 1.43 & 1.54 & 1.46 & & $4 \mathrm{~L}$ & 1.45 & 1.48 & 1.48 & 1.42 & 1.40 & 1.42 & 1.52 & 1.45 & 1.44 & 1.44 \\
\hline & $5 \mathrm{~L}$ & 1.37 & 1.40 & 1.44 & 1.43 & 1.45 & 1.47 & 1.02 & 1.42 & 1.46 & 1.50 & & $5 \mathrm{~L}$ & 1.45 & 1.48 & 1.48 & 1.33 & 1.38 & 1.52 & 1.45 & 1.56 & 1.48 & 1.37 \\
\hline \multirow[t]{5}{*}{ TT15 } & $1 \mathrm{~L}$ & 1.27 & 1.30 & 1.19 & 1.32 & 1.50 & 1.27 & 1.35 & 1.30 & 1.20 & 1.41 & \multirow[t]{5}{*}{ TT30 } & $1 \mathrm{~L}$ & 1.24 & 1.29 & 1.18 & 1.35 & 1.28 & 1.23 & 1.31 & 1.30 & 1.26 & 1.34 \\
\hline & $2 \mathrm{~L}$ & 1.38 & 1.42 & 1.43 & 1.48 & 1.43 & 1.44 & 1.46 & 1.48 & 1.50 & 1.52 & & $2 \mathrm{~L}$ & 1.38 & 1.40 & & 1.50 & 1.40 & 1.44 & 1.43 & 1.45 & 1.48 & 1.48 \\
\hline & $3 \mathrm{~L}$ & 1.43 & 1.43 & 1.48 & 1.45 & 1.38 & 1.46 & 1.41 & 1.43 & 1.42 & 1.52 & & $3 \mathrm{~L}$ & 1.72 & 1.44 & 1.50 & 1.44 & 1.40 & 1.42 & 1.42 & 1.44 & 1.42 & \\
\hline & $4 \mathrm{~L}$ & 1.43 & 1.48 & 1.52 & 1.46 & 1.46 & 1.42 & 1.50 & 1.43 & 1.45 & 1.48 & & $4 \mathrm{~L}$ & 1.45 & 1.48 & 1.63 & 1.44 & 1.47 & 1.45 & 1.48 & 1.42 & 1.47 & 1.50 \\
\hline & $5 \mathrm{~L}$ & 1.45 & 1.46 & 1.41 & 1.46 & 1.38 & 1.44 & 1.42 & 1.40 & 1.38 & 1.39 & & $5 \mathrm{~L}$ & 1.54 & 1.43 & 1.45 & 1.42 & 1.44 & 1.42 & 1.40 & 1.36 & 1.42 & 1.46 \\
\hline
\end{tabular}




\subsubsection{Emissor modelo L}

Esse modelo de emissor apresentou CVQ inicial geral para os tratamentos e para as testemunhas próximo de $8,8 \%$ como se observa na Figura 21.

Em todos os tratamentos e testemunhas, houve leve tendência de redução de vazão. Não se observou nenhum emissor com redução total de vazão.

Observou-se também que a vazão real desse emissor esteve próxima da vazão nominal fornecida pelo fabricante.

Não se observaram vazões extremas, bem como valores elevados do CVQ.

Os tratamentos não apresentaram evidencia até a última determinação de vazão, como pode ser observa analisando-se a Figura 21.

O desempenho das testemunhas manteve-se normal tanto para 0 parâmetro vazão relativa como para o coeficiente de variação de vazão.

A ocorrência de células vazias na Tabela 14 se deveu à nãodeterminação de vazões, por motivo de vazamentos nos conectores de alimentação e vedação do tubo gotejador. As conexões utilizadas para esse propósito não eram específicas para este modelo de tubo gotejador.

O emissor modelo $L$ não possui mecanismo de compensação de pressão, e seu desempenho quanto aos parâmetros avaliados até a última determinação de vazão apresentou superioridade quando comparado com os outros modelos de emissores ensaiados. Seu desempenho deve-se provavelmente ao elevado padrão de fabricação e projeto ao criterioso do emissor. 

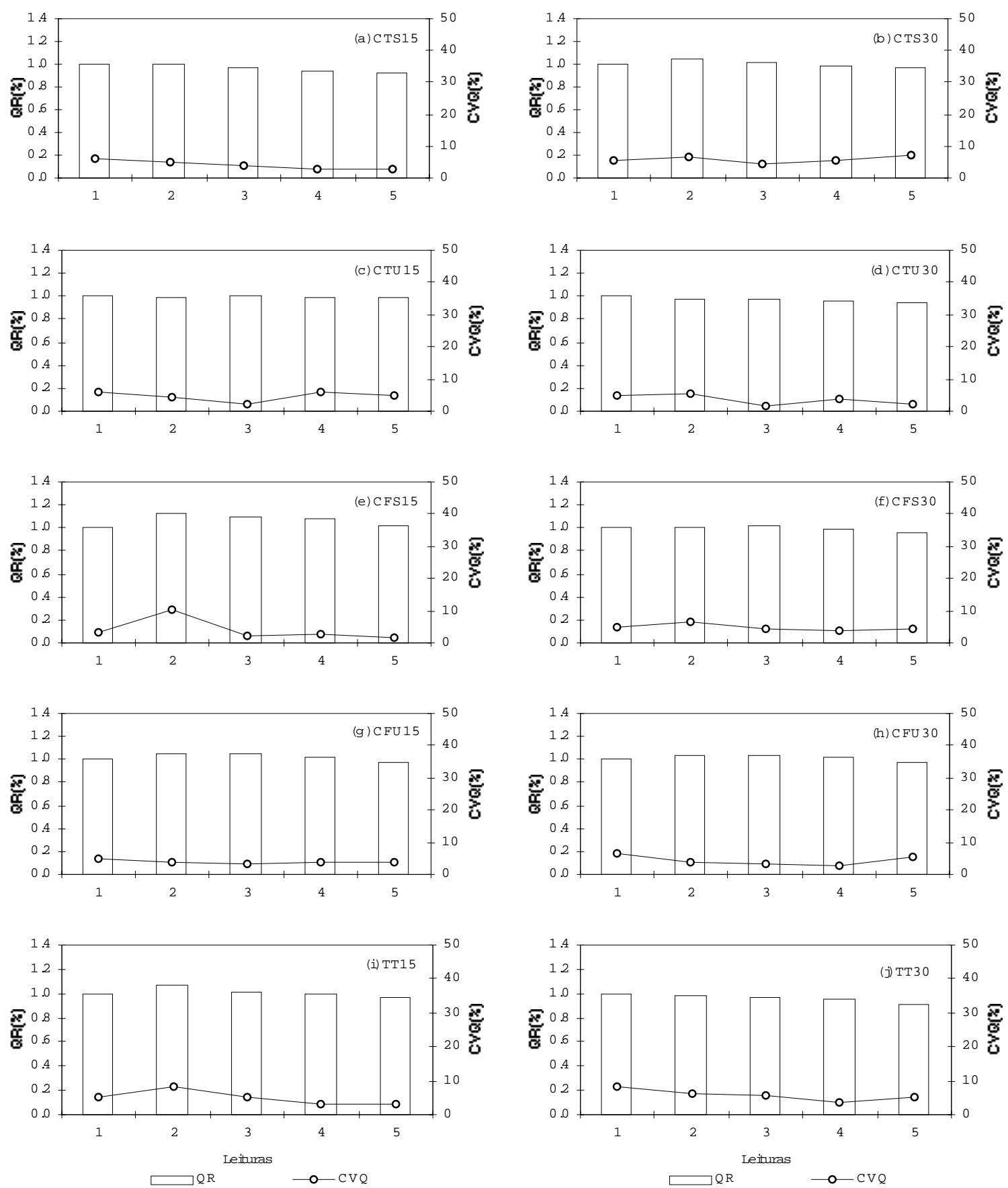

Figura 21 - QR e CVQ para o emissor modelo L: (a) citros seco $15 \mathrm{~cm}$; (b) citros seco $30 \mathrm{~cm}$; (c) citros úmido $15 \mathrm{~cm}$; (d) citros úmido $30 \mathrm{~cm}$; (e) café seco $15 \mathrm{~cm}$, (f) café seco $30 \mathrm{~cm}$; $(\mathrm{g})$ café úmido $15 \mathrm{~cm}$; (h) café úmido $30 \mathrm{~cm}$; (i) testemunha $15 \mathrm{~cm}$; (j) testemunha $30 \mathrm{~cm}$. 
Tabela 14. Vazões do emissor modelo $L$ em $L . h^{-1}$ para as cinco leituras realizadas (1L até $\left.5 \mathrm{~L}\right)$, dez repetições (R1 até $\left.R 10\right)$ para todos os tratamentos (CTS15, CTS30, CTU15, CTU30, CFS15, CFS30, CFU15, CFU30, TT15 e TT30).

\begin{tabular}{|c|c|c|c|c|c|c|c|c|c|c|c|c|c|c|c|c|c|c|c|c|c|c|c|}
\hline & & R1 & $\overline{R 2}$ & R3 & R4 & R5 & R6 & R7 & $\begin{array}{l}\text { R8 } \\
\end{array}$ & R9 & R10 & & & R1 & $\overline{R 2}$ & R3 & R4 & R5 & $\mathrm{R} 6$ & R7 & $\begin{array}{l}\mathrm{R} 8 \\
\end{array}$ & R9 & R10 \\
\hline \multirow[t]{5}{*}{ CTS15 } & $\overline{1 L}$ & 2.08 & 2.02 & & 2.27 & 2.14 & & 1.95 & 2.32 & & 2.21 & 30 & $1 \mathrm{~L}$ & 2.12 & 1.96 & 2.07 & 2.17 & 1.82 & 1.92 & 1.96 & 1.98 & 2.11 & \\
\hline & $2 \mathrm{~L}$ & & 2.12 & & 2.21 & 2.26 & & 2.18 & & & 1.98 & & $2 \mathrm{~L}$ & 2.35 & 1.98 & 1.97 & 2.09 & 2.02 & 2.28 & 2.15 & 2.12 & 2.00 & \\
\hline & $3 \mathrm{~L}$ & 2.02 & 2.13 & 2.23 & 2.10 & 2.14 & 1.97 & 1.96 & 2.05 & 2.08 & 2.00 & & $3 \mathrm{~L}$ & 2.13 & 1.90 & 2.17 & 2.11 & 1.96 & 2.12 & 1.97 & 2.00 & 2.08 & \\
\hline & $4 \mathrm{~L}$ & 1.96 & 2.14 & 2.02 & 1.94 & 2.00 & 2.00 & 2.02 & 2.00 & 1.95 & 2.02 & & $4 \mathrm{~L}$ & 2.10 & 1.86 & 2.04 & 2.00 & 1.75 & 2.04 & 1.98 & 2.03 & 1.93 & \\
\hline & $5 \mathrm{~L}$ & 1.97 & 2.03 & 2.05 & 1.92 & 1.93 & 1.93 & 2.00 & 2.04 & 2.02 & 2.02 & & $5 \mathrm{~L}$ & 2.07 & 1.72 & 2.00 & 1.85 & 2.22 & 1.88 & 1.95 & 1.92 & 1.81 & 1.97 \\
\hline
\end{tabular}

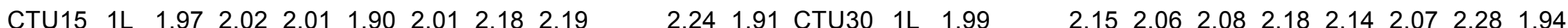
$\begin{array}{llllllllllllllllllllll}2 \mathrm{~L} & 1.98 & 1.96 & 1.98 & 1.98 & 2.00 & 2.16 & 2.17 & 2.18 & 1.98 & 2.02 & & \text { 2L } & 1.92 & 2.02 & 2.18 & 2.03 & 2.12 & 2.15 & 2.06 & 1.84 & 2.05\end{array}$

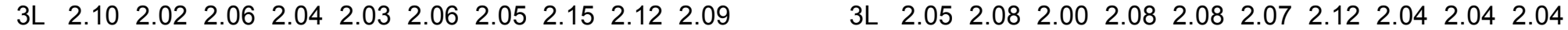
4L $1.94 \begin{array}{llllllllllllllllllllll} & 1.98 & 2.02 & 2.02 & 2.05 & 2.34 & 1.97 & 2.00 & 1.94 & 1.94 & & \text { 4L } & 2.17 & 2.03 & 1.97 & 2.10 & 2.03 & 2.05 & 2.00 & 1.90 & 1.95 & 2.00\end{array}$

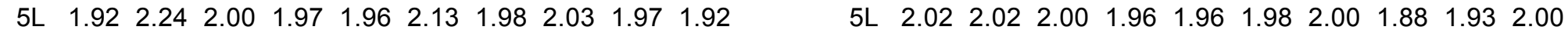

$\begin{array}{lllllllllllllllllllllllllll}\text { CFS15 } & 1 \mathrm{~L} & 1.90 & 1.91 & 1.84 & 1.97 & 1.86 & 1.85 & 1.95 & 1.96 & & 2.03 & \text { CFS30 } & 1 \mathrm{~L} & 2.21 & 1.90 & 1.90 & 1.85 & 1.91 & 1.94 & 2.12 & 1.92 & 2.05 & 1.90\end{array}$ 2L $\begin{array}{llllllllllllllllllll}2.72 & 2.06 & 2.13 & 2.18 & 2.12 & 1.97 & 2.02 & 2.00 & 2.16 & 2 \mathrm{~L} & 2.14 & 2.15 & 2.03 & 2.33 & 2.02 & 2.07 & 2.00 & 2.18 & 1.86\end{array}$ 3L $\begin{array}{llllllllllllllllllllll}2.03 & 2.08 & 2.16 & 2.08 & 2.08 & 2.07 & 2.08 & 2.18 & 2.06 & 2.15 & & 3 \mathrm{~L} & 2.13 & 2.14 & 2.10 & 2.02 & 2.32 & 2.12 & 2.04 & 2.07 & 2.23 & 2.05\end{array}$ $\begin{array}{llllllllllll}4 \mathrm{~L} & 2.05 & 2.05 & 2.13 & 2.13 & 2.04 & 2.02 & 2.05 & 2.06 & 1.98 & 2.13\end{array}$ $\begin{array}{lllllllllll}4 \mathrm{~L} & 2.10 & 2.08 & 2.24 & 2.01 & 2.05 & 2.04 & 2.03 & 1.96 & 2.06 & 2.02\end{array}$ SL $\begin{array}{lllllllllll}1.95 & 1.97 & 1.96 & 1.98 & 2.17 & 2.06 & 1.95 & 1.88 & 1.97 & 1.85\end{array}$

$\begin{array}{lllllllllllllllllllllll}\text { CFU15 } & 1 \mathrm{~L} & 1.88 & 2.03 & 2.02 & 2.01 & 1.91 & 2.18 & 2.01 & 2.03 & 1.90 & 1.85 & \text { CFU30 } & 1 \mathrm{~L} & 2.03 & 2.01 & 2.11 & 2.10 & 1.98 & 2.00 & 1.93 & 1.67 & 2.02\end{array}$ $\begin{array}{llllllllllll}2 \mathrm{~L} & 2.12 & 2.17 & 2.03 & 2.13 & 1.92 & 2.04 & 2.06 & 2.13 & 2.16 & 2.06\end{array}$ $\begin{array}{lllllllllll}3 \mathrm{~L} & 1.96 & 2.08 & 2.04 & 2.13 & 1.96 & 2.15 & 2.07 & 2.12 & 2.17 & 2.08\end{array}$ $\begin{array}{lllllllllll}4 \mathrm{~L} & 2.05 & 2.06 & 2.03 & 2.10 & 1.98 & 2.06 & 1.88 & 2.00 & 2.12 & 1.94\end{array}$ $\begin{array}{llllllll}2 \mathrm{~L} & 2.06 & 2.08 & 2.18 & 2.02 & 2.07 & 1.93 & 2.04\end{array}$ $\begin{array}{lllllllllll}3 \mathrm{~L} & 2.03 & 1.98 & 2.08 & 1.96 & 2.15 & 2.06 & 2.10 & 2.08 & 1.95 & 2.13\end{array}$ $\begin{array}{lllllllllll}4 \mathrm{~L} & 2.04 & 2.07 & 2.08 & 1.94 & 2.09 & 2.08 & 2.05 & 1.97 & 1.98 & 2.02\end{array}$ $\begin{array}{lllllllllll}5 \mathrm{~L} & 1.93 & 1.92 & 1.96 & 1.85 & 2.22 & 1.88 & 1.95 & 1.92 & 1.81 & 1.97\end{array}$

$\begin{array}{llllllllllll}\text { TT15 } & 1 \mathrm{~L} & 2.15 & 2.02 & 1.94 & 2.07 & 2.06 & 1.80 & 2.01 & 2.13 & 2.13 & 1.97\end{array}$ 2L $\begin{array}{llllllllll}2.18 & 2.08 & 2.17 & 2.20 & 2.23 & 2.03 & 2.05 & 2.60 & 2.02\end{array}$

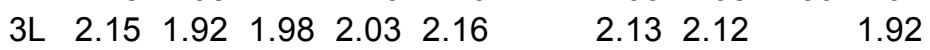
$\begin{array}{llllllllllll}\text { TT30 } & 1 \mathrm{~L} & 1.92 & 2.14 & 2.07 & 2.05 & 2.05 & 2.38 & 1.97 & 2.02 & 2.43 & 1.93\end{array}$ $\begin{array}{lllllllllll}2 \mathrm{~L} & 1.94 & 2.22 & 2.25 & 2.17 & 1.96 & 1.96 & 1.96 & 2.14 & 1.98\end{array}$ $\begin{array}{lllllllllll}4 \mathrm{~L} & 2.12 & 2.02 & 2.00 & 2.04 & 2.02 & 1.87 & 1.98 & 2.03 & 2.04 & 1.97\end{array}$ $\begin{array}{lllllllllll}5 \mathrm{~L} & 2.00 & 1.94 & 1.88 & 1.98 & 2.04 & 2.04 & 1.92 & 1.93 & 2.00 & 1.88\end{array}$

$3 \mathrm{~L} \quad 1.88$

4L 1.86 


\subsubsection{Emissor modelo $M$}

Esse modelo de emissor apresentou CVQ inicial geral de 15\%, valor considerado elevado para uma amostra de emissores novos. Já o CVQ inicial para os tratamentos demonstrou elevada variabilidade, principalmente para os tratamentos CFU15, CFS30, CFU30 e para a TT15, como se observa na Figura 22.

Não se observa tendência evidente de comportamento da vazão, pois, para tratamentos como CTS15 e CFU30, este parâmetro apresentou-se constante. Já para CFU15 e CTU30, o comportamento foi de elevação de vazão, e para CTU15 ocorreu redução de vazão.

Foram observados picos elevados para os dois parâmetros avaliados, como em CFU15 e CTS30. Tal comportamento se deveu à presença de emissores que apresentaram elevação de vazão, como se observa na Tabela 15, onde alguns emissores apresentaram vazão $250 \%$ superior à vazão inicial, como o emissor R3 do tratamento CTS30.

O desempenho das testemunhas apresentou desuniformidade entre estas quanto aos parâmetros analisados. O desempenho da testemunha a $30 \mathrm{~cm}$ mostrou-se superior a $15 \mathrm{~cm}$.

Foi observado valor extremo de vazão, como em CFU15, chegando a 12,7 L. $\mathrm{h}^{-1}$. Como este modelo de emissor é autocompensante, pode ser que tenha ocorrido desequilíbrio na membrana de autocompensação, provocando elevação de vazão.

De maneira geral, esse modelo de emissor apresentou desempenho medíocre quanto aos parâmetros analisados. Caso tal comportamento se repetisse em campo de maneira generalizada, o equilíbrio hidráulico do sistema de irrigação ficaria comprometido, pois, na ocorrência de vazões elevadas dos emissores, o sistema de bombeamento talvez não conseguisse pressurizar o sistema. 

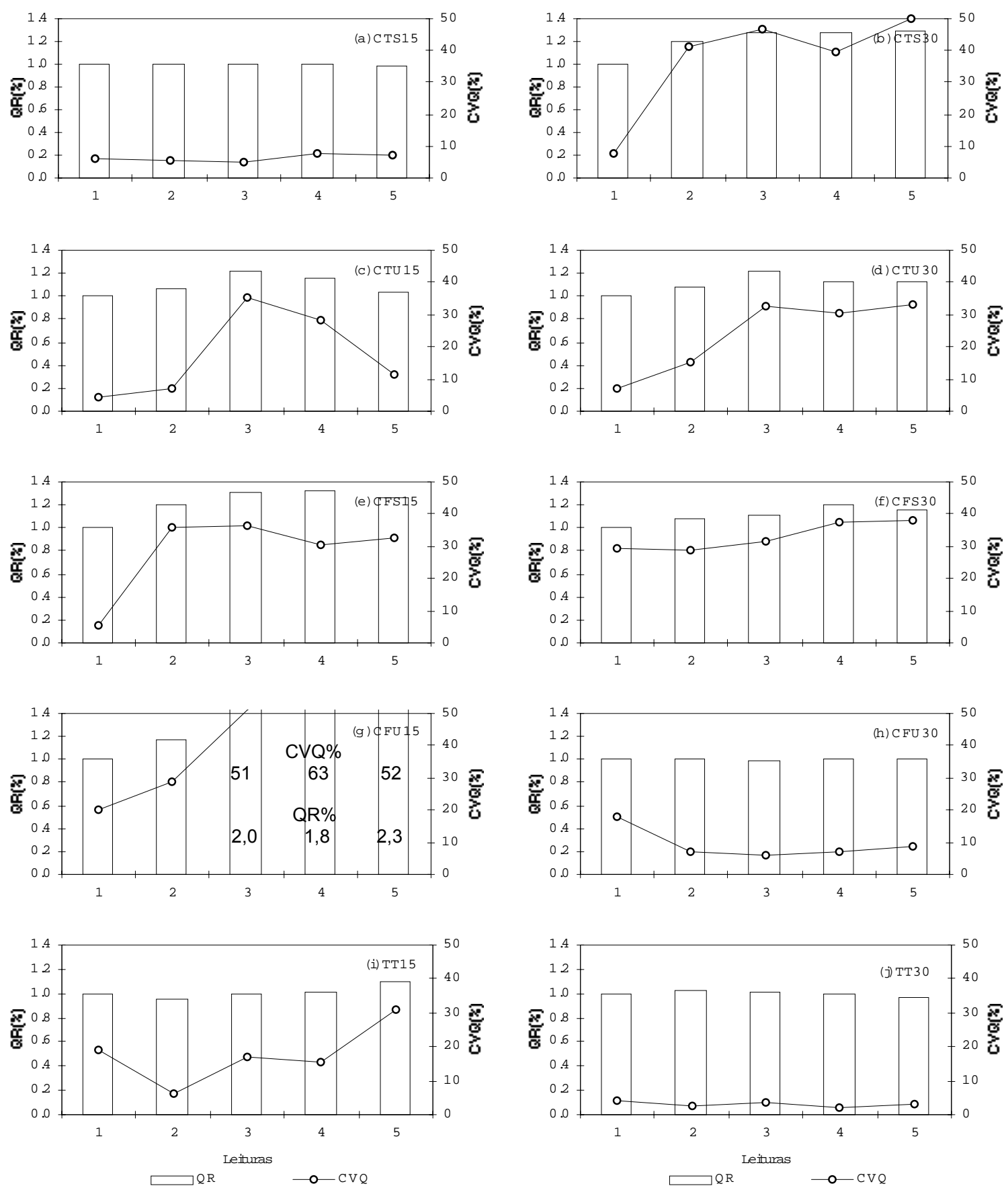

Figura 22 - QR e CVQ para o emissor modelo M: (a) citros seco $15 \mathrm{~cm}$; (b) citros seco $30 \mathrm{~cm}$; (c) citros úmido $15 \mathrm{~cm}$; (d) citros úmido $30 \mathrm{~cm}$; (e) café seco $15 \mathrm{~cm}$, (f) café seco $30 \mathrm{~cm}$; (g) café úmido $15 \mathrm{~cm}$; (h) café úmido $30 \mathrm{~cm}$; (i) testemunha $15 \mathrm{~cm}$; (j) testemunha $30 \mathrm{~cm}$. 
Tabela 15. Vazões do emissor modelo $M$ em L. $h^{-1}$ para as cinco leituras realizadas (1L até $5 \mathrm{~L}$ ), dez repetições (R1 até $\left.R 10\right)$ para todos os tratamentos (CTS15, CTS30, CTU15, CTU30, CFS15, CFS30, CFU15, CFU30, TT15 e TT30).

\begin{tabular}{|c|c|c|c|c|c|c|c|c|c|c|c|c|c|c|c|c|c|c|c|c|c|c|c|}
\hline & & R1 & R2 & R3 & $\overline{R 4}$ & R5 & $\mathrm{R} 6$ & R7 & R8 & R9 & R10 & & & R1 & R2 & R3 & R4 & R5 & R6 & R7 & R8 & $\overline{\mathrm{R} 9}$ & R1 \\
\hline \multirow[t]{5}{*}{ CTS15 } & $1 \mathrm{~L}$ & 2.88 & 2.52 & 2.48 & 2.46 & 2.43 & 2.52 & 2.48 & 2.34 & 2.68 & 2.67 & SS30 & $1 \mathrm{~L}$ & 2.68 & & 2.77 & 2.35 & 2.37 & 2.27 & 2.53 & 2.48 & 2.74 & 2.72 \\
\hline & $2 \mathrm{~L}$ & 2.63 & & 2.41 & 43 & 2.46 & 2.62 & 2.58 & 2.42 & 2.82 & 2.68 & & $2 \mathrm{~L}$ & 2.57 & 6.58 & 3.28 & 2.33 & 2.52 & 2.52 & 2.60 & 2.67 & 2.94 & 2.66 \\
\hline & $3 \mathrm{~L}$ & 2.46 & 2.58 & 2.37 & 2.56 & 2.54 & 2.52 & 2.50 & 2.37 & 2.74 & 2.70 & & $3 \mathrm{~L}$ & 2.65 & 6.62 & 5.58 & 2.37 & 2.54 & 2.32 & 2.62 & 2.46 & 2.74 & 2.65 \\
\hline & $4 \mathrm{~L}$ & 2.78 & 2.52 & 2.34 & 2.37 & 2.44 & 2.45 & 2.48 & 2.37 & 2.82 & 2.86 & & $4 \mathrm{~L}$ & 2.64 & 6.16 & 4.54 & 2.30 & 2.56 & 2.38 & 2.62 & 2.50 & .34 & 64 \\
\hline & $5 \mathrm{~L}$ & 2.68 & .53 & .32 & 2.36 & 2.42 & 2.58 & 2.50 & 2.28 & 2.76 & 2.78 & & $5 \mathrm{~L}$ & 2.70 & 5.63 & 7.04 & 2.33 & 2.40 & 2.50 & 2.48 & 2.72 & 2.28 & 2.77 \\
\hline \multirow[t]{5}{*}{ CTU15 } & $1 \mathrm{~L}$ & 2.49 & 67 & 2.58 & 2.49 & & 2.56 & 2.48 & 2.83 & 2.58 & 2.48 & & $1 \mathrm{~L}$ & 2.32 & 2.41 & 2.45 & 2.26 & 2.58 & 2.57 & 2.84 & 2.67 & 2.58 & 2.42 \\
\hline & $2 \mathrm{~L}$ & 67 & 82 & 92 & 93 & & 88 & 52 & 09 & 2.57 & 2.58 & & $2 \mathrm{~L}$ & 2.42 & 3.08 & 2.46 & 2.36 & 2.58 & 2.70 & 2.83 & 3.78 & 2.53 & 2.46 \\
\hline & $3 \mathrm{~L}$ & 2.72 & 74 & 53 & 00 & 2.56 & 2.58 & 2.42 & 36 & 2.75 & 2.52 & & $3 \mathrm{~L}$ & 2.42 & 5.48 & 2.43 & 2.35 & 2.50 & 2.88 & 2.82 & 4.06 & 2.65 & 2.84 \\
\hline & $4 \mathrm{~L}$ & 2.64 & 68 & .42 & 13 & 2.65 & 2.67 & 2.40 & 2.88 & 2.78 & 2.50 & & $4 \mathrm{~L}$ & 2.38 & 5.23 & 2.54 & 2.34 & 2.60 & 2.74 & 2.71 & 2.83 & 2.34 & 2.48 \\
\hline & $5 \mathrm{~L}$ & 2.64 & 45 & 35 & 73 & .57 & 2.57 & 2.43 & .74 & 2.68 & 2.53 & & $5 \mathrm{~L}$ & 2.37 & 5.46 & 2.45 & 2.34 & 2.54 & 2.75 & 2.75 & 2.66 & 2.47 & 2.44 \\
\hline \multirow[t]{5}{*}{ CFS15 } & $1 \mathrm{~L}$ & 2.46 & .46 & 38 & 2.49 & 2.41 & 2.18 & 2.56 & 2.64 & 2.53 & 2.35 & & $1 \mathrm{~L}$ & 2.43 & 4.87 & 2.40 & 2.35 & 2.24 & 2.56 & 2.56 & 2.27 & 2.41 & 2.67 \\
\hline & $2 \mathrm{~L}$ & 68 & 70 & 66 & 58 & 63 & 34 & 2.83 & 46 & 5.93 & .67 & & $2 \mathrm{~L}$ & 2.60 & 5.26 & 2.62 & 2.88 & 2.48 & 2.63 & 2.67 & 2.46 & 2.56 & 2.68 \\
\hline & $3 \mathrm{~L}$ & 2.60 & 75 & 66 & 50 & 08 & .46 & 2.77 & 2.64 & 5.64 & 2.82 & & $3 \mathrm{~L}$ & 2.50 & 5.52 & 2.54 & 3.42 & 2.58 & 2.67 & 2.75 & 2.46 & 2.55 & 2.8 \\
\hline & $4 \mathrm{~L}$ & 2.77 & 72 & .76 & .64 & .08 & 2.40 & 2.73 & 4.04 & 5.47 & 2.63 & & $4 \mathrm{~L}$ & 2.57 & 5.36 & 2.46 & 3.34 & 5.58 & 2.65 & 2.64 & 2.41 & 2.46 & 2.75 \\
\hline & $5 \mathrm{~L}$ & 2.62 & 62 & .44 & 2.52 & .83 & 2.26 & 2.70 & 4.06 & 5.43 & 2.58 & & $5 \mathrm{~L}$ & 2.32 & 5.02 & 2.32 & 3.16 & 5.54 & 2.66 & 2.64 & 2.30 & 2.42 & 2.60 \\
\hline \multirow[t]{5}{*}{ CFU15 } & $1 \mathrm{~L}$ & .54 & 46 & 2.35 & 56 & 2.52 & 3.42 & 2.48 & 2.16 & 2.44 & 3.92 & & $1 \mathrm{~L}$ & 2.24 & 2.44 & 2.42 & 2.30 & 2.53 & 2.53 & 2.36 & 2.52 & 2.17 & 3.78 \\
\hline & $2 \mathrm{~L}$ & 2.73 & 53 & .48 & 25 & 2.56 & 3.42 & 2.54 & 5.44 & 2.74 & 95 & & $2 \mathrm{~L}$ & 2.43 & & 2.63 & 2.34 & 2.47 & 2.57 & 2.48 & 2.78 & 2.30 & 2.83 \\
\hline & $3 \mathrm{~L}$ & .88 & .50 & 68 & 3.94 & 9.46 & 4.24 & 2.56 & 10.33 & 7.26 & 5.85 & & $3 \mathrm{~L}$ & 2.37 & & 2.60 & 2.38 & 2.40 & 2.52 & 2.58 & 2.66 & 2.24 & 2.70 \\
\hline & $4 \mathrm{~L}$ & 23 & 2.53 & 3.55 & 4.74 & 10.60 & .83 & 2.42 & 10.52 & 5.88 & 85 & & $4 \mathrm{~L}$ & 2.50 & & 2.53 & 2.35 & 2.58 & 2.53 & 2.46 & 2.69 & 2.32 & 2.90 \\
\hline & $5 \mathrm{~L}$ & 5.97 & 2.43 & 58 & 47 & 10.12 & .17 & 35 & 12.76 & 6 & 98 & & $5 \mathrm{~L}$ & 2.92 & & 2.47 & 33 & 2.40 & 2.50 & 2.48 & 2.72 & 2.28 & 2.77 \\
\hline \multirow[t]{5}{*}{ TT15 } & $1 \mathrm{~L}$ & 4.03 & 2.27 & .04 & 2.52 & 2.50 & 2.67 & 2.76 & & 2.50 & .47 & TT30 & $1 \mathrm{~L}$ & 2.67 & 2.42 & 2.60 & 2.47 & 2.49 & 2.34 & 2.44 & 2.53 & 2.34 & 2.43 \\
\hline & $2 \mathrm{~L}$ & 2.72 & 2.36 & & & 2.64 & 2.86 & 2.72 & .4 & 2.55 & 2.55 & & $2 \mathrm{~L}$ & 2.52 & 2.53 & 2.63 & 2.57 & 2.58 & & 2.52 & 2.47 & 2.38 & 2.5 \\
\hline & $3 \mathrm{~L}$ & 2.76 & 2.23 & 98 & 2.50 & 2.58 & 2.75 & 2.80 & 2.58 & 2.54 & 2.53 & & $3 \mathrm{~L}$ & 2.47 & 2.46 & 2.54 & 2.43 & 2.66 & & 2.56 & 2.52 & 2.32 & 2.46 \\
\hline & $4 \mathrm{~L}$ & 2.75 & 2.43 & 3.93 & 2.93 & 2.63 & 2.65 & 2.78 & 2.53 & 2.54 & 2.57 & & $4 \mathrm{~L}$ & 2.52 & 2.48 & 2.46 & 2.47 & 2.43 & 2.43 & 2.56 & 2.50 & 2.37 & 2.48 \\
\hline & $5 \mathrm{~L}$ & 2.68 & .35 & .05 & 2.64 & 2.86 & 2.71 & 2.70 & 2.41 & 2.52 & 2.45 & & $5 \mathrm{~L}$ & 2.43 & 2.46 & 2.42 & 2.45 & 2.38 & 2.35 & 2.45 & 2.42 & 2.23 & 2.4 \\
\hline
\end{tabular}




\subsubsection{Emissor modelo $\mathrm{N}$}

O CVQ inicial geral para esse modelo de emissor foi de 11,2\%. Já o CVQ inicial dos tratamentos apresentou valores próximos do CVQ inicial geral.

Houve tendência geral de redução de vazão para todos os tratamentos e testemunhas, apresentando valor mínimo em CFU30, como se observa na Figura 23 (h).

Foram observados valores extremos do parâmetro CVQ para os tratamentos café úmido às duas profundidades. Estes valores extremos do CVQ são explicados pela redução de vazão de alguns emissores, como se observa na Tabela 16.

Aparentemente, pode-se afirmar ter havido evidência dos tratamentos para o café úmido, pois os valores do coeficiente de variação de vazão para esses casos diferiram-se dos demais.

Já as testemunhas a 15 e $30 \mathrm{~cm}$ apresentaram desempenho normal, quanto os parâmetros analisados, não tendo sido observadas variações entres as leituras.

Foi observada redução total de vazão, como se verifica na Tabela 16, no tratamento CFU15, emissor da terceira repetição (R3).

O presente emissor não possui mecanismo de autocompensação, o que pode explicar a baixa variabilidade das vazões. Seu desempenho de maneira geral apresentou-se favorável. 

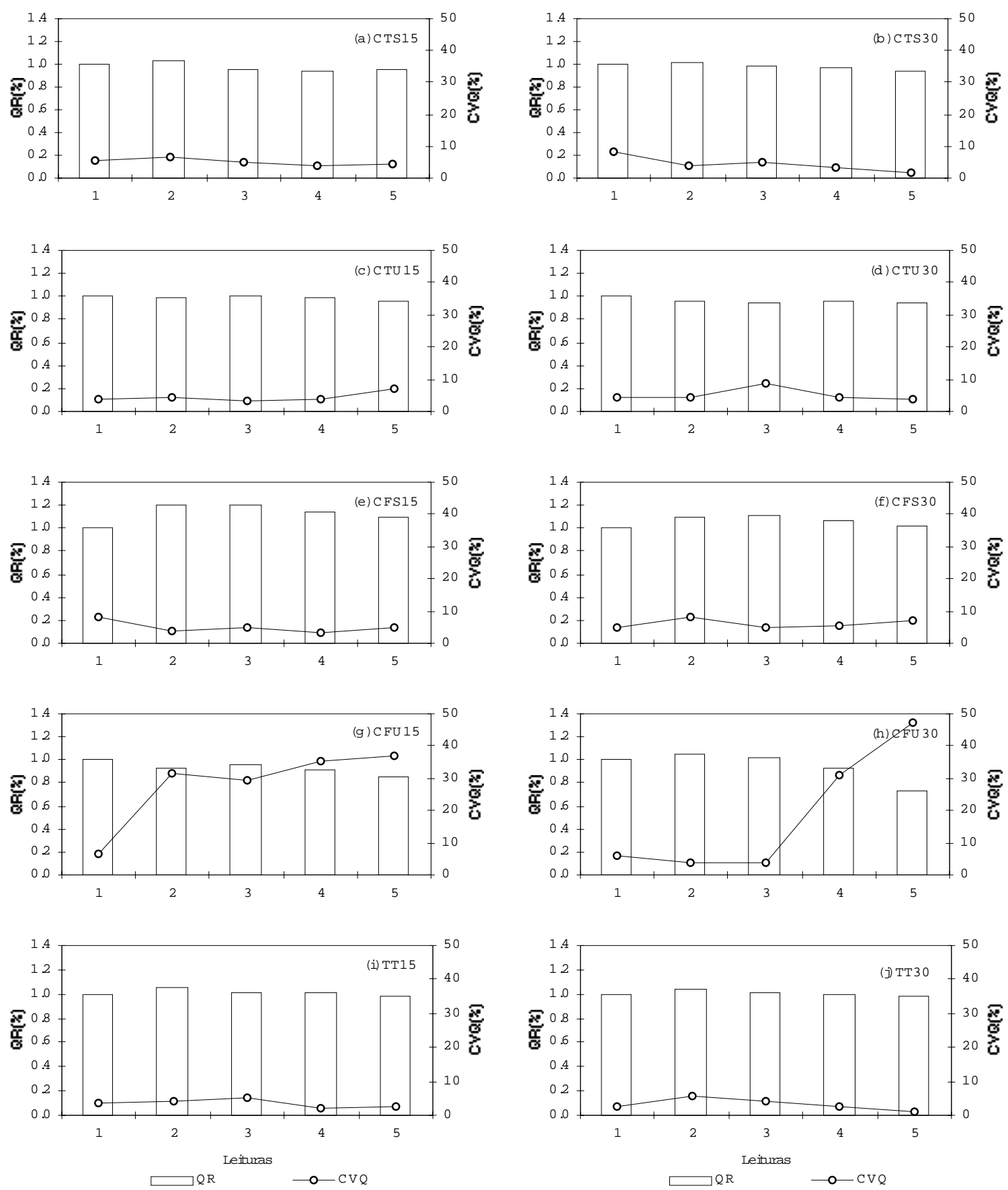

Figura 23 - QR e CVQ para o emissor modelo N: (a) citros seco $15 \mathrm{~cm}$; (b) citros seco $30 \mathrm{~cm}$; (c) citros úmido $15 \mathrm{~cm}$; (d) citros úmido $30 \mathrm{~cm}$; (e) café seco $15 \mathrm{~cm}$, (f) café seco $30 \mathrm{~cm}$; $(\mathrm{g})$ café úmido $15 \mathrm{~cm}$; (h) café úmido $30 \mathrm{~cm}$; (i) testemunha $15 \mathrm{~cm}$; (j) testemunha $30 \mathrm{~cm}$. 
Tabela 16. Vazões do emissor modelo $\mathrm{N}$ em $\mathrm{L} \cdot \mathrm{h}^{-1}$ para as cinco leituras realizadas (1L até $5 \mathrm{~L}$ ), dez repetições (R1 até $\left.\mathrm{R} 10\right)$ para todos os tratamentos (CTS15, CTS30, CTU15, CTU30, CFS15, CFS30, CFU15, CFU30, TT15 e TT30).

\begin{tabular}{|c|c|c|c|c|c|c|c|c|c|c|c|c|c|c|c|c|c|c|c|c|c|c|c|}
\hline & & R1 & R2 & R3 & R4 & R5 & $\mathrm{R} 6$ & R7 & $\begin{array}{l}\mathrm{R} 8 \\
\end{array}$ & R9 & R10 & & & R1 & $\overline{R 2}$ & R3 & R4 & R5 & R6 & R7 & $\overline{R 8}$ & $\overline{\mathrm{R} 9}$ & R10 \\
\hline \multirow[t]{5}{*}{ CTS15 } & $\overline{1 L}$ & 2.07 & 2.53 & 2.24 & 2.21 & 2.24 & 2.11 & 2.21 & 2.17 & 2.13 & 2.18 & 30 & $1 \mathrm{~L}$ & 2.01 & 2.04 & 2.12 & 2.56 & 2.24 & 2.04 & 2.08 & & & 2.23 \\
\hline & $2 \mathrm{~L}$ & 2.36 & & & 2.15 & 2.42 & & & 2.46 & 2.23 & 2.08 & & $2 \mathrm{~L}$ & 2.23 & 2.33 & 2.16 & & & & 2.28 & & 2.17 & 2.08 \\
\hline & $3 \mathrm{~L}$ & 2.12 & 2.16 & 2.25 & 2.28 & 2.23 & 2.07 & 1.96 & 2.08 & 2.07 & 1.98 & & $3 \mathrm{~L}$ & 1.97 & 2.20 & 2.21 & 2.20 & 2.32 & 2.08 & 2.16 & 10 & .07 & 2.02 \\
\hline & $4 \mathrm{~L}$ & 2.06 & 00 & .07 & 10 & 2.23 & 98 & 2.08 & 2.17 & 2.05 & .04 & & $4 \mathrm{~L}$ & 2.02 & 2.02 & 2.12 & 2.12 & 2.25 & 2.12 & 2.14 & 14 & 14 & 2.02 \\
\hline & $5 \mathrm{~L}$ & 2.03 & 98 & 08 & .05 & 2.10 & 2.23 & 2.15 & 2.26 & 2.04 & 2.06 & & $5 \mathrm{~L}$ & 2.00 & 2.00 & 2.03 & 2.02 & 2.08 & 2.05 & 2.10 & 04 & 10 & 2.02 \\
\hline \multirow[t]{5}{*}{ CTU15 } & $1 \mathrm{~L}$ & 2.04 & 2.21 & 2.13 & 2.06 & 2.13 & 2.13 & 2.24 & 2.21 & 2.21 & 2.01 & & 1L & 2.18 & 2.23 & 2.20 & 2.16 & 2.16 & 2.44 & 2.35 & 2.26 & 2.16 & 2.21 \\
\hline & $2 \mathrm{~L}$ & .02 & & 09 & 12 & & 15 & 26 & 25 & 11 & 02 & & $2 \mathrm{~L}$ & 2.05 & 2.08 & 2.23 & 2.12 & 2.18 & 2.35 & 2.17 & .08 & .08 & \\
\hline & $3 \mathrm{~L}$ & 2.16 & 2.21 & 2.15 & .10 & 2.10 & 2.00 & 2.22 & 2.23 & 2.22 & 2.16 & & 3L & 2.12 & 2.23 & 2.18 & 2.18 & 2.05 & 2.23 & 2.18 & 2.18 & 2.24 & 1.62 \\
\hline & $4 \mathrm{~L}$ & 2.04 & .13 & 11 & 17 & 2.25 & 2.08 & 2.18 & 2.08 & 2.02 & 2.00 & & $4 \mathrm{~L}$ & 2.23 & 2.18 & 2.26 & 2.22 & 2.20 & 2.21 & 2.07 & .06 & 2.08 & 2.00 \\
\hline & $5 \mathrm{~L}$ & 2.12 & 14 & .08 & .08 & 2.22 & 1.67 & 2.07 & 2.14 & 2.05 & 2.06 & & $5 \mathrm{~L}$ & 2.16 & 2.22 & 2.13 & 2.14 & 2.06 & 2.22 & 2.04 & 2.10 & 2.12 & 1.97 \\
\hline \multirow[t]{5}{*}{ CFS15 } & $1 \mathrm{~L}$ & 2.43 & .03 & .14 & 2.08 & 1.88 & .93 & 2.00 & & 2.13 & 2.07 & ט & 1L & 2.07 & 2.13 & 2.00 & 1.91 & 1.96 & 2.06 & 2.06 & 2.14 & 1.8 & 1.89 \\
\hline & $2 \mathrm{~L}$ & .20 & 35 & 22 & 34 & 2.26 & 24 & .05 & 2.36 & 2.23 & 2.25 & & $2 \mathrm{~L}$ & & 2.23 & 2.32 & 2.04 & 2.46 & 2.17 & 2.28 & 2.36 & 2.24 & 1.86 \\
\hline & $3 \mathrm{~L}$ & .12 & 34 & 25 & 32 & 2.15 & .44 & 13 & .23 & .17 & 2.32 & & $3 \mathrm{~L}$ & 2.16 & 2.26 & 2.27 & 2.05 & 2.43 & 2.26 & 2.28 & 2.22 & 19 & 2.10 \\
\hline & $4 \mathrm{~L}$ & 2.17 & .22 & .17 & 20 & 2.07 & .10 & 2.03 & 2.24 & 2.14 & 2.20 & & $4 \mathrm{~L}$ & 2.27 & 2.23 & 2.10 & 1.91 & 2.13 & 2.21 & 2.22 & 2.16 & 2.18 & 2.00 \\
\hline & $5 \mathrm{~L}$ & 1.98 & 10 & .04 & 2.20 & 2.00 & 2.20 & .86 & 13 & 2.03 & 2.05 & & $5 \mathrm{~L}$ & 2.12 & 2.12 & 1.98 & 1.73 & 2.12 & 2.14 & 2.16 & .20 & 2.03 & .90 \\
\hline \multirow[t]{5}{*}{ CFU15 } & $1 \mathrm{~L}$ & 1.94 & 2.06 & 99 & 2.06 & 2.07 & 2.10 & .12 & 2.15 & 1.84 & 2.34 & & $1 \mathrm{~L}$ & 1.92 & 2.06 & 2.03 & 2.07 & 2.20 & 2.23 & 2.27 & 2.20 & 1.90 & 2.09 \\
\hline & $2 \mathrm{~L}$ & 2.25 & 26 & 32 & 13 & 2.02 & 04 & & 18 & 08 & 2.03 & & $2 \mathrm{~L}$ & 2.17 & 2.24 & 18 & 66 & & 28 & 24 & 32 & Jठ & 2.18 \\
\hline & $3 \mathrm{~L}$ & .03 & 13 & 35 & 17 & 2.12 & .18 & 2.20 & .15 & 2.15 & 2.30 & & $3 \mathrm{~L}$ & 2.04 & 2.08 & 2.10 & 2.06 & 2.16 & 2.23 & 2.12 & 2.26 & 2.16 & 2.26 \\
\hline & $4 \mathrm{~L}$ & 2.07 & 2.00 & 00 & .22 & 2.21 & 17 & 2.08 & .08 & 2.00 & 2.12 & & $4 \mathrm{~L}$ & 2.03 & 2.09 & 2.10 & 2.16 & 2.13 & 2.28 & 0.25 & 2.20 & 2.16 & 2.14 \\
\hline & $5 \mathrm{~L}$ & 2.02 & 2.06 & 0.00 & 2.07 & 1.97 & 1.38 & 2.10 & 2.04 & 1.97 & 1.98 & & $5 \mathrm{~L}$ & 1.96 & & 2.04 & 0.91 & 1.86 & 2.02 & 0.10 & 0.84 & 2.10 & 2.02 \\
\hline \multirow[t]{5}{*}{ TT15 } & $1 \mathrm{~L}$ & 2.02 & 2.08 & 2.07 & 2.11 & 2.04 & 2.07 & 2.16 & 2.13 & 2.18 & 2.26 & TT30 & $1 \mathrm{~L}$ & 2.10 & 2.07 & 2.24 & 2.15 & 2.07 & 2.06 & 2.08 & 2.17 & 2.16 & 2.1 \\
\hline & $2 \mathrm{~L}$ & 2.15 & 2.23 & 2.25 & 2.32 & 2.28 & 2.24 & 2.15 & 2.08 & 2.10 & 2.35 & & $2 \mathrm{~L}$ & 2.23 & 2.42 & & & 2.32 & 2.14 & 2.12 & 2.07 & 2.11 & 2.24 \\
\hline & $3 \mathrm{~L}$ & 2.08 & 1.95 & 2.06 & 2.05 & 2.12 & 2.26 & 2.32 & 2.20 & 2.07 & 2.22 & & $3 \mathrm{~L}$ & 2.18 & 2.13 & & 02 & 2.16 & 2.24 & 2.26 & 2.19 & 2.02 & 2.13 \\
\hline & $4 \mathrm{~L}$ & 2.08 & 2.17 & 2.08 & 2.14 & 2.05 & 2.15 & 2.18 & 2.16 & 2.16 & 2.1 & & $4 \mathrm{~L}$ & 2.07 & 2.20 & 2.13 & 2.17 & 2.03 & 2.12 & 2.14 & 2.12 & 2.06 & 2.18 \\
\hline & $5 \mathrm{~L}$ & 2.08 & 2.12 & 2.04 & 2.05 & 2.00 & 2.10 & 2.07 & 2.00 & 2.07 & 2.17 & & $5 \mathrm{~L}$ & 2.08 & 2.10 & 2.05 & 2.08 & 2.08 & 2.05 & 2.03 & 2.05 & 2.08 & 2.07 \\
\hline
\end{tabular}




\subsubsection{Emissor modelo 0}

O CVQ inicial geral para esse modelo de emissor foi de 8,9\%. Já o CVQ inicial dos tratamentos e testemunhas apresentou valores próximos ao anteriormente apresentado, exceto para os tratamentos CTU15 e CFS30, conforme Figura 24 (c) e (f).

Quanto ao parâmetro $Q R$, houve tendência geral de queda discreta, exceto para o tratamento CTU15, onde ocorreu elevação nesse parâmetro.

Foram observados picos no parâmetro CVQ nos tratamentos CTU15 e CFS30. Tal fato deveu-se, para o primeiro caso à elevação de vazão dos emissores nas repetições (R5 e R9) e, no segundo caso, à redução de vazão nas repetições ( $R 6$ e $R 8$ ).

Os efeitos dos tratamentos não foram conclusivos, mesmo tendo havido evidência dos tratamentos em CTU15 e CFS30, pois a tendência de vazão foi inversa para ambos os casos.

Já as testemunhas apresentaram desempenho normal quanto aos parâmetros avaliados para as duas profundidades.

Foi observado que a vazão real desse modelo de emissor apresentou-se próxima da nominal fornecida pelo fabricante. Observando a Tabela 17, notam-se poucas células onde não se registrou o valor de vazão, pois o tubo gotejador em questão possui parede espessa, facilitando a vedação nos conectores.

De maneira geral, o comportamento desse modelo de emissor até a determinação da última vazão apresentou-se medianamente favorável, até por se tratar de emissor autocompensante. 

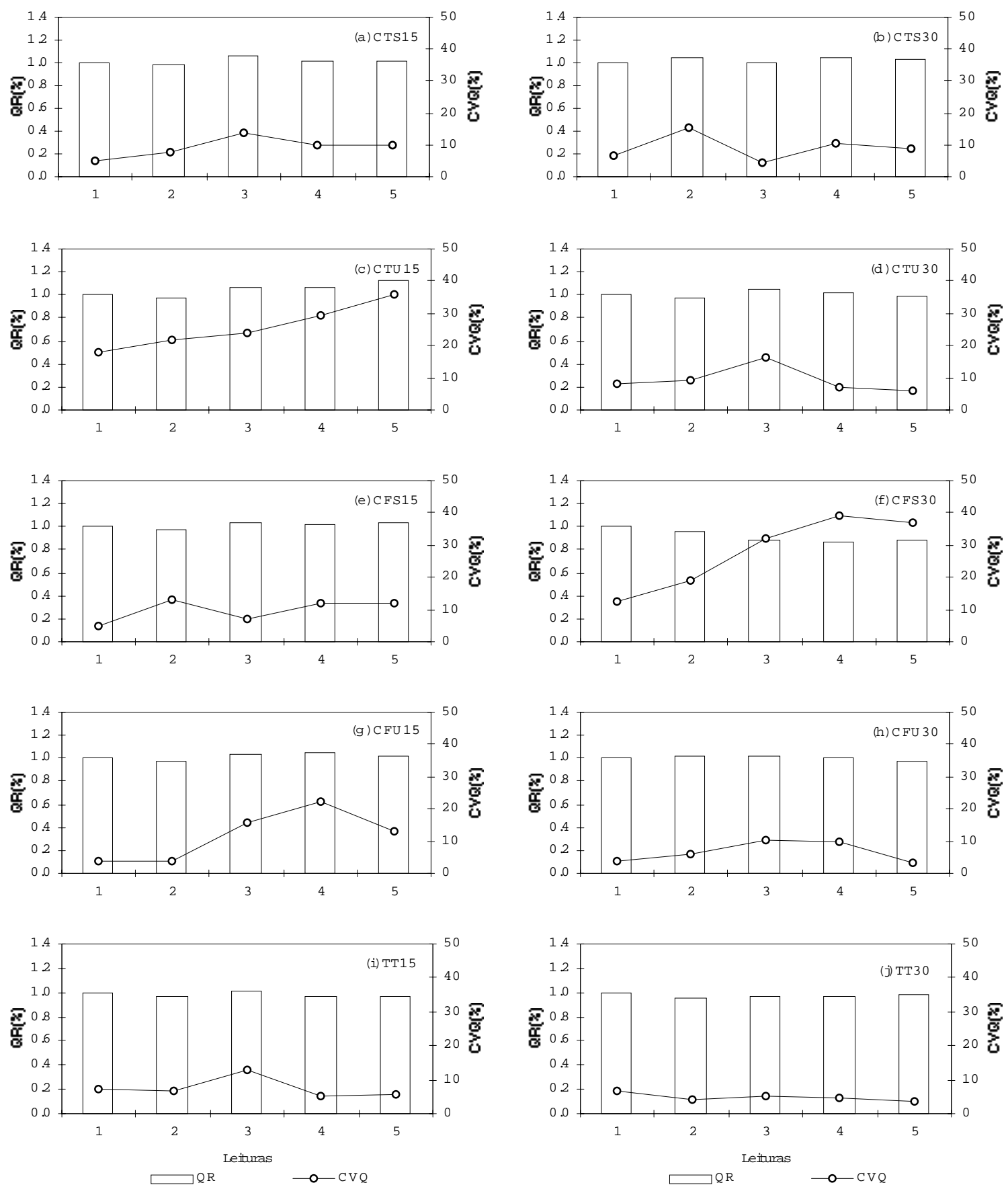

Figura 24 - QR e CVQ para o emissor modelo O: (a) citros seco $15 \mathrm{~cm}$; (b) citros seco $30 \mathrm{~cm}$; (c) citros úmido $15 \mathrm{~cm}$; (d) citros úmido $30 \mathrm{~cm}$; (e) café seco $15 \mathrm{~cm}$, (f) café seco $30 \mathrm{~cm}$; $(\mathrm{g})$ café úmido $15 \mathrm{~cm}$; (h) café úmido $30 \mathrm{~cm}$; (i) testemunha $15 \mathrm{~cm}$; (j) testemunha $30 \mathrm{~cm}$. 
Tabela 17. Vazões do emissor modelo $O$ em $L . h^{-1}$ para as cinco leituras realizadas (1L até $5 \mathrm{~L}$ ), dez repetições (R1 até $\left.R 10\right)$ para todos os tratamentos (CTS15, CTS30, CTU15, CTU30, CFS15, CFS30, CFU15, CFU30, TT15 e TT30).

\begin{tabular}{cccccccccccc}
\hline & & R1 & R2 & R3 & R4 & R5 & R6 & R7 & R8 & R9 & R10 \\
\hline CTS15 & 1L & 2.39 & 2.51 & & & 2.36 & 2.23 & 2.47 & 2.29 & 2.21 & \\
& 2L & & 2.23 & & 2.72 & 2.16 & 2.28 & 2.38 & 2.18 & 2.29 & 2.40 \\
& 3L & 2.72 & 2.18 & 3.36 & 2.36 & 2.45 & 2.26 & 2.48 & 2.35 & 2.26 & 2.56 \\
& 4L & 2.35 & 2.35 & 3.06 & 2.38 & 2.32 & 2.23 & 2.46 & 2.30 & 2.22 & 2.34 \\
5L & 2.32 & 2.20 & 2.94 & 2.38 & 2.56 & 2.23 & 2.45 & 2.24 & 2.18 & 2.28
\end{tabular}

$\begin{array}{cccccccccccc} & & \text { R1 } & \text { R2 } & \text { R3 } & \text { R4 } & \text { R5 } & \text { R6 } & \text { R7 } & \text { R8 } & \text { R9 } & \text { R10 } \\ \text { CTS30 } & \text { 1L } & 2.34 & 2.39 & 2.32 & 2.18 & 2.41 & 2.55 & 2.24 & 2.10 & & 2.13 \\ & \text { 2L } & 2.37 & 2.27 & 3.32 & 2.12 & 2.10 & 2.43 & 2.26 & 2.27 & & 2.42 \\ & \text { 3L } & 2.40 & 2.37 & 2.30 & 2.14 & 2.21 & 2.48 & 2.31 & 2.25 & 2.26 & 2.37 \\ & \text { 4L } & 2.26 & 2.84 & 2.36 & 2.14 & 2.18 & 2.83 & 2.38 & 2.18 & 2.42 & 2.44 \\ & \text { 5L } & 2.93 & 2.43 & 2.42 & 2.40 & 2.26 & 2.28 & 2.15 & 2.25 & 2.28 & 2.32\end{array}$

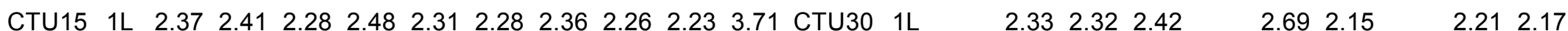

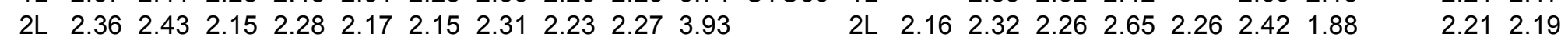

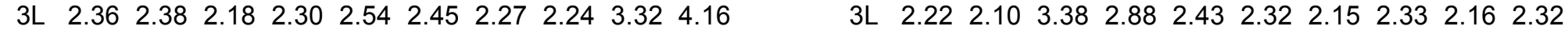
$\begin{array}{lllllllllllllllllllllllll}4 \mathrm{~L} & 2.47 & 2.38 & 2.13 & 2.37 & 2.46 & 2.40 & 2.22 & 2.33 & 4.76 & 2.82 & & 4 \mathrm{~L} & 2.34 & 2.74 & 2.34 & 2.33 & 2.14 & 2.46 & 2.28 & 2.35 & 2.21 & 2.38\end{array}$ $\begin{array}{llllllllllllllllllllllll}5 \mathrm{~L} & 2.42 & 2.54 & 2.20 & 2.10 & 3.54 & 2.34 & 2.14 & 2.52 & 5.32 & 2.52 & & 5 \mathrm{~L} & 2.23 & 2.54 & 2.30 & 2.17 & 2.15 & 2.48 & 2.20 & 2.20 & 2.26 & 2.36\end{array}$

$\begin{array}{lllllllllllllll}\text { CFS15 } & 1 \mathrm{~L} & 2.46 & 2.30 & 2.45 & 2.12 & 2.30 & 2.41 & 2.31 & 2.42 & 2.25 & \mathrm{CF} & \end{array}$ $\begin{array}{lllllllllll}2 \mathrm{~L} & 2.39 & 2.34 & 2.28 & 2.48 & 2.26 & 2.47 & 2.52 & 1.46 & 2.38 & 2.34\end{array}$ $\begin{array}{llllllllllll}3 \mathrm{~L} & 2.32 & 2.40 & 2.43 & 2.42 & 2.36 & 2.84 & 2.35 & 2.32 & 2.43 & 2.26\end{array}$ $\begin{array}{lllllllllll}4 \mathrm{~L} & 2.33 & 2.25 & 2.30 & 2.36 & 2.28 & 3.18 & 2.33 & 2.35 & 2.32 & 2.16\end{array}$ $\begin{array}{llllllllllll}5 \mathrm{~L} & 2.37 & 2.18 & 2.32 & 2.44 & 2.20 & 3.16 & 2.38 & 2.37 & 2.38 & 2.20\end{array}$

$\begin{array}{lllllllllllll}\text { CFU15 } & 1 \mathrm{~L} & 2.41 & 2.51 & 2.49 & 2.43 & 2.46 & 2.31 & 2.37 & 2.24 & 2.49 & 2.36 & \text { CFU30 }\end{array}$ $\begin{array}{lllllllllll}2 \mathrm{~L} & 2.23 & 2.34 & 2.54 & 2.38 & 2.38 & 2.28 & 2.35 & 2.45 & 2.27\end{array}$ $\begin{array}{llllllllllll}3 \mathrm{~L} & 2.30 & 2.43 & 2.46 & 2.45 & 3.55 & 2.26 & 2.47 & 2.17 & 2.47 & 2.33\end{array}$ $\begin{array}{lllllllllll}4 \mathrm{~L} & 2.25 & 2.37 & 2.48 & 2.26 & 3.08 & 2.12 & 3.96 & 2.21 & 2.25 & 2.40\end{array}$ $\begin{array}{llllllllllll}5 \mathrm{~L} & 2.28 & 2.48 & 2.38 & 2.32 & 2.57 & 2.35 & 3.27 & 2.17 & 2.33 & 2.25\end{array}$

$\begin{array}{llllllllllll}\text { TT15 } & 1 \mathrm{~L} & 2.22 & 2.22 & 2.35 & 2.39 & 2.37 & 2.78 & 2.31 & 2.21 & 2.31 & 2.24\end{array}$ $\begin{array}{llllllllll}2 \mathrm{~L} & 2.24 & 2.13 & 2.23 & 2.28 & 2.18 & 2.26 & 2.16 & 2.64 & 2.25\end{array}$ $\begin{array}{llllllllllll}3 \mathrm{~L} & 2.12 & 2.20 & 2.25 & 2.28 & 2.25 & 2.32 & 3.15 & 2.15 & 2.58 & 2.26\end{array}$ $\begin{array}{lllllllllll}4 \mathrm{~L} & 2.15 & 2.23 & 2.27 & 2.27 & 2.25 & 2.12 & 2.40 & 2.08 & 2.44 & 2.30\end{array}$ $\begin{array}{lllllllllll}5 \mathrm{~L} & 2.16 & 2.22 & 2.26 & 2.28 & 2.34 & 2.17 & 2.27 & 2.06 & 2.54 & 2.34\end{array}$

$\begin{array}{llllllllllll}\text { CFS30 } & 1 \mathrm{~L} & 2.27 & 2.30 & 2.36 & 2.38 & 2.35 & 2.34 & 2.38 & 1.56 & 2.72 & 2.43\end{array}$ $\begin{array}{lllllllllll}2 \mathrm{~L} & 2.58 & 2.27 & 2.36 & 2.23 & 2.20 & 1.43 & 2.48 & 1.46 & 2.70 & 2.38\end{array}$ $\begin{array}{lllllllllll}3 \mathrm{~L} & 2.05 & 2.35 & 2.44 & 2.27 & 2.18 & 0.52 & 2.35 & 1.26 & 2.68 & 2.34\end{array}$ $\begin{array}{lllllllllll}4 \mathrm{~L} & 2.02 & 2.34 & 2.18 & 2.25 & 2.54 & 0.13 & 2.44 & 1.15 & 2.78 & 2.27\end{array}$ $\begin{array}{lllllllllll}5 \mathrm{~L} & 2.38 & 2.35 & 2.36 & 2.28 & 2.46 & 0.22 & 2.42 & 1.12 & 2.28 & 2.35\end{array}$ $\begin{array}{lllllllllll}1 \mathrm{~L} & 2.46 & 2.44 & 2.26 & 2.44 & 2.20 & 2.26 & 2.31 & 2.33 & 2.35\end{array}$ $\begin{array}{lllllllllll}2 \mathrm{~L} & 2.24 & 2.56 & 2.55 & 2.45 & 2.52 & 2.52 & 2.41 & 2.14 & 2.28 & 2.28\end{array}$ $\begin{array}{llllllllllll}3 \mathrm{~L} & 2.32 & 2.40 & 2.42 & 2.42 & 3.04 & 2.21 & 2.13 & 2.23 & 2.35 & 2.28\end{array}$ $\begin{array}{lllllllllll}4 \mathrm{~L} & 2.27 & 2.46 & 2.40 & 2.94 & 2.38 & 2.17 & 2.28 & 2.20 & 2.24 & 2.19\end{array}$ $\begin{array}{lllllllllll}5 \mathrm{~L} & 2.25 & 2.32 & 2.40 & 2.40 & 2.26 & 2.28 & 2.15 & 2.25 & 2.28 & 2.32\end{array}$ $\begin{array}{llllllllllll}\text { TT30 } & 1 \mathrm{~L} & 2.31 & 2.32 & 2.37 & 2.30 & 2.34 & 2.34 & 2.05 & 2.70 & 2.28 & 2.30\end{array}$ $\begin{array}{lllllllllll}2 \mathrm{~L} & 2.28 & 2.20 & 2.33 & 2.24 & 2.20 & 2.17 & 2.00 & 2.28 & 2.23 & 2.25\end{array}$ $\begin{array}{lllllllllll}3 \mathrm{~L} & 2.34 & 2.30 & 2.42 & 2.22 & 2.10 & 2.22 & 2.04 & 2.37 & 2.32 & 2.36\end{array}$ $\begin{array}{lllllllllll}4 \mathrm{~L} & 2.28 & 2.26 & 2.38 & 2.23 & 2.24 & 2.20 & 2.03 & 2.36 & 2.24 & 2.35\end{array}$ \begin{tabular}{lllllllllll}
$5 \mathrm{~L}$ & 2.33 & 2.25 & 2.38 & 2.28 & 2.36 & 2.32 & 2.11 & 2.38 & 2.28 & 2.30 \\
\hline
\end{tabular} 


\subsection{Intrusão radicular}

$\mathrm{Na}$ ocasião da abertura dos vasos para a verificação do desenvolvimento radicular, verificou-se também a ocorrência de intrusão radicular nos emissores. Na Figura 25 são apresentados detalhes de intrusão radicular observada em alguns modelos de gotejadores ensaiados.
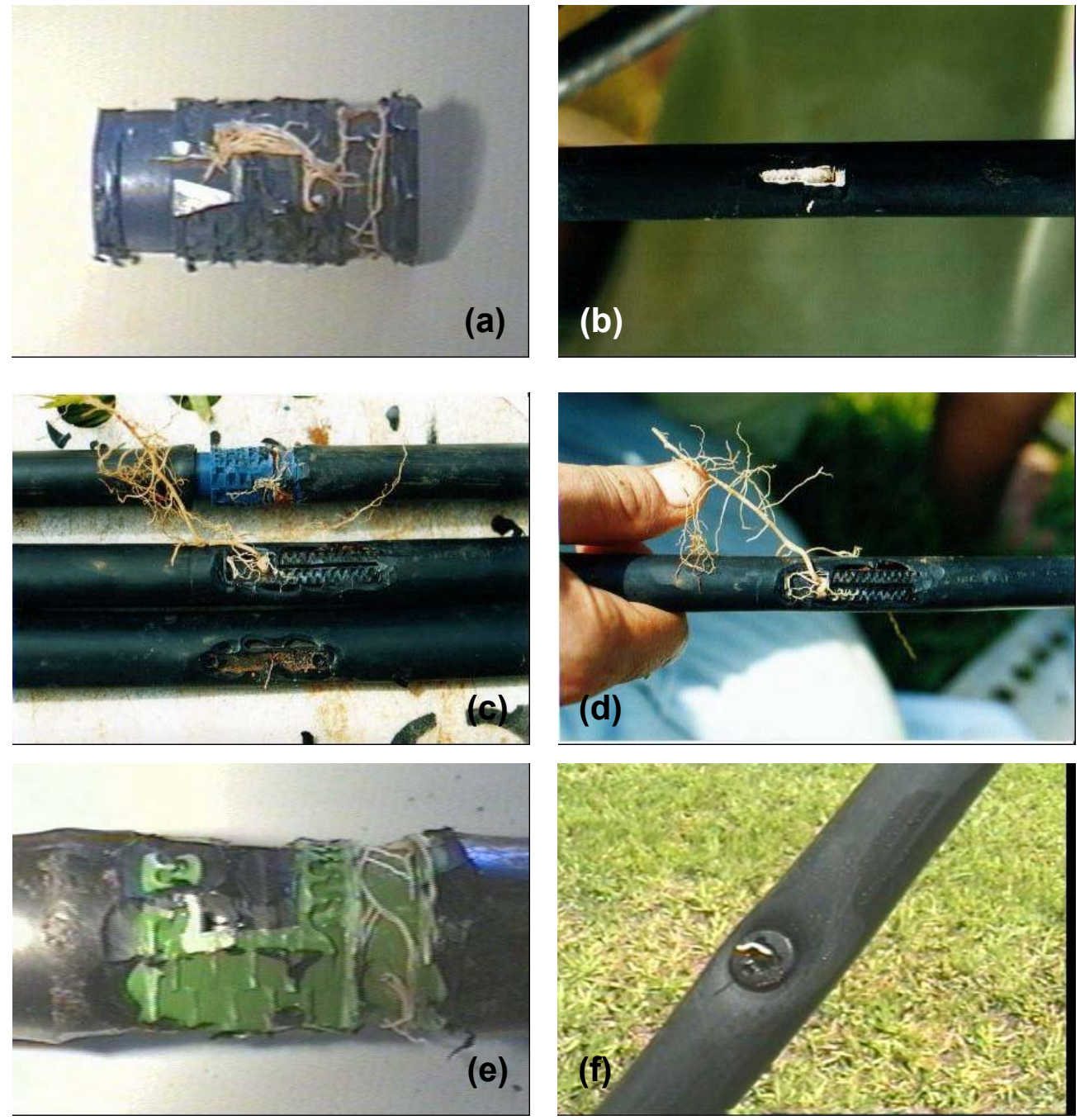

Figura 25 - Intrusão radicular nos emissores: (a) emissor cilíndrico; (b) emissor plano; (c) emissores diversos; (d) emissor plano; (e) emissor cilíndrico; (f) emissor botão. 
Nota-se na Figura 25 que ocorreu intrusão radicular aleatória, não havendo uma tendência por tipo específico de emissor. As ocorrências verificadas de intrusão radicular foram detectadas no estagio inicial de penetração nos labirintos dos emissores, o que certamente provocaria redução de vazão significativa no futuro, dependendo da arquitetura do emissor e das dimensões das raízes. Notou-se também que, mesmo para emissores cilíndricos, que possuem arquitetura interna com câmaras e caminhos complexos, as raízes haviam iniciado a penetração nos labirintos.

A intrusão radicular observada não se destacou para nenhum dos tratamentos, tendo sido encontrados emissores com raízes para as duas culturas, para as duas profundidades, para os dois níveis de irrigação e para os diferentes tipos de emissores.

Observou-se também a presença de solo no interior de alguns emissores. Ressalta-se que o sistema de irrigação apresentava dispositivo antivácuo, o que parece não ter evitado a sucção de partículas sólidas. 


\section{CONCLUSÕES}

Nas condições em que o experimento foi conduzido, e face ao caráter pioneiro do mesmo, pode-se chegar às seguintes conclusões:

a) A intrusão radicular no gotejamento enterrado é aleatória, sendo que a amostragem destrutiva do sistema radicular no vaso, tanto na cultura do café quanto na cultura do citros, não apresentou evidências de que existia um crescimento preferencial das raízes em direção ao emissor enterrado. Aparentemente o sistema radicular vai se espalhando pelo solo e se coincidir do orifício do gotejador estar na direção de crescimento da coifa radicular a intrusão ocorrerá de maneira irreversível;

b) A hipótese de que o sistema radicular sob estresse hídrico seria mais agressivo ao gotejamento enterrado não se confirmou de maneira conclusiva. O sistema radicular das plantas bem irrigadas apresentou um notável vigor que poderá ser também bastante agressivo aos emissores;

c) Variações de vazão nos gotejadores enterrados foram mais freqüentes para a cultura do café na profundidade de $30 \mathrm{~cm}$. A confirmação da hipótese da cultura do café ser mais agressiva que a cultura de citros ao gotejamento subsuperficial, somente será possível com a continuidade do experimento por um maior período de tempo;

d) Diferentes modelos de gotejadores, apresentaram diferentes graus de sensibilidade às variações de vazão no gotejamento subsuperficial. De maneira geral os emissores autocompensáveis são mais instáveis, tendendo a apresentar aumento de vazão nos emissores enterrados na 
presença de raízes e partículas de solo, enquanto os emissores normais são mais estáveis, tendendo a apresentar redução de vazão. distúrbios de vazão nos gotejadores ensaiados foram mais pronunciados em determinados modelos de alguns fabricantes, o que evidencia a diferença tecnológica entre as empresas de equipamentos de irrigação analisadas.

e) Quanto ao aspecto construtivo (barreiras físicas), nenhum dos emissores ensaiados demonstrou possuir mecanismos que impeçam efetivamente a penetração das raízes em seu interior, mesmo aqueles que usualmente são recomendados para uso no gotejamento subsuperficial. 


\section{REFERÊNCIAS BIBLIOGRÁFICAS}

ASSOCIAÇÃO BRASILEIRA DE NORMAS TÉCNICAS. Requisitos mínimos para elaboração de projeto de sistema de irrigação localizada; PNBR 12:02-08-022. São Paulo, 1986. 18p.

AMARO, A.A. Citricultura. Informações Econômicas, v.29. n.12. p.65-74. 1999.

AMERICAN SOCIEY OF AGRICULTURAL ENGINEERS (ASAE/EP - 405.1). Standards: engineering pratices. Saint Joseph, 1994. 819p.

ALMEIDA, F.S.; RODRIGUES, B.N. Guia de herbicidas: contribuição para o uso adequado em plantio direto e convencional. Londrina: IAPAR, 1985. $468 p$.

AYARS, J.E.; PHENE, C.J.; HUTMACHER, R.B.; DAVIS, K.R.; SCHONEMAN, R.A.; VAIL, S.S.; MEAD, R.M. Subsurface drip irrigation of row crops: a review of 15 years of research at the Water Management Research Laboratory. In: Agricultural water management. Amsterdam: Elsevier, 1999. p.1-27. 
BERNARDO, S. Manual de irrigação. 6. ed. Viçosa: Imprensa Universitária, 1995. 657p.

BOTREL, T.A.; FRIZZONE, J.A. Ensaios e certificação de sistemas e equipamentos para irrigação. In: MIALHE, L.G. Máquinas agrícolas: ensaio e certificação. Piracicaba: Fealq, 1996. p. 571-634.

BRALTS, V.F.; EDWARDS, D.M.; WU, I.P. Drip irrigation desing and evaluation based on the statistical uniformity concept. Advances in irrigation. New York: Academic Press, 1987. p. 67-117.

BRALTS, V.F.; KESNER, C.D. Drip irrigation field uniformity estimation. Transaction of the ASAE. v. 26, n. 4, p. 1369-1374, 1983.

BURT, C.M. Is buried drip the future with permanent crops. Irrigation Business Technology, v.3, n.1, p. 20-22, 1995.

CAIXETA, G.Z.T. Comportamento atual do mercado de café. Informe Agropecuário, v.19, n.193, p. 9-13, 1998.

CAMP, C.R. Subsurface drip irrigation: a review. Transaction of the ASAE. v. 41 , n. 5 , p. $1353-1367,1988$.

CHRISTIANSEN, J.E. Irrigation by sprinkling. Berkeley: University of California, Experiment Station. 1942. 124p. (Bulletin, 670).

CHRISTOFIDIS, D. Os recursos hídricos e a prática da irrigação no Brasil e no mundo. ITEM - Irrigação e tecnologia moderna, n. 49, p. 8-13, 2001. 
COSTA, C. C. Estudo da susceptibilidade de tubos gotejadores ao entupimento por precipitados químicos de ferro. Lavras, 2000. 85p. Dissertação (Mestrado) - Universidade Federal de Lavras.

FAVETTA, G.M.; BOTREL, T.A.; FRIZZONE, J.A. Correlação entre três métodos de estimativa da uniformidade de distribuição em irrigação localizada. Engenharia Rural, n. 4, p. 117-125, 1993.

FNP CONSULTORIA \& COMÉRCIO. AGRIANUAL 2001: anuário da agricultura brasileira. São Paulo, 2000. 303p.

GELMINI, G.A. Agrotóxicos: legislação básica. Campinas: Fundação Cargill, 1991. v. 1, 398p.

GHAEMI, A.; CHIENG, S. Emitter clogging and hydraulics in micro-irrigation lines. / Annual International Meeting, ASAE/CSAE-SCGR, Toronto, 1999.

HILLEL, D. Advances in irrigation. New York: Academic Press, 1982. v. 1, $302 p$.

HILLS, D.J.; TAJRISHY, M.A.M.; GU, Y. Hydraulic consideration for compressed subsurface drip tape. Transaction of the ASAE. v. 32, n. 4, p. 1197-1201, 1989.

INTERNATIONAL ORGANIZATIONS FOR STANDARDIZATION (ISO/9261). Agricultural irrigation equipment-emitting-pipe systemsspecification and test methods. Switzerland, 1991. 7p.

KARMELI, D.; KELLER, J. Trickle irrigation design. Glendora: Rain Bird Manafacturing Corporation, 1975. 132p. 
KELLER, J.; BLIESNER, D.R. Sprinkler and trickle irrigation. New York: Van Nostrand Reinhold, 1990.652p.

LEITE, J.A.O. Avaliação da susceptibilidade de tubogotejadores ao entupimento por precipitados químicos de carbonato de cálcio. Lavras, 1995. 64p. Dissertação (Mestrado) Universidade Federal de Lavras.

LÓPEZ, J.R.; ABREU, J.M.H.; REGALADO, A.P.; HERNÁNDEZ, J.F. Riego localizado. Madrid: Mundi-Prensa, 1992. 505p.

MACIEL, J.L. Distribuição do fósforo e do potássio no perfil do solo aplicado via água de irrigação por gotejamento subsuperficial. Fortaleza, 1998. 59p. Dissertação (Mestrado) - Universidade Federal do Ceará.

\section{MEAD, R. Root intrusion prevention.}

www.microirrigationforum.com/new/archives/rootpre.html (10 jan. 2002)

NAKAYAMA, F.S. Operational principles/Walter treatament. In: NAKAYAMA, F.S.;BULKS, D.A. Trickle irrigation for crop production. Amsterdam: Elsevier, 1986. cap.3. p.164-187.

NAKAYAMA, F.S.; BUCKS, D.A. Trickle irrigation for crop production: design, operation and management. New York: Elsevier, 1996. 383p.

NEVES, E.M. Economia da produção citrícolas e efeitos alocativos. Preços Agrícolas, n.4. p. 9-12, 2000.

PIZARRO CABELLO, F. Riegos localizados de alta frecuencia. 3. ed. Madrid: Mundi-Prensa, 1996. 513p. 
POVOA, A.F.; HILLS, D.J. Sensitivity of microirrigation system pressure to emitter plugging and lateral line perforations. Transaction of the ASAE. v. 37, n. 3, p. 793-799, 1984.

RESENDE, R.S. Suscetibilidade de gotejadores ao entupimento de causa biológica e avaliação do desentupimento via cloração da água de irrigação. Piracicaba, 1999. 77p. Dissertação (Mestrado) - Escola Superior de Agricultura "Luiz de Queiroz", Universidade de São Paulo.

RUSKIN, R. Factors in the design, installation and operation of a subsurface drip irrigation system for permanent crops. www.microirrigationforum.com/new/archives/rootpre.html (10 jan. 2002)

RUSKIN, R.; FERGUSON, K.R. Protection of subsurface drip irrigation systems from root intrusion.

www.microirrigationforum.com/new/archives/rootpre.html (10 jan. 2002)

SÁNCHEZ, C.C. Riego por goteo subterráneo en olivar, vip underground. Fruticultura Profesional, n.77, p.18-32, mar./abr. 1996.

SOLOMON, K.H. Yield related interpretations of irrigation uniformity and efficiency measures. Irrigation Science. n. 5, p. 161-172, 1984.

SOLOMON, K.H. Global uniformity of trickle irrigation system. Transaction of the ASAE. v. 28, n. 4, p. 1151-1158, 1985.

SOLOMON, K.H.; JORGENSEN, G. Subsurface drip irrigation. Research Report. Center for irrigation technology. www.cati.csufreno.edu/cit (10 jan. 2002) 
SUAREZ-REY, E.; CHOI, C.Y.; WALLER, P.M. Feasibility of subsurface drip irrigation on turf in Arizona. / Annual International Meeting, ASAE/CSAESCGR, Toronto, 1999.

WU, I. P.; LIN O. Y.; LAU, L. S. Plugging evaluation in the re-use of sewage effluent by drip irrigation. / Irrigation and Drainage - Proc. ASCE Speciality Conference, Honolulu, 1991.

YUAN, Z.; WALLER, P. M.; CHOI, C. Y. Effects of organic acids on salt precipitation in drip emitters and soil. Transactions of the ASAE. v. 41, n. 6, p. 1689-1696, 1998.

ZOLDOSKE, D.; STRIEGLER, R.K.; BERG, G.T.; JORGENSON, G.; LAKE, C.B.; GRAVES, S.G.; BURNETT, D.M. Evaluation of trellis system and subsurface drip irrigation for wine grape production: a progress report. 1998: Center for Irrigation Technology. www.cati.csufreno.edu/cit (10 jan. 2002) 